\title{
"Rooted" and "Vernacular" Cosmopolitanism in Context: Conceptions of World-Citizenship from the Classical to the Postcolonial Age
}

Nikolas Helm

\section{Introduction: Cosmopolitan Fashion}

In our day and age the idea of cosmopolitanism or cosmopolitans is usually associated with the world of fashion. According to this vague sense of the word, the cosmopolitan appears to be a kind of chic entrepreneur, who divides her/his time between the trendy capitals of the world: London and Barcelona, New York and Paris, Tokyo and Milan. He is always chasing the latest flavours of the mouth, and constantly re-making and re-modelling himself accordingly. But cosmopolitanism is also the name of an old Occidental idea, an idea that goes back to ancient Greece and Rome, to the Cynics and Stoics. And it is an idea that was famously reactivated by philosophers such as Christoph Martin Wieland and Immanuel Kant during the eighteenth century and, thus, became inextricably linked to the universal aspirations of the Enlightenment.

Recently, the notion of cosmopolitanism has become a fashion within the discourse of postcolonial studies. It has been taken up and explored by a number of 
key-theorists such as Homi Bhabha or the black British intellectual Paul Gilroy'; and it is possibly related to what Edward Said described as the task of humanism in a new preface to his classic study Orientalism in the year of his death. ${ }^{2}$ Somewhat unsurprisingly, the term has - in a way buzzwords usually do - managed to polarize debates within postcolonial studies. However, unlike other notions such as identity, diaspora, or hybridity, the challenge that the concept of cosmopolitanism poses to the discourse of postcolonialism seems particularly hard-bitten. The influential postcolonial critic and sociologist Stuart Hall intimates his distrust of the idea in an interview in the following way:

You know, I hesitate before I use the term. Because a certain view of cosmopolitanism was built into the Enlightenment and Kant's famous question, "What is Enlightenment?" Kant is the architect of this universalist version of cosmopolitanism. And I resist that kind of cosmopolitanism, not because there weren't enlarging 'universalising' elements in it, but because, as we know very well, it is a version of cosmopolitanism that represented itself as 'universal' but that universality inevitably became harnessed back to the West. 'We' were the enlightened ones, whose civilizational duty and burden it was to enlighten everyone else - the unenlightened, the noncosmopolitan. ${ }^{3}$

What Hall expresses in this quote is a suspicion of cosmopolitanism's roots in Enlightenment universalism. Mistrust of the Enlightenment tradition is not unusual in postcolonial theorists. Nor does it appear particularly unfounded when, arguably, Enlightenment ideas were instrumental in forging the overseas empires of the British. However, there remains a sense (even for Hall) that a dismissal of cosmopolitanism on grounds of its relation to the Enlightenment and to universalism might be hasty. For, would not an abstention from any kind of universalizing vision of humanity reduce the project of postcolonial studies to a mere negation of colonialism (in its historical and contemporary guises) that lacks an alternative overarching conception of how humans may connect across difference, a positive horizon of human cooperation and mutual understanding? I daresay this is exactly what Edward Said saw in 2003 when he spoke affirmatively about Goethe's notion of Weltliteratur ${ }^{4}$ and the "need to concentrate on the slow working together of cultures that overlap, borrow from one another, and live together $[\ldots] . "{ }^{5}$ I sense in Said's plea for humanism a profound urging not to leave the

1 See especially his elaborations on the subject in Paul Gilroy, After Empire: Melancholia or Convivial Culture, London/New York 2004, pp. 29-92.

2 Edward Said, Orientalism, London 2003 (originally published 1978), pp. xviii-xx; xxii.

3 Pnina Werbner, "Cosmopolitanism, Globalisation and Diaspora: Stuart Hall in Conversation with Pnina Werbner, March 2006”, in: Idem (ed.), Anthropology and the New Cosmopolitanism: Rooted, Feminist and Vernacular Perspectives (ASA Monographs 45), Oxford/New York 2008, p. 349.

4 Said, Orientalism, pp. xviii-xix.

5 Ibid., p. xxii. 
connecting of different human communities to those who are insufficiently aware of its potential colonial implications and intricacies. And I believe this is precisely what lies behind many recent attempts to re-imagine cosmopolitanism from a postcolonial perspective.

But Hall's objection has alarmed us and we find ourselves asking: In how far are these new kinds of cosmopolitanism rooted in Western philosophy? Do they necessarily perpetuate Euro-centrism? What is still useful in Western philosophy for postcolonial critics and what should they reject? These are very important questions and - like most, if not all, truly profound issues theory raises and wrestles with - they may never be finally answered. However, currently the new cosmopolitan perspectives that are developing within postcolonial studies are not yet very well understood. And there remains a sense that we may yet make some headway by interrogating, disassembling and contextualizing these ideas before we either write them off as leftovers of colonial discourse or praise them uncritically.

In this essay I want to go some way towards finding answers to the questions posed above - answers which, in turn, may serve as a starting-point (not an endpoint) for further critical engagement with the idea of cosmopolitanism and especially those cosmopolitan perspectives developed under postcolonial auspices. To this end I want to fully portray two such postcolonial conceptions of cosmopolitanism: Kwame Anthony Appiah's so-called "rooted cosmopolitanism" and Homi Bhabha's notion of "vernacular cosmopolitanism." (see chapters 3.2 to 3.3) These two conceptions will be set and developed against the background of the historical discourse on cosmopolitanism as it runs from its earliest antecedents in ancient Greek philosophy to its contemporary incarnations in political and social theory (see chapters 2.1 to 2.3). In chapter $4 \mathrm{I}$ will evaluate the various perspectives against one another and draw conclusions as to relations among them. In this part I will also assess to what extent the two postcolonial cosmopolitanisms of Bhabha and Appiah may be regarded as rooted in Western philosophical discourse.

One additional task I set myself is to thoroughly compare the two perspectives of Bhabha and Appiah and to attempt to turn out their respective points of concurrence as well as their differences (see chapter 3.4). Some may object to such an endeavour on the basis that it is hardly surprising that two different authors who are both writing about cosmopolitanism may, nevertheless, concur on certain issues while simultaneously disagreeing on others. However, Bhabha and Appiah speak from different disciplinary perspectives, utilizing different theoretical languages to relate their ideas. Thus, it is not self-evident that they should be compatible with one another at all. But nevertheless - and notwithstanding the fact that some differences inevitably remain - there exist a great deal of overall similarities and agreements between them. In some way this is the proof of the pudding in the eating: For, it is a central claim of cosmopolitanism that conversation across difference is possible without conflating it into sameness. Thus, by comparing Bhabha and Appiah in this way I want to suggest that the discourse of postcoloni- 
al studies is already cosmopolitan in the sense that in it many different disciplinary perspectives and theoretical orientations take part in a discussion which leaves the differences among them in place but also turns out new and unexpected points of concurrence - a discussion which is productive of new and innovative transdisciplinary perspectives.

I shall now proceed in the following way:

- I will describe the discourse of cosmopolitanism from the classical to contemporary perspectives.

- After that I will portray and develop in all detail the two postcolonial perspectives, which I will compare and evaluate against one another.

- Finally, in my concluding section I shall draw on the various perspectives I have developed to describe in what way they are related to each other and to offer some answers as to how far the new postcolonial cosmopolitanisms are connected to specifically Western conceptions and whether this is damaging.

\section{Cosmopolitanism: Classical to Contemporary Perspectives}

\subsection{Diogenes and Cynic Cosmopolitanism in Ancient Greece}

"I am a citizen of the cosmos (kosmopoliteirs)." The person who first said these words and, thus, coined the term cosmopolitanism as such was the fifth-century BCE Greek philosopher Diogenes of Sinope. ${ }^{6}$ Diogenes was also the first Cynic philosopher and an unusual one for that. The term cynic literally means "doggish" and derives from Diogenes' byname "the dog." This byname was given to him because of his alleged shamelessness - a trait the Greeks thought of as characteristic of dogs. 7 About Diogenes' life not much is known, albeit many of the details about him that have come down to us are preserved in the form of anecdotes and stories others tell about him. ${ }^{8}$ Yet there is a sense that Diogenes would have embraced his being called a dog as his philosophy held nature and the realm of the animals in high regard. The assumption that the essence of virtue lies in living according to nature, and that such life is, in fact, the only true life may be taken as the central Cynic axiom. ${ }^{9}$ This is a simple yet very radical message and, allegedly,

6 Diogenes coined the term 'cosmopolitanism' and it was mostly associated with his movement. More broadly speaking, cosmopolitan attitudes, however, were already held by philosophers who chronologically preceded the Cynics. (John L. Moles, "The Cynics", in: Christopher Rowe/Malcolm Schofield [et al.] (eds.), The Cambridge History of Greek and Roman Political Thought, Cambridge/New York/Melbourne [et al.] 2000, p. 424.)

7 Ibid., p. 417; 419

8 Ibid., pp. 414-416.

9 Ibid., pp. 420-421. 
Diogenes did not merely submit it as a teaching but based his life on it. He lived according to radical life and he encouraged others to follow his example.

Being exiled from his native Sinope after an incident with the local authorities, he dwelled homeless on the streets of Athens and Corinth. He allegedly slept in a whine barrel, begged and stole for sustenance. ${ }^{10}$ Together with his followers, he publicly addressed passers-by and sought to convince them of the fundamental truth that a life according to nature, a life of simplicity and without personal possessions was truly good and lead to happiness. Yet Diogenes' mode of persuasion did not take the form of currying favours. Rather he attacked and slandered the citizens for their "vices." His public shamelessness - Diogenes notoriously urinated and defecated as well as masturbated and had sex in public ${ }^{11}$ - and his often vulgar rhetoric that targeted especially the rich as well as other philosophers took the form of bizarre public spectacles, aimed at offending audiences rather than winning them over. In these public spectacles as well as in their writing Diogenes and his Cynics often made use of theatrical and literary elements ${ }^{12}$, whose entertaining qualities they seemingly deemed better suited for the purpose of reaching an audience than the dry syllogisms philosophers were known for. This is not to say that the Cynics were all show and no good philosophers. Diogenes single surviving work Politeia showcases that he was well versed in the technicalities of philosophical discourse. He also debated with Plato and others in public and was officially acknowledged as a philosopher ${ }^{13}$, even though his teachings were often attacked as repulsive. ${ }^{14}$ It is, of course, nothing short of a paradox that Diogenes and his followers should have sought to attract the public through their literary and theatrical styling, only to repulse them. But as a matter of fact, paradox is one of the reigning principles of Cynicism and it is especially present in Diogenes' notion of cosmopolitanism

In order to come to terms with Diogenes' notion of cosmopolitanism we need to realize that the world of the ancient Greeks consisted of a landscape of interrelated city-states, so-called poleis. Each of these states endowed some of the individuals living in it, but not all, with the privilege of citizenship. Whoever was regarded a citizen was a matter of social standing, wealth and education. Also, women were not citizens, nor were slaves. In fact, being a slave was the very opposite of being a citizen. Strangers and people who were citizens of other cities were not considered citizens either. ${ }^{15}$ The prime achievement of the polis consisted in ena-

$10 \quad$ Ibid., p. 418.

11 Ibid., pp. 418-419.

12 Ibid., p. 419; 420

13 Ibid.

14 Diogenes defended incest (ibid., p. 430) as well as cannibalism (John L. Moles, "Cynic Cosmopolitanism”, in: Robert Bracht Branham/Marie-Odile Goulet-Cazé (eds.), The Cynics: The Cynic Movement in Antiquity and Its Legacy (Hellenistic Culture and Society 23), Berkeley/Los Angeles/London 1996, p. 112) on the basis that they occurred in nature.

15 Ibid., p. 17. 
bling its citizens' freedom. However, this understanding of freedom should not be thought of as synonymous with the modern notion of freedom: It did not result in personal rights but in the right to help direct the enterprises of the political community. ${ }^{16}$ The sum of all citizens of a polis was the political community and there were no state and no governmental bureaucracy in the modern sense. ${ }^{17}$ Outside of this landscape of poleis existed 'barbarian' people, who lived under tyranny and who served as the Other of the Greek republican self-image. ${ }^{18}$

In reflecting upon what Diogenes meant when he described himself as a cosmopolitan, it is quite important to bear in mind that he was a stranger to the Greek cities where he lived and taught. But he had also lost Sinopean citizenship. Hence, the question of citizenship must have been highly programmatic to him as it referred to the problem of his own political status in the world. ${ }^{19}$ It has often been suggested that Cynic cosmopolitanism is merely negative in that it fundamentally rejects government of any kind and the notion of positive citizenship along with it. Paradoxically, this is correct but not entirely so: It is true that Cynics were political anarchists, who rejected any form of government as unnatural. However, Diogenes did not say that he was no citizen. Rather he said that the polis he owed allegiance to was simply coextensive with the universe. ${ }^{20}$ The word cosmopolitanism is actually an oxymoron as it suggests an exclusive category that is simultaneously all encompassing. What is noteworthy is that the Cynics' aversion toward government never took the form of active rebellion. Diogenes and his disciples opposed the state as unnatural but they also forbade that Cynics use violence, which they considered a vice stemming from civilization. ${ }^{21}$

Now what is one to make of this? What concrete and positive form could Diogenes' polis possibly have, considering he forbade all government? How could it even exist when Greece at that time factually consisted of many different cities? As John L. Moles has suggested in his heterodox reading of Cynicism, the Cynic state (politeia) simply denotes "the 'state' of being a Cynic." 22 And this, simple as it may seem, is the positive aspect of Cynic cosmopolitanism. The Cynics publicly attacked wealth, power as well as established customs and norms. This was done to the end that citizens might question their given notions of good and bad, and to literally convert them to Cynicism. ${ }^{23}$ From this context we may then also understand why the Cynics seemingly sought to affront and disgust rather than to win over their listeners. It was only through the public proof that a life in accord-

16 Paul Cartledge, "Greek Political Thought: The Historical Context", in: History of Greek and Roman Political Thought, p. 16.

17 Ibid., p. 17.

18 Ibid., p. 16.

19 Moles, “The Cynics", p. 424.

20 Ibid., pp. 426-427

$21 \quad$ Ibid., p. 431.

$22 \quad$ Ibid., p. 427.

23 Ibid., p. 422. 
ance with nature and in fierce opposition to the established norms of civilization and the lifestyle of the polis was actually practicable, that Cynic claims could appear at all credible to their audience. ${ }^{24}$ The Cynics strove to convince others that to live in accordance with nature was the only ethical state of existence, the only true life. Whoever accepted this Diogenes called his fellow citizen. This was why the polis he envisaged was potentially everywhere. Surely even those whom the Greeks looked down upon in an ethnocentric fashion as barbarians could agree with this. In fact, Diogenes alleged that many of the people thus denoted lived in more true and natural a fashion than did ordinary Greek citizens. ${ }^{25}$ One is faced at this point with an element of Cynic cosmopolitanism that is essential to bear in mind as it recurs especially in the cosmopolitanism promoted by postcolonial theorists: To be a cosmopolitan, on this take, is to recognize the existence of ties that transcend those allegiances most obvious to us and that we customarily recognize as most immediate and necessary. In this Diogenes claims an actual proximity to, a familiarity with what the Greeks considered Other - namely, with barbarians. However, Diogenes did not claim this allegiance just for himself. What might have been the most challenging about his assertion was that it suggested a potential allegiance between so-called barbarians and all Greeks as, in turn, all Greeks were potential citizens of Diogenes' kosmopolis.

However, Diogenes' questioning binary oppositions was not merely directed toward the outer boundaries of the polis. I have mentioned beforehand that women were not entitled to citizenship. Diogenes' cosmopolitanism protested against this treatment of women as second-class people. Obviously women have the same capacity to live in accordance with nature as men. Naturally they can be cosmopolitans, too. Diogenes assaulted the customary notion that women were inferior to men. In fact, he alleged that partnerships should cease being arranged and that women should only live with men they personally chose to live with. ${ }^{26}$

This makes Cynic cosmopolitanism appear very modern. However, Cynic cosmopolitanism is specifically unlike more recent perspectives on cosmopolitanism in that it contains a spiritual dimension. The ancient Greek understanding of kosmos did not merely comprise the world, the diverse peoples and gendered bodies living in it but reached out further to encompass even the heavenly realm, as well as ghosts and spirits. The Cynics actually thought of themselves as mediators between ordinary men and the gods. They even considered themselves god-like. ${ }^{27}$ This religious or spiritual element is absent from all other perspectives.

\footnotetext{
24 Ibid., p. 421.

25 Ibid., p. 422; Moles, "Cynic Cosmopolitanism”, pp. 110-111.

26 Moles, "The Cynics", p. 422; 430.

27 Moles, "Cynic Cosmopolitanism", pp. 112-113.
} 


\subsection{Kant and the Enlightenment's View of Cosmopolitanism}

\subsubsection{Stoic Influence on Kant's Cosmopolitanism}

After antiquity the philosophical concept of cosmopolitanism became popular again during the Age of Enlightenment. During the last quarter of the eighteenth century there developed a substantial scholarly debate over the term and its implications, to which especially German intellectuals contributed. What likely prompted their interest in cosmopolitanism, which to the contemporary mind described an attitude of openness toward and curiosity about other cultures, was the overall political situation of German-speaking people during that period. Most German speakers lived within the confines of the Holy Roman Empire of the German Nation. The empire was not centrally governed but fractured into a great number of different territories, some of which - as, for example, Prussia - lay only partially within the empire itself. The territories of the empire largely followed liberal immigration policies, which meant that many foreigners escaping war and poverty settled among German-speakers, bringing along with them their foreign cultural and religious practices. What made the situation even more contingent was that German was also spoken in territories outside the empire, where it was not the only language and where German-speakers often lived together in close contact with other cultural, linguistic and ethnic groups. ${ }^{28}$

Among the many contributors to the philosophical debate over cosmopolitanism was the influential Prussian philosopher Immanuel Kant. Kant, partly due to the circumstances described above, characterized Germans as ideal cosmopolitans. According to him, the Germans of the period were curious about other cultures, hospitable toward foreigners and not overtly proud of their own traditions and country. ${ }^{29}$ In fact, it would not be an exaggeration to claim that there existed only a very vague sense of national belonging among German-speakers in the eighteenth century. Furthermore, German cultural heritage was attached little value to by leading German intellectuals, who instead were a lot more interested in the cultural achievements of others..$^{30}$ All of this was swept aside by the nineteenth century and its strong concern for the nation; ${ }^{31}$ so that today it is difficult to imagine how Germans could ever not have conceived of themselves as a nation. However, during the period Kant lived in the idea of a unified German people living together in a clear-cut nation-state was not a dominant one. This created a general atmosphere of tolerance and openness.

In this intellectual and social climate philosophers, who studied the texts of the ancient Greeks, revived the notion of cosmopolitanism, and Kant was at the fore-

28 Pauline Kleingeld, Kant and Cosmopolitanism: The Philosophical Ideal of World Citizenship, Cambridge/New York/Melbourne [et al.] 2012, pp. 9-10.

29 Ibid., p. 1.

30 Ibid., p. 10

31 Ibid. 
front of this movement. The term figured prominently in most of his political writing. But, as Pauline Kleingeld has shown, cosmopolitanism in Kant comes in many shapes, touching upon a diverse set of issues. Accordingly, I have decided to limit my discussion to two separate but interrelated aspects of Kant's work: his moral and political cosmopolitanism. ${ }^{32}$

Kant's moral cosmopolitanism, as may be expected, is rooted in ancient philosophy; yet not in Cynicism but Stoicism. I have already mentioned that Diogenes' cosmopolitanism is often taken to be wholly negative in that it renounces all specific allegiances. Against this I have argued that Diogenes' cosmopolitanism is not egotistic but recognizes the community of the wise. However, one may very well ask what is to become of the running of the economy and the managing of public affairs if all citizens were to become Cynics and reject government. On purely logical grounds this argument may, of course, be countered by stating that if all citizens were Cynics, there would be no-one left to worry because Cynics are dedicated to poverty. But this argument appears flawed because Diogenes and the Cynics never lived in entire poverty. But they lived of the goods they stole or were given, goods that had been produced by women and men who did not follow the Cynics' way. This circumstance does not exactly make Cynicism appear politically credible. The Stoics' attitude towards government was more positive than that of most Cynics ${ }^{33}$ and many of them served as political officials; especially in the Roman world. There are, for instance, Cicero and Seneca - the latter being a political adviser to Nero; and there is Marcus Aurelius, who was a powerful emperor of the Roman Empire. ${ }^{34}$ Yet this does not make the Stoic cosmopolitanism less radical as will become obvious shortly.

The core axiom of Stoic cosmopolitanism, which was also adopted by Kant, is the assumption that all human beings are equal by virtue of being capable of reason. This capacity, according to the Stoics, is a spark of the divine that lives in everyone and that makes all human beings morally equal and, therefore, equally valuable. ${ }^{35}$ Thus, to the Stoics it did not matter whether one was a beggar or a king, a Chinese or a Roman. It did not matter where one came from or which class one had been born into because everyone could have been born anywhere. ${ }^{36}$ By virtue of being equal, all human beings are citizens in a universal moral polity that transcends all particular allegiances..$^{37}$

One of the reasons why the Stoics opted for such a strong claim was that in their capacity as political theorists and advisers they became aware that many great

\footnotetext{
32 Ibid., p. 3.

33 Significantly, there is a sub-current within later Cynicism that was less hostile toward government. (Moles, "Cynic Cosmopolitanism", p. 108.)

34 Martha C. Nussbaum, "Kant and Stoic Cosmopolitanism", in: The Journal of Philosophy 5:1 1997, p. 6.

35 Ibid., pp. 6-7.

36 Ibid., p. 7.

37 Ibid., p. 6.
} 
evils result from political faction and separatism. ${ }^{38}$ Thus the Stoics did not merely assert it a truth that all humans are equal in this way, but also meant that it would be desirable if everyone believed so, that is, if everyone perceived her/himself as morally responsible for everyone else. ${ }^{39}$ This would eliminate political faction. It would bring about a situation, in which nobody could easily kill or injure an enemy as s/he would be faced with the other person's humanity. Marcus Aurelius, in an almost Buddhist fashion, held that everyone must identify with one's enemies in this way, look upon them with understanding and even attempt to imagine her/himself as sharing a common goal with them. ${ }^{40}$ If everyone adopted this principle war, as a political instrument, would either vanish entirely or become limited to the purpose of self-defence. ${ }^{41}$

As becomes obvious from this, Stoic cosmopolitanism is profoundly dedicated to peace and this appealed to Kant, who adopted its stance that all humans are equal by virtue of their shared capacity of reason and that, accordingly, all humans are citizens of an implicit universal moral polity and subject to common moral laws. ${ }^{42}$ Kant's approach to a large extent is concerned with how one may eliminate what he called the "state of nature" between states, that is, a state wherein war is a constant possibility. This desire on Kant's part is clearly rooted in the historical context of the early modern period, which was an epoch of intense bellicosity. One need only think of the Thirty Years' War (1618-1648), which utterly devastated Europe in the seventeenth century. Closer to Kant's time there were, for example, the War of the Spanish Succession (1701-1714), the Seven Years' War (1754-1763) and, finally, the Napoleonic expansion that was already under way when Kant lived. Also, during the eighteenth century bigger European conflicts reached a global scale as they were carried into the newly colonized territories..$^{43}$ Under the impression of ever-present warfare and violent conflicts that increased in the scale of their destructive force as well as in scope, Kant desperately sought for a way to regulate the interaction of states so as to induce a process that would eventually lead to perpetual peace.

\subsubsection{Constitutional Right: Republicanism and Patriotism}

There are several interrelated ways in which the Stoic cosmopolitanism that influenced Kant must appear problematic. According to the Stoics, we should take into primary view in our political deliberations not what is good for us or our commu-

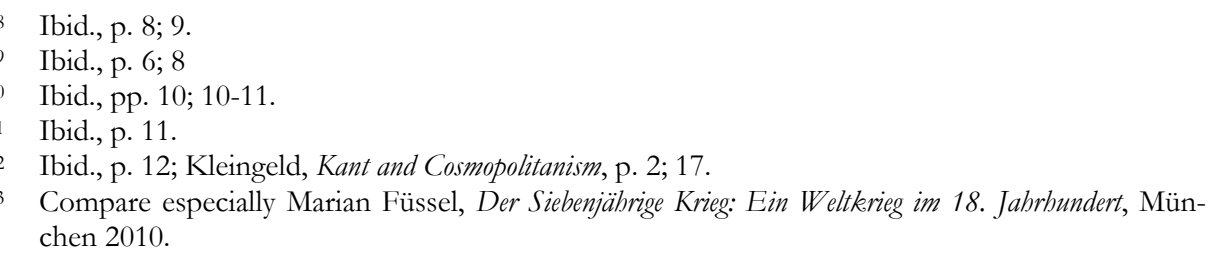


nity but what is good for the whole of humanity. ${ }^{44}$ This assumption is consistent with the view that all human beings are related with each other as citizens of a world-wide moral polity, which somehow transcends local allegiances. What the Stoics have done here is derive a principle for political practice from moral reasoning. But this principle seems to demand something unpractical. For there is a sense that, in order to fully embrace it, we might need to violate the allegiance we owe to our own country, state or community. This is because we can easily imagine situations in which the interest of humanity at large is not the same as the interest of our country. It becomes obvious at this point that this was already a potential problem of Cynic cosmopolitanism. But because the Cynics categorically refuse serious political commitment they do not have to face up to it the way Kant and the Stoics have to. From this point of view it seems that the Stoics' moral premise is a fallacy to begin with.Just imagine you had to consider every stranger in the street, even people living at the other end of the world and whom you have never met as just as valuable to yourself as your own parents, your siblings or your friends. ${ }^{45}$

Kant resists these objections. To him, the assumption that we have moral obligations toward humanity at large is not absurd. He denies that this must lead to the loss of our identity and claims that love of one's country is not only compatible with but even necessary for cosmopolitanism.

I want to examine Kant's defence of moral cosmopolitanism first. The issue at hand iswhether we must give up our special attachment to our family and friends if we consider all human beings to be equally valuable? Obviously we could never easily accept such a demand. But is that what moral cosmopolitanism means? Is it really meant to override particular allegiances in this way? An important way in which Kant fends off the allegation that moral cosmopolitanism is necessarily opposed to particular allegiances is by demonstrating that there is a difference between perfect and imperfect duties. Perfect duties oblige one to commit certain acts, whereas imperfect duties merely compel one to take up certain maxims. If interpreted as obliging us in an imperfect sense moral cosmopolitanism is fully compatible with maintaining particular allegiances for we may have one maxim to love our parents and another to embrace all of humanity. These maxims do not have to be at odds. But if they were it would be legitimate for us to fail one of them; provided, of course, that we had actually taken it up. ${ }^{46}$

This solution justifies political cosmopolitanism, too. But Kant does not merely claim that attending to the needs of one's country is compatible with cosmopol-

44 Nussbaum, "Kant and Stoic Cosmopolitanism", p. 6.

45 Kleingeld, Kant and Cosmopolitanism, p. 19; For the sake of making a clear argument in my treatment of Kant's defence of moral and political cosmopolitanism, I diverge slightly from Kleingeld, whose distinction between these two dimensions of cosmopolitanism is less pronounced.

46 Ibid., p. 32. 
itanism but that it is necessary for it. In order to appreciate how Kant bases this claim, I have to go further and examine his understanding of republicanism. What is of utmost importance in the normative evaluation of a political system to Kant is its capacity to guarantee the individual freedom of each of its citizens. ${ }^{47} \mathrm{Kant}$ claims that republics are best at this and that they represent the most just form of government. ${ }^{48}$ In theory there exists a state before individuals form a state. This is what Kant calls "the state of nature." The state of nature is characterized by the existence of constant potential threats to the individual's freedom. There are no laws regulating human interaction. Anyone can be killed or injured at random or have her/his property taken away from her/him. ${ }^{49}$ Thus, it is reasonable that people who interact with one another on a constant basis invent rules regarding how they should behave and, thus, bring the potential threat to their freedom, which prevails in the state of nature, under control. In Kantian terms this means that they form a state and to form a state means to exit the natural state. ${ }^{50}$ It becomes obvious this way why Kant conceives of the implementation of individual freedom as the decisive factor in judging a political system. On Kant's account individuals enter the state to have their individual freedom enforced. ${ }^{51}$ But if a political system is not able to do so because it implements slavery or serfdom, the value of the state is questionable; hence, a republic follows with necessity.

In a republic the individuals gives up her "wild freedom" 52 but retrieve it in the form of citizenship. That is, they must submit to the prevailing laws but these laws also work in their interest. What is more, as citizens they hold the right to politically influence the passing of laws through representatives. ${ }^{33}$ This ensures that the citizens do not fall victim to the terror of unjust laws that were passed by their forefathers. What is important here is Kant's emphasis on justice. For him "patriotism", as he calls it, does not pertain to one's membership in an ethnic, religious or national group but to a just political system. ${ }^{54}$ What becomes clear from this is that the form of local allegiance Kant wishes to uphold is not equivalent with nationalism. Nationalism is the uncompromising belief that one's own country is 'the best country' and that it is always right. But this attitude is unreasonable and therefore simply indefensible within Kant's framework. What justifiies the pride we take in our country is that it is pride about the justice of our political system, which guarantees our freedom. But of course there is no real guarantee that our country will remain this way. We must do something in order for this status to prevail. Accordingly, we are not merely free to monitor the state of justice in our

47 Ibid., pp. 28-29.

48 Ibid., pp. 27-28.

49 Ibid., p. 29.

50 Ibid.

51 Ibid.

52 For this term see ibid., p. 48; 50.

53 Ibid.

54 Ibid., p. 20. 
state and to uphold and further it but we have a duty to do so. ${ }^{55}$ Patriotism is a necessary condition for the existence of a republic. Significantly, this duty includes that we must criticize our country when it adopts policies that are unjust toward foreigners. ${ }^{56}$ It is due to the circumstance that patriotism is not just conducive to the state of justice in a republic but a condition of its possibility, that it turns out to be necessary for cosmopolitanism, too. Actually patriotism is a form of political cosmopolitanism, which contributes directly to Kant's project of perpetual peace. Ergo, everyone being a patriot is a condition for the possibility of a world, wherein there would only be republics. Republics, according to Kant, do not tend toward warlike conduct among one another. ${ }^{57}$ One of the deeper reasons as to why republics abstain from waging with each other is that in a republic the cost of war is born by the citizens. ${ }^{58}$ Moreover, it is not conducive to trade and economic relations in which the citizens take an interest. ${ }^{59}$

\subsubsection{International Right: Republicanism and World-Government}

One may or may not aree with Kant's assessment that republics do not tend towards war. . What would appear to be accurate is that democratically governed states have not tended to fight among one another historically. However, what is most surprising about Kant is how from his argument flows a sense that in order to establish perpetual peace and international justice the differences between states need to be abandoned. After all, states interact with one another just like individuals do. Also, we have already seen that Kant conceptualizes the phenomenon of war in analogy to the natural state that exists between individuals before common government is established. On this take, it would make sense to advocate that all states be absorbed into one state encompassing the entire globe and all peoples. Yet such a conclusion would contradict Kant's argument in favour of patriotism, which implies a multiplicity of fatherlands. In fact, Kant advocated a federal republic of different states as ideal. ${ }^{60}$ However, during Kant's period there were theorists who held that the establishment of a world-state was exactly what was needed in order to implement peace and progress. To them, the coercive establishment of a world-state seemed justified. ${ }^{61}$

Kant opposed such attempts at an ad hoc implementation of a worldgovernment. ${ }^{62}$ According to him, a world-state cannot be established through coercion because non-coercion is an international right. This is due to a significant

\footnotetext{
Ibid., pp. 29-31.

Ibid., p. 33.

Ibid., pp. 31-32.

Ibid., p. 33.

Ibid., p. 83.

Ibid., pp. 50-51.

Ibid., pp. 40-41.

Ibid., p. 51.
} 
incongruity between the state of nature as concerning the interaction among individuals and among states. On the level of individuals a person may be coerced into joining a state when $\mathrm{s} / \mathrm{he}$ interacts with its citizens on a regular basis. In this case Kant judges coercion to be justified because the state defends every citizen's personal freedom. Thus, joining it is in the interest of the coerced individual. But this does not apply at an international level. This is because states grant political autonomy as a constitutional right to their citizens, which is something an individual existing in the state of nature does not possess. Thus, citizens already are politically self-determined, and to seek to override their political autonomy is arbitrary. ${ }^{63}$ Moreover, it is implausible to try to overcome the international state of nature by resorting to coercion, whose effects are worse than that state.

The most important lesson which may be learned from Kant is that inimagining the overcoming of the international state of nature one must think historically and in terms of process. Historically the creation of different states antedates the moment in time from which we envisage world-government as desirable. The historical process of the dwelling of individuals in states naturalizes the existence of states ${ }^{64}$ and even though all humans are equal on moral grounds and ought to be so politically they may not want to live together in a world-state. Yet what they want is what matters in Kant's republican line of argument. ${ }^{65}$ What needs to be done in order to establish peace, Kant suggests, is the founding of a voluntary league, wherein the different member-states cooperatively legislate rules and regulations for interaction. ${ }^{66}$ This will initiate a historical process toward perpetual peace ${ }^{67}$ as the members, thriving and dedicated to both internal as well as external peace and justice, will attract more and more participants. ${ }^{68}$

\subsubsection{Cosmopolitan Right: Hospitality and Sovereignty}

Kant's discussion of cosmopolitanism is not limited to questions of constitutional and international right. Another important way in which Kant thinks about cosmopolitanism is with regard to cosmopolitan right. This pertains to the interaction between individuals and states and, thus, is not covered by international agreement, which only concerns relations between states. ${ }^{69}$ It applies, for instance, in the case of merchants, who try to establish and maintain business relationships with other states. In the course of such business interactions the individuals involved potentially impact on each others' freedom. To Kant it is imperative that

\footnotetext{
63 Ibid., pp. 53-57.

64 Ibid., pp. 63-64.

65 Ibid., p. 51.

66 Ibid.

67 Ibid.

68 Ibid., pp. 65-67.

69 Ibid., p. 72; 74-75.
} 
such interaction be regulated. For otherwise the international state of nature may not be completely overcome. ${ }^{70}$

Kant's immediate impetus for engaging with this issue was provided by the way in which early modern Japan and China conducted business with foreign traders. The Japanese, for instance, allowed contact with Dutch traders only once a year. When the Dutch came they were kept contained on a small island off the Japanese coast. They were not allowed to enter the mainland. During Kant's time it became a point of debate among Europeans whether countries had a right to deny individuals access to their domain in this way. ${ }^{71}$ Kant's contribution to this issue is often overlooked, even though it is of importance to his theory of international relations. I have mentioned that Kant insists that states engaging in a loose league, in the context of which they negotiate multilateral legal agreements, do not have to sacrifice their sovereignty. The issue of cosmopolitan right, however, touches directly upon how such sovereignty may in fact be limited by the rights of individuals. In the end Kant ruled in favour of Chinese and Japanese politics of reclusiveness. He defended their right to act in this way on the basis that they merely wished to forestall European colonial intrusion, which by that time had already established its hold on various places in Asia. On Kant's interpretation their acting in this way amounted to making use of the right to self-defence. ${ }^{72}$

Having argued in this way Kant nevertheless left no doubt that there were instances in which states could be obliged to provide what he called "hospitality." 73 Requests for access to a state's domain may be made by persons at any time. States have the duty to audition such requests but hold the right to deny access. In this case their duty to provide hospitality goes no further than to meet the requests with non-hostility. ${ }^{74}$ However, there are certain requests for hospitality that cannot be denied. This would be the case if a person could be denied hospitality only at the expense of his/her "demise." 75 Kant justifies this principle by arguing that individuals have an innate right to freedom. We have already seen why this is the case. But being free requires existence, and existence requires a place to exist in. If the refugee cannot help being where $\mathrm{s} /$ he is, $\mathrm{s} /$ he must be permitted to stay on. ${ }^{76}$

One may point out that, in suggesting such a principle, Kant anticipated the discussion over the rights of refugees that ensued in the twentieth century. ${ }^{77}$ Modern people are therefore likely to find Kant's argument laudable. It, nevertheless, runs into problems when we imagine that an individual, in claiming hospitality,

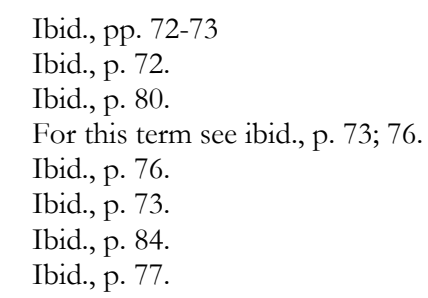


might infringe upon the private property of another individual. Kant calls to attention that individual states may raise taxes to finance welfare. He suggests that in analogy to this a universal state might oblige individual world-citizens to solidarity with their fellow citizens in need and to permit encroachment on their property in case this is vital to the maintenance of another person's existence. ${ }^{78}$

Another problem concerns Kant's interpretation of the reclusive behaviour of China and Japan. For his argument that the Chinese and Japanese use self-defence may be challenged by way of pointing out that the political systems of Japan and China are applying undue coercion by depriving their citizens of the possibility of establishing relationships with foreigners, which they might otherwise approve of. ${ }^{79}$ One way of loosening up the grip of this counter-argument is to point out that if the Japanese and Chinese citizens had a say, it would not be illegal if they came to exactly the same decision as their rulers. ${ }^{80}$ Kant also makes it clear that whether a state is a republic or not is a matter of the internal affairs of that state, in which cosmopolitan right has no say ${ }^{81}$, which is consistent with the principle of non-coercion.

What this shows is that Kant's cosmopolitan right concerns a number of issues that cut across the rather straightforward international regulations in a complex way. It complicates Kantian theory and deepens its insights as to the relation between individuals and states. It also contains the proper realization of the demands made by moral cosmopolitanism. For, the cosmopolitan right is shared by all people regardless of their local or national affiliations. ${ }^{82}$

From this point one may still go a lot further in exploring Kant's cosmopolitanism. I shall presently content myself with a concluding summary regarding the differences and similarities between Kant's understanding of cosmopolitanism and that of the Stoics and Cynics. In doing so, we may note that Kant's approach differs from that of Diogenes in that cosmopolitanism serves a different and quite specific purpose: the establishment of international peace. This notion was already present in the Stoics' moral cosmopolitanism but Kant's approach is also different from theirs as he does not limit his efforts to positing normativeprinciples. Even though he agrees with the Stoic humanitarian ideology, Kant has accepted that human beings have selfish urges, which they must follow. Among other things, he seeks out ways in which our selfish desires may be reasonably compatible with these humanitarian ideals and on that basis wishes to construct regulatory mechanisms for social interaction. In doing so, Kant develops cosmopolitanism further from its anarchist seclusion in Diogenes to a more government-affirmative position, which makes him akin to the Stoics. But unlike the Stoics Kant transforms

\footnotetext{
78 Ibid., pp. 85-86.

79 Ibid., p. 80.

80 Ibid., p. 81.

81 Ibid.

82 Ibid., p. 75 .
} 
cosmopolitanism from a guideline for politicians to a legal principle that is practically binding for everyone. Most importantly, Kant demonstrates that the cosmopolitan ideal is compatible with more local allegiances - a problem that was not solved well by the Stoics.

Finally, using the notion of cosmopolitan right, Kant opens up a space for the legal regulation of social interaction that involves individuals as well as states but that takes place beyond the level of individual states. This is where we encounter Kant at his most cosmopolitan. Moreover, there is a lingering sense in Kant's philosophy that the achievement of peace must be imagined not only in terms of reason but also in terms of process and of history. Nothing could be more damaging than to take quick action once we have identified what is rationally desirable. Our theories also need to meet the requirements of empirical reality. Accordingly, Kant suggests the issue of peace may not be forced. We may only hope to initiate a process that will eventually lead us there.

\subsection{Contemporary Cosmopolitanism: World Citizenship in the Age of Globalization}

\subsubsection{Cosmopolitan Order versus Westphalian Order}

As was implied earlier, in the period immediately succeeding Kant's time there emerged a heightened sense of nationalism in many European countries. ${ }^{83}$ In 1871 a German nation-state was founded, uniting the greater part of German-speakers within a centrally governed territory. The fascination with newly discovered national identities, especially in Germany, turned into an obsession, an exaggerated notion of the significance of national belonging that culminated in two world wars in the twentieth century, which drove Europe and the world to the brink of destruction. During this period of increased particularism the project of cosmopolitanism lay dormant. One could not say that it was completely forgotten. But when it was addressed by intellectuals such as the historian Friedrich Meinecke or the philosopher Edmund Pfleiderer it was typically subjected to ridicule. ${ }^{84}$

Why cosmopolitanism appeared incompatible with nineteenth and early twentieth century nationalist sentiment should already be obvious: Nationalism is the belief in impenetrable, almost natural boundaries that distinguish peoples from one another. Cosmopolitanism, on the other hand, is more about how such boundaries may not be absolute and that we may reach out across them. Kant even suggested that there is a necessity to do so and, although he held the political autonomy of individual states in high regard, his notion of cosmopolitan right indicates that this

83 For a full account of the rise of nationalism in nineteenth and twentieth century see: Eric Hobesbawm, Nations and Nationalism since 1780: Programme, Myth, Reality (Wiles Lectures given at the Queen's University Belfast), Cambridge/New York/Melbourne [et al.] 1990. 
autonomy may be positively limited. This notion contradicted the Westphalian Order, the dominant ideology of international politics in the nineteenth and early twentieth century, which conceptualized states as possessing absolute sovereignty. ${ }^{85}$ It was not until World War II that the Westphalian Order was recognized not to have paid off. The Westphalian order was ultimately overcome with the holding of the Nuremburg Trials, the foundation of the United Nations (UN) and the proclamation of the Universal Declaration of Human Rights and a number of other international rights ${ }^{86}$ On the basis of such agreements states were to be made accountable for the measures they inflicted upon their citizens.

However, it was not until after the Cold War that the new order could fully come to the fore. When the Berlin Wall came down and released the world from its bipolar interlock, this event coincided with the emergence of an increased awareness of the global interconnectedness and interdependence in terms of financial markets, communication and environmental problems. ${ }^{87}$ Not only did a return tothe Westphalian model appear historically undesirable but the institution of the nation-state had been radically undercut by global economic developments. It was in this context that the idea of cosmopolitanism came to flourish again. The anthropologist Pnina Werbner has identified three strands of "normative cosmopolitanism" which emerged in this context, two of which I will treat in some detail. 88 There is the notion of cosmopolitan democracy, whose main proponents are the political scientists Daniele Archibugi and David Held, and which will be discussed in the immediately succeeding chapter. Ulrich Beck's approach to cosmopolitanism, which will be discussed under headings 2.3.3 and 2.3.4, is of specific interest as Beck is a sociologist. Accordingly, his approach to cosmopolitanism differs in some respects from the more philosophical understanding of cosmopolitanism I have developed so far.

\subsubsection{Cosmopolitan Democracy: Globalizing Democracy and Democratizing Globalization}

David Held's and Daniele Archibugi's notion of cosmopolitanism - the term cosmopolitan democracy suggests as much - is profoundly intertwined with democracy. This, of course, suggests a theoretical proximity to Kant, who deemed republicanism an essential means for the overcoming of the international state of nature. As a matter of fact, cosmopolitan democracy is rooted in Kantianism. Yet it also diverges from it in important ways. Significantly, Held synthesizes Kant's approach with insights from the hermeneutical tradition.

85 Pnina Werbner, "Introduction: Toward a New Cosmopolitan Anthropology", in: Anthropology and the New Cosmopolitanism, p. 3.

86 Ibid.

87 Ibid.

88 Ibid., pp. 2-8; I do not entirely concur with Werbner's characterization of these perspectives as normative. She applies this label to Jürgen Habermas and David Held, which, to me, is fine. However, I do not see how Beck's perspective could be said to be normative in the same sense. 
One way in which cosmopolitan democracy diverges from Kant is in that it conceptualizes cosmopolitanism not solely as a means of overcoming the threat of international warfare. ${ }^{89}$ Of course, this is still a problem and a very important one for that. But there are other issues pertaining, for example, to the regulation of international financial exchange or environmental pollution. Due to increased global interdependencies issues such as these can no longer be democratically resolved by state-based decision-making. For example, the United States should not unilaterally decide to violate the Kyoto Protocol because the result of such an infringement does not merely affect Americans but all of humanity. ${ }^{90}$ But the effects of global processes need not necessarily concern humanity at large to pose a problem.Some processes may impact upon individual members of a religious community who live in different countries. In a similar way employers of a multinational company may be equally affected by the fortunes and misfortunes of their company. ${ }^{91}$ The point is that due to the increasingly global dimension of economic, social, religious and cultural processes the stakeholders in such processes are increasingly less correspondent with nations. This phenomenon, which David Held calls "overlapping communities of fate" 92 , poses a problem because current institutions of global governance, so-called international governmental organizations (IGOs), like the UN are dominated by governmental officials. But such officials represent the interests of states, which have gradually become less equivalent with the communities affected by global political decision-making. ${ }^{93}$ According to Held and Archibugi, all of this suggests that we require more specialized forms of democratic participation. Much of the current literature on cosmopolitan democracy explores what institutional reforms and innovations are necessary in order to democratize globalization. ${ }^{94}$

However, the wider point of cosmopolitan democracy is not that states need to be abandoned. Archibugi acknowledges that the nation-state has been instrumental in granting rights to minorities and may continue to do so. ${ }^{95}$ Also, the cosmopolitan

89 Daniele Archibugi, "Cosmopolitan Democracy and its Critics: A Review", in: European Journal of International Relations 10:3 (2004), p. 442.

90 Ibid., p. 443.

91 Ibid.

92 Ibid.; Jean-Paul Gagnon, "An Interview with Professor David Held: Exploring the Concepts of Cosmopolitanism and Democracy", in: Journal of Democratic Theory 1:1 (2011), p. 3.

93 Archibugi, "Cosmopolitan Democracy", p. 443.

94 In his interview with Gagnon David Held explains how he began working on the project of cosmopolitan democracy many years ago under the influence of Horkheimer and Adorno. Held expresses dissatisfaction with these authors' tendency to simply criticize the existing state of affairs without making substantial suggestions as to how it may be changed for the better. (Gagnon, "An Interview", pp. 6-7.) As a remedy Held suggests that political theory ought to operate at different levels. One such level which Held designates "agitatorial" is specifically designed to translate more abstract philosophical reasoning into suggestions for institutional reform and innovation. (Ibid., p. 6.)

95 Archibugi, "Cosmopolitan Democracy", p. 447. 
effort is not restricted to the democratization of IGOs. Rather, cosmopolitan democracy aims to extend democratic principles to all levels of government, be they local, regional in a sub-national sense, national, regional in a supra-national sense, or global. ${ }^{96}$ Held argues that a laudable attempt at such a "multilayered citizenship" can be found in the EU: A person living in Glasgow, for instance, may participate in local, regional and national elections, as well as in the United Kingdom general elections and EU elections. ${ }^{97}$ All the relations we stand in ought to be democratized in this way. Importantly, however, Held admits that it is as yet unforeseeable where exactly this process of democratization will finally take us and what forms of democratic deliberation and participation it will generate..$^{98}$ This is partly a lesson learned from globalization. In all likelihood the world will keep being transformed in unpredictable ways, will remain dynamic, and we will always have to re-think and re-adjust our efforts to consolidate democracy and the rule of law. This is also the point at which Held incorporates principles from hermeneutics into his approach. According to him, we always have to re-interpret democracy as we apply it to a new social context or situation ${ }^{99}$ and this process is potentially never-ending. ${ }^{100}$

This leads me to what the term cosmopolitanism actually designates within Held's and Archibugi's framework. In many of his publications Held describes cosmopolitanism as a set of universal principles underlying democracy ${ }^{101}$, which he partly derives from empirical inquiry into the nature of various historical political systems that qualify as democratic. ${ }^{102}$ For example, like Kant and the Stoics he, firstly, argues that all humans are of equal moral value and deserve to be treated equally by the state. To this Held adds the notion that all humans possess what he calls "transformative agency", which means the capacity to make decisions regarding issues that concern them. ${ }^{103}$ Accordingly, all human beings should be regarded as capable of self-determination and this capacity must be safeguarded and respected by politics. This idea was also implicit in my earlier account of Kantian cosmopolitanism, specifically with regard to Kant's notion of republicanism, which may be understood to imply a democratic participatory system. From Held's point regarding transformative agency follow, thirdly, responsibility and accountability: In their transformative capacity social agents may often change the world in ways that affect others and what needs to be ascertained that these

\footnotetext{
96 Gagnon, “An Interview”, p. 2.

97 Ibid.

98 Archibugi, “Cosmopolitan Democracy”, p. 440.

99 Gagnon, “An Interview”, p. 8.

100 Archibugi, "Cosmopolitan Democracy", p. 440.

101 Held argues that, for him, cosmopolitanism corresponds to the principles of democracy without territorial borders. (Gagnon, "An Interview”, p. 2.)

102 Held alludes to his empirical research on democratic models several times throughout his interview with Jean-Paul Gagnon. (Ibid., p. 1; 7-8.)

103 Ibid., p. 2.
} 
changes are not harmful. This, in turn, necessitates the principle of collective decision-making and so on. ${ }^{104}$

When comparing Held's definition of cosmopolitanism as the universal principles underlying democracy and his insistence on the hermeneutical maxim, according to which democracy will always have to be re-interpreted and, thus, transformed, it might not immediately be clear how these two notions should be compatible with one another. Held has argued that democracy will always have to be translated into specific contexts. However, in order to translate democracy in this way we need to have principles first. Accordingly we could not abandon one of the essential principles on which democracy is based in our interpretation - such as the idea of accountability of political agents or that of the right to equal participation of all citizens - and claim that we were upholding democracy. Conversely, the interpretation and application of the principles may not be pursued outside the context of public dialogue ${ }^{105}$, to which the democratization of institutions cosmopolitan democracy suggests should be conducive. Held, at some point, claims that his principles for democracy are universal but not eternal. ${ }^{106}$ What this paradoxical statement seems to suggest is that he regards his account of the principles of democracy as fallible. Hence, anyone can reasonably object to his account, add or contest principles or suggest adjustments. Held is not insisting on his account of principles but on the necessity of principles more generally.

Another possible objection to cosmopolitan democracy is that it disregards the plurality of culturally derived value-orientations and interpretive standpoints by superimposing Western standards onto international procedures. ${ }^{107}$ Held rejects this by arguing that it is precisely because cosmopolitan democracy acknowledges that people differ in their understanding of right and wrong that it seeks to establish a framework for discussion. ${ }^{108}$ Cosmopolitan democracy is dedicated to ethical neutrality and ethical pluralism. Yet in order to enable pluralism cosmopolitan democracy requires commitment to a political structure that facilitates the imposition of possible sanctions on ethical positions that are actually harmful to that pluralism. ${ }^{109}$ The notion that democracy belongs purely to the West has become more difficult to maintain in the light of the democratic aspirations of the Arab Spring or the political movements of many Third World national minorities demanding participation and equality (e.g. untouchables in India). What is more, anthropological research such as that of David Graeber has demonstrated that if we strip democracy to its core principles, we suddenly become peculiarly aware

104 Ibid. Held's entire set of principles is also mentioned in David Held, "Cultural Diversity, Cosmopolitan Principles and the Limits of Sovereignty", in: Idem/Henrietta L. Moore (eds.), Cultural Politics in a Global Age: Uncertainty, Solidarity and Innovation, Oxford 2008, p. 159.

106 Held, "Cultural Diversity", p. 161.

107 Ibid., p. 160.

108 Ibid., pp. 160-161.

109 Ibid., p. 162. 
that it is and was by no means restricted to 'the West' but played a role in the history of many different cultures at different times. ${ }^{110}$ David Held argues that in particular Islam's contribution to this tradition has been significant. ${ }^{111}$

\subsubsection{Cosmopolitan Sociology, Cosmopolitanization and World Risk Society}

As I have already indicated, Ulrich Beck's approach to cosmopolitanism differs from the more philosophical cosmopolitanisms of Held, Kant and Diogenes. All of the latter denote ways of thinking about what we ought to do and what institutions we ought to create in order to transform the world in an ideal way. Beck's approach, however, is not philosophical and, for that, is not normative in the same sense. To be sure, Beck also advocates something as ideal, thinks that we should do something and this something is also called cosmopolitanism. However, Beck thinks of cosmopolitanism more in terms of a new methodology for social science. He advocates what he calls a "methodological cosmopolitanism" in the social sciences or a "cosmopolitan sociology."

As in the case of cosmopolitan democracy, Beck's demand for a "methodological cosmopolitanism" must be understood as a reaction to globalization. He starts off on the diagnosis of a profound ontological transformation of global social structures to the extent that these have become increasingly transnational. ${ }^{112}$ It is Beck's central contention that the framework of traditional sociology, has become insufficient in dealing with these new ontological conditions ${ }^{113}$ which Beck calls "Second Modernity."114

One way in which this conventional "methodological nationalism", as Beck calls it, fails is in the development of an appropriate framework for assessing and analyzing global inequality. According to Beck, the fact that many social scientific and economic statistics merely assess social inequality within nation-states leads to the belief that such issues are mere national phenomena. ${ }^{115}$ However, this is not so and Beck argues that there is sufficient reason to believe that the more developed countries of Europe and North America frequently pass on poverty risks to less developed states. As an example Beck names the protectionist policies Europeans

110 David Graeber, "On Cosmopolitan and (Vernacular) Democratic Creativity: Or, There Never was a West", in: Anthropology and the New Cosmopolitanism, pp. 281-305. Note that Werbner mentions Graeber's work in the same context in her introduction (Werbner, "Introduction", p. 3).

111 Held, "Cultural Diversity", p. 163.

112 Ulrich Beck, "The Cosmopolitan Society and Its Enemies", in: Theory, Culture \& Society: Explorations in Critical Social Science 19:17 (2002), p. 29.

113 Ibid., p. 24; Ulrich Beck, "Kosmopolitisierung ohne Kosmopolitik: Zehn Thesen zum Unterschied zwischen Kosmopolitismus in Philosophie und Sozialwissenschaft", in: Helmuth Berking (ed.), Die Macht des Lokalen in einer Welt obne Grenzen, Frankfurt [a.M.]/New York 2006, p. 252.

114 For a definition of Beck's notion of First and Second Modernity see ibid., p. 264.

115 Ibid., p. 265. 
and the US apply to their agrarian commodity markets in order to save them from having to compete with African and Latin American goods. ${ }^{116}$

According to Beck, problems such as these cannot be properly analyzed and understood at present because they hardly ever show up on the radar of social sciences. He makes many suggestions as to how the framework of social science might be reformed in order to make it more sensitive to the increased transnational interdependencies of social, economic and political processes.117 One phenomenon that Beck thinks social science needs to come to terms with is what he calls "cosmopolitanization." Cosmopolitanization, according to Beck, is about how globalization transforms nation-state societies from inside. ${ }^{118}$ It is essentially the increased intermixing and confrontation of alternative (cultural) ways of life within territories that used to be more culturally homogenous. ${ }^{119}$ This process, of course, may be much older than the rather recent post-Cold War economic trends that we refer to as globalization. After all, peoples and cultural groups have been settling, re-settling and intermingling with others all throughout history. No doubt Beck means to suggest that cosmopolitanization is now accelerated not only by an increased degree of international migration but also by the spread of telecommunication and internet, both of which, in turn, are facilitated by economic globalization. ${ }^{120}$ Thus, cosmopolitanization is an old process that is increasing in scope but - and this is most significant to Beck - what is new is that we are increasingly becoming aware of it. ${ }^{121}$

This phenomenon Beck refers to as "globality" or "reflexive globalization."122 Before I discuss this I want to more fully explore what cosmopolitanization entails. The reason why Beck refers to this process as cosmopolitanization is, as he claims, because it has made some of the dreams of philosophical cosmopolitanism come true and that this has happened mostly without any of the institutional guidance that cosmopolitan philosophers usually demand. ${ }^{123}$ One of these dreams was the wish to include the excluded. But this, Beck claims, is exactly what reality today is like. ${ }^{124}$ People increasingly lead transnational lifestyles and that this is not limited to rich Western entrepreneurial classes. One may imagine, for instance, a Pakistani working in the US, whose family stays behind in Islamabad but who,

116 Ibid., p. 266.

117 Note, for instance, Beck's adaption of Saskia Sassen's notion of the city as a node of international flows (Beck, "The Cosmopolitan Society", p. 23) or his discussion of concepts such as "de-territorialization" and "imagined presence" (Ibid., p. 31).

118 Ibid., p. 17.

119 Ibid., p. 18

120 Beck at some point seemingly agrees with Kant that cosmopolitanism or cosmopolitanization, as he calls it, is brought on by the global spread of economic relations (Ibid., p. 29).

121 Beck, "Kosmopolitisierung ohne Kosmopoliten", p. 260.

122 Beck, "The Cosmopolitan Society", p. 21.

123 Beck, "Kosmopolitisierung ohne Kosmopoliten", p. 255.

124 Ibid. 
nevertheless, retains a presence in the imagination of his family at home ("imagined presence"), which is aided by telecommunication and the internet. ${ }^{125}$ Beck suggests that people like this simultaneously belong to two different places, that in a sense they even are in both places at once ${ }^{126}$. Hence, clear-cut differences between being a citizen or not, belonging to a place or not, the principle of either-or, which pervaded throughout and ordered "First Modernity" is increasingly being undermined. ${ }^{127}$ This is what Beck calls "cosmopolitan realism." Nineteenthcentury polemic attacks on Kant ridiculed his notion of cosmopolitanism as "idealistic" because national egotism was the way in which reality was apparently structured. Beck claims that the tables have turned and that now nationalism and, therefore, methodological nationalism are outmoded because reality is ontologically increasingly cosmopolitan. ${ }^{128}$

Nevertheless, Beck is mindful not to give the impression that the cosmopolitanization will necessarily produce a rosy cosmopolitan future. He states that there is, in fact, a dialectical relation between cosmopolitanization and anticosmopolitanization. This may, for instance, be seen in the rise of popular rightwing parties within Europe such as the UK Independence Party, or Lega Nord. ${ }^{129}$ Another example is the increased focus on national security in the US and other countries after $9 / 11 .{ }^{130}$ There is a sense that cosmopolitanization and especially our becoming aware of it may exactly lead to renewed efforts of drawing boundaries. Yet Beck also suggests that this tendencymay not persevere since there is yet another dialectical process interfering with it. This other dialectic is related to what Beck calls "world risk society." According to this theory, globality (or reflexive globalization) will ultimately produce a global awareness of great future risks such as the threat of ecological disaster or poverty and that these risks are equally shared by all human beings. This will necessitate global consensus for political action and provide humans with a shared sense of belonging. Thus, the more threatening shared risks will appear, the more urgent will be the need to lay aside differences and come to agreements. ${ }^{131}$

\subsubsection{Universalism, Hegemony and Relativism}

In summary, what may be noted, again, is that one major aspect that sets Beck's approach apart from the more philosophical understanding of cosmopolitanism is his focus on the need to re-think categories, concepts and theories of empirical

125 Beck, "The Cosmopolitan Society", pp. 30-31.

126 Beck, "Kosmopolitisierung ohne Kosmopoliten", p. 257.

127 Ibid. Note also Beck's discussion of what he calls "exclusion crisis" (Beck, "The Cosmopolitan Society", pp. 19-20).

128 Beck, "Kosmopolitisierung ohne Kosmopoliten", p. 253.

129 Ibid., p. 256.

130 Ibid.

131 Ibid., p. 263. 
sociological research. Yet this does not mean that Beck has nothing to contribute to the more philosophical discussion. In fact, he contributes some important coordinates from social theory that can be used to complement the more philosophical analysis: This is the opposition between the principles of universalism and relativism. To be sure, this antagonism between universalism and relativism will ultimately play a role in my discussion of the two postcolonial theorists.

Beck first describes the "two faces of universalism" as corresponding to Samuel P. Huntington's notion of the "clash of civilizations" on the one hand and Francis Fukuyama's idea of the "end of history" on the other. According to Beck, Huntington's universalism is a "universalism of difference": There are hierarchies between different cultures. Some are more advanced than others and, hence, are superior. These differences are universal and unbridgeable. This is why the West and Islamic civilization are culturally fundamentally opposed to one another. Fukuyama's universalism, by contrast, is a "universalism of sameness": There are cultural differences but they are not so important. In fact, they are transcended by an underlying universal sameness of all human beings. ${ }^{132}$ Beck compares this model to Christian universalism, which enabled missionaries to defend the equal humanity of indigenous people against claims that they were racially inferior to Europeans. ${ }^{133}$

Significantly, Beck at this point does not go on to discuss Huntington's universalism of difference, which is chauvinistic. However, he also makes a critical point about Fukuyama's universalism. There is, of course, something incredibly desirable about this type of universalism. It enables one to transcend perceived difference and to feel for strangers as sincerely as we feel for ourselves and our kind.134 It enables identification. Its shortcoming is more difficult to understand but it helps to imagine what would happen if one was to absolutize this principle. What would happen is that the difference of others would cease being valuable in itself. We could not appreciate someone for just being different from us but s/he would only matter as far as s/he reaffirmed our sense of self. ${ }^{135}$ Beck gives the example of American citizenship: In the United States there are many different people bearing all sorts of different cultural heritages. However, they are all united as Americans. Beck claims that what one encounters here is a dialectic between difference and conformity: The more internal difference a society possesses, the stronger becomes the pressure on individual groups to conform to overarching universal values. ${ }^{136}$ However, the problem is that what is considered universal might just be instituted by a particular social group. It is a 'pseudo-universalism'

\footnotetext{
132 Ulrich Beck, "Realistic Cosmopolitanism: How Do Societies Handle Otherness?", in: Cultural Politics, pp. 61-62.

133 Ibid., p. 62.

134 Beck uses similar imagery to describe the positive side of universalism in his section on relativism (ibid., p. 65).

135 Ibid., pp. 62-63; 64.

136 Ibid., 63.
} 
that is particular to the dominant social group within that society and, thus, absolutized universalism of sameness is hegemonic. ${ }^{137}$ It gaps the difference of the Other at the expense of making this difference insignificant.

It is important to treat this issue at some length and come to a clear understanding of it. This is because all cosmopolitanisms are underpinned by universalism to some extent. Universalism is to some extent necessary for cosmopolitanism. But absolutized universalism is vulnerable to political instrumentalization.

This leads me straight to Beck's discussion of relativism. To Beck, relativism is on the opposite side of the spectrum. It is the contention that the Other has a unique perspective that is different from ours and that this perspective has a right to exist as well as value in itself. ${ }^{138}$ This is what keeps universalism from being a demand to conformity. However, just like universalism relativism may not be absolutized. For if this is done, we find that our perspective and the perspective of the Other are essentially incommensurable, and that the Other is so alien that mutual understanding must be impossible. Extreme relativism, thus, achieves exactly what it tries to avoid: essentialism. ${ }^{139} \mathrm{I}$ might add that such an idea is also critical since it would appear to negate the legitimacy of universal human rights.

\section{The Postcolonial Perspectives: Rooted and Vernacular Cosmopolitanism}

\subsection{What is Postcolonial?}

Before I get started on the two postcolonial conceptions of cosmopolitanism Kwame Anthony Appiah's notion of "rooted cosmopolitanism" and Homi Bhabha's "vernacular cosmopolitanism" - I feel it in order to address briefly the question of what the term 'postcolonial' may entail in the present context. Generally, one may ask things like what or who is postcolonial, what is the 'postcolonial age' and what do 'postcolonial studies' do? Of course, the most obvious thing would be to believe that the term 'postcolonial' simply refers to the way things are after the end of colonialism. This, however, leaves us stranded with the problem of defining 'colonialism.' All throughout history, empires existed and, thus, instances of colonialism. Are all these instances of colonialism the same, or do we have to talk in terms of different colonialisms? To be sure, the use of the term postcoloni$\mathrm{al}$ is not stable to the extent that its meaning may be finally settled. However, there are typical ways in which the term is used by postcolonial critics. One such way is

\footnotetext{
137 Ibid., pp. 62-63; 64.

138 Ibid., p. 65.

139 Ibid.
} 
by thinking the postcolonial precisely not as merely referring to the state of affairs that prevails after the end of colonialism. This view we encounter, for instance, in Bill Ashcroft's, Gareth Griffith's and Helen Tiffin's interesting study of postcolonial literatures called The Empire Writes Back. The authors describe their approach in the following way:

We use the term 'post-colonial' [...] to cover all the culture affected by the imperial process from the moment of colonization to the present day. This is because there is a continuity of preoccupations throughout the historical process initiated by European imperial aggression. We also suggest that it is most appropriate as the term for the new cross-cultural criticism which has emerged in recent years and for the discourse through which this is constituted. In this sense this book is concerned with the world as it exists during and after the period of European colonial domination and the effects of this on contemporary literatures. ${ }^{140}$

From this one may, at first, be inclined to think that Ashcroft's use of the term postcolonial is deliberately misleading. This is because the 'post' in postcolonial clearly suggests that something has ended, namely: colonialism. What is more, we actually know that the colonialism Ashcroft is referring to has ended since he clearly means European colonialism. We know, for instance, that India gained its independence from the British in 1947 and that Hong Kong ceased being a British colony in 1997. And yet Ashcroft, Griffith and Tiffin speak of "a continuity of preoccupations" and wish to subsume under the postcolonial both colonial and, hence, historical, as well as formerly colonial cultures.

However, one must not misunderstand the authors here. For their aim is not to suggest that European colonialism did not officially end but that, while it lasted, colonialism impacted on the cultures engaged in "the imperial process" to such an extent that it continues to be felt in the present. Accordingly, after colonialism is not before colonialism. Cultures which were at one point engaged in the imperial process do not simply revert to their pre-colonial state once colonialism has officially ended, but remain forever changed by their experience of it. For instance, many, if not all, formerly colonized countries depend in their present form as nations on a concept derived from their Western colonizers. Would India ever have become a nation-state if it had not been for Gandhi, who adopted the idea of national autonomy from the British? Would many, if not all, of the states of Africa exist in their present form if it had not been for the Europeans' 'Scramble for Africa'? This is precisely why the authors think of their subject-matter and approach as postcolonial rather than colonial: More conventional approaches to colonialism think of it as restricted to the past. But the authors suggest that we may actually understand the present through the colonial past, that we may best

140 Bill Ashcroft/Gareth Griffith/Helen Tiffin, The Empire Writes Back: Theory and Practice in PostColonial Literatures, London/New York 1989, p. 2. 
conceptualize it as a result of colonialism. On this take, the term postcolonial refers to the phenomenon of colonialism in its continuing impact upon its own aftermath. Postcolonial studies is the field of study that inquires into this phenomenon.

But I have quoted Ashcroft, Griffith and Tiffin at some length because the authors offer even more clues pertaining to the present state of postcolonial studies. It is also true, for instance, that, following their example, much of the postcolonial debate has focused on the effects of "European imperial aggression" of the eighteenth, nineteenth and twentieth centuries. However, one must not believe that postcolonial analyses are necessarily restricted to modern and contemporary history. As I indicated above, it is quite difficult to define what colonialism actually is. But while it is undoubtedly true that the modern period witnessed an unprecedented rise of colonial domination, one may ask whether the history of what we call 'Europe' or 'the West' is not itself marked by colonial conquest and domination? There were the Roman Empire, the process of Christianization or Charlemagne's Carolingian Empire. What this makes us recognize is that, strictlyspeaking, the postcolonial is not necessarily confined to one particular period but that it constitutes a conceptual framework that may be applied to a great number of ethnically, politically, culturally, economically and religiously motivated forms of domination that existed throughout history. ${ }^{141}$ Nevertheless, the way the term postcolonial is mostly used by postcolonial theorists and as it appears in the title of this work refers to the present and how it has become what it is.

According to the authors, postcolonial studies are also concerned with 'culture.' The way I see it, the term culture is even more complex and semantically unstable than colonialism. At the most basic level one may conceive of culture culture as opposed to nature, as something that is not given to us by birth. Instead it denotes how our behaviour, our way of thinking, our actions and various, if not all, of our personal features are constituted and shaped by the way in which we relate to other persons and to the various groups we are part of (social constructivism). One basic underlying assumption of this understanding of culture is that what we perceive as our self, our identity is not 'given' but socially constituted and, thus, conditioned by our environment and experiences in complex ways, which may not be positively and finally disentangled and elucidated. ${ }^{142}$ Hence, we may never analyze culture itself but only analyze something in terms of culture.

141 There are some interesting attempts to apply concepts from post-colonial theory to medieval literature and history: Jeffrey Jerome Cohen, Hybridity, Identity, and Monstrosity in Medieval Britain: On Difficult Middles (The New Middle Ages), New York 2006; Jeffrey Jerome Cohen (ed.), The Postcolonial Middle Ages, New York 2000; Ananya Jahanara Kabir/Deanne Williams (ed.), Postcolonial Approaches to the European Middle Ages (Cambridge Studies in Medieval Literature 54), Cambridge 2005 .

142 There is a highly elucidating discussion of the concept of identity in Stuart Hall, "Introduction: Who Needs Identity", in: Idem/Paul Du Gay (eds.), Questions of Cultural Identity, London/Thousand Oaks/New Delhi 2003 (originally published 1996), pp. 1-17. 
This means that culture, just like the notion of the postcolonial, represents a conceptual framework rather than an object. From the cultural perspective one may analyze a great number of, if not all, social phenomena as culturally constituted and, thus, relative rather than natural and necessary. But since culture is the potential driving-force behind all behaviour, every discourse and mindset, cultural analysis cannot be limited to fictional literature. Rather, cinema, biographical narratives, visual art, newspaper articles, material objects and many other things may also be regarded as expressions of culture and, hence, as potential objects of cultural analysis. Thus, the authors' mention of "all the culture affected by the imperial process" as postcolonial implies that they wish to open postcolonial studies to the analysis of all the different objects that are potentially implied by the term culture.

This points to an important feature of the self-image of postcolonial studies. Postcolonial theory and postcolonial empirical analyses may have been pioneered by literary critics. Yet the academic field of postcolonial criticism is in no way restricted to the analysis of literature but regards itself as trans-disciplinary. Consequently, there exist postcolonial niches in disciplines as diverse as history, anthropology, film and media studies, economics, sociology and art history, which have facilitated and advanced the methodological and theoretical exchange between these disciplines.

Finally, the authors also suggest that the term postcolonial may not only be applied to the culture generated and conditioned by the postcolonial experience but that it also designates the discussion of and academic commentary on this culture. As far as literary studies are concerned, much of this "new cross-cultural criticism" harks back to Edward Said's seminal study Orientalism. Said, arguably, was the first to consistently apply post-structuralist methodology to the study of colonialism. In the wake of his work the field of postcolonial theory has emerged as a discourse that seeks to synthesize different theoretical and methodological insights from different disciplines, as well as different frameworks like Marxism, psychoanalysis, structuralism, post-structuralism and feminism. ${ }^{143}$

What becomes obvious from this is that postcolonial theory is not theoretically and conceptually homogenous but encourages diversity and debate among different positions and many theorists have multiple theoretical allegiances. Homi Bhabha, for example, tends strongly towards post-structuralism and psychoanalysis. Kwame Anthony Appiah, by contrast, argues from the standpoint of analytical philosophy. However, alongside his strong affiliation with philosophy Appiah is also a literary critic and literary theorist. In many ways Appiah appears much less attached to the specific conceptual framework of the postcolonial as outlined

143 It is worth mentioning at this point that certain authors associated with anti-colonialism (especially Frantz Fanon), or the American Civil Rights movement (especially W.E.B. Du Bois) may be regarded as early precursors of postcolonial studies, who were practising a kind of postcolonial criticism before Said. To be sure, they remain important points of reference for contemporary theorists. 
above than Bhabha. Hence, it is all the more surprising that, as we shall see, Appiah and Bhabha share certain perspectives in their respective conceptions of cosmopolitanism.

\subsection{Kwame Anthony Appiah's ‘Rooted Cosmopolitanism’}

\subsubsection{Appiab's Justification of Liberalism}

In the preceding chapter I have already suggested that Kwame Anthony Appiah's theoretical and disciplinary allegiance differ significantly from that of Homi Bhabha, whom I will deal with in the subsequent sub-section. Appiah is an analytical philosopher while Bhabha's approach is more methodologically eclectic. I will, of course, also argue that despite their differences Appiah and Bhabha have similar things to say. But before I get to that, it is imperative to make certain differences clear. This is also important because the way Appiah differs from Homi Bhabha is how he differs from most proponents of postcolonial theory; and this is in three ways, the first of which I have already alluded to:

- Appiah is primarily a philosopher,

- his cosmopolitanism is a moral philosophy,

- his approach is from the perspective of liberalism.

Given the eclecticism of postcolonial theory in general, I do not think that Appiah's being a philosopher or his practising moral philosophy require justification. As I said before, the discourse of postcolonial studies is unusually open-minded and welcoming of many different perspectives and points of view. Yet, arguably, Appiah's liberalism does require justification. This is because there have been strong arguments from postcolonial critics in the past, showing that many proponents of traditional liberalism, with whom Appiah shares a framework, have lent support to colonialism and, as in Kant's case, have even propagated a supposed racial inferiority of Indians and Africans. ${ }^{144}$ For instance, Edward Said made the following observation about the nineteenth-century utilitarian philosopher John Stuart Mill that

it will not take a modern Victorian specialist long to admit that liberal cultural heroes like Mill [...] had definite views on race and imperialism, which are quite easily to be found at work in their writing. So even a specialist must deal with the knowledge that Mill [...] made it clear in On Liberty and Representative Government that his views there could not be applied to India $[\ldots]$ because the Indians were civilizationally, if not racially, inferior. ${ }^{145}$

144 Kleingeld, Kant and Cosmopolitanism, p. 7; 18 and especially pp. 92-120.

145 Said, Orientalism, p. 14. 
I have argued before that the postcolonial implies that even though colonialism has officially ended, its legacy drags on and, like the Freudian repressed, keeps resurfacing in unexpected ways. Certain dependencies between postcolonial states and their formerly colonizing societies have remained in place to a great extent. And it is in this context that postcolonial theorists might be critical of liberalism, which, albeit in new clothing as neo-liberalism, still serves the underlabouring of a new and more subtle form of $21^{\text {st }}$ century economic and ideological exploitation, namely: of neo-colonialism. But if liberalism was and still is involved in colonialism, if it has no basis in the 'Third World' traditions and societies it helped to colonize (and still does), it must be an imposition of Western forms of thinking onto postcolonial societies. ${ }^{146}$ Consequently, it cannot be an adequate tool for the analysis of this imposition or a means of emancipation from colonialism.

These objections are very serious and cannot easily be dismissed. The tradition of liberal philosophy partly approved of colonialism. Postcolonial studies is built on an opposition to colonialism and, thus, it affiliates itself with the victims of colonial oppression; and rightfully so. This is one reason why a liberal approach may seem like an oddity within postcolonial studies and might sit uneasy with some theorists. On the other hand we cannot so easily pin the responsibility for this onto the entire liberal tradition. If we did that, we could not account, for instance, for Kant's later rejection of colonialism, which I have already alluded to, or his change of heart regarding race. ${ }^{147}$

Maybe it is not so much that the ideas of liberal philosophy are at fault but that philosophers operating within this tradition were often too inconsistent to cash them in. Appiah suggests as much when in the context of his treatment of postmodern anti-universalism he states:

Often [...] attacks on something called 'Enlightenment humanism' have been attacks not on the universality of Enlightenment pretensions but on the Eurocentrism of their real bases: Hume's or Kant's or Hegel's inability to imagine that a 'Negro' could achieve anything in the sphere of 'arts and letters' is objectionable not because it is humanist or universalistic but because it is neither. A large part of the motivation for this recent antiuniversalism has been a conviction that past universalism was a projection of European values and interests: this is a critique that is best expressed by saying that the actually existing Enlightenment was not Enlightened; it is not an argument that Enlightenment was the wrong project. ${ }^{148}$

146 The term "postcolonial state" in this context merely refers to a nation-state that emerged out of a former colony. Thus, the meaning of "postcolonial" is not identical with the one I derived from Ashcroft et al. However, it does not exclude it either. This is the way in which Appiah uses this term.

147 Kleingeld, Kant and Cosmopolitanism, pp. 111-120.

148 Kwame Anthony Appiah, "Citizen of the World", in: Matthew J. Gibney (ed.), Globalizing Rights: The Oxford Amnesty Lectures 1999, Oxford 2003 p. 205. 
Appiah makes clear that the problem with liberal thought lies not with its universalistic aspirations or its humanism but with the fact that these were used as if they applied only to a fracture of humanity, namely: to Europeans.

I have suggested before that postcolonial studies to some extent naturally and rightfully takes the side of the colonized. It attempts to find out about the mechanisms of oppression and critiques them. But if this is true, then to rehabilitate a liberal approach in postcolonial theory means to demonstrate that liberalism can also be a source of emancipation for the oppressed and that it is not necessarily just a Western ideology for colonial domination. This, I believe, Appiah demonstrates in a convincing and way.

Appiah has a habit: In nearly every single piece he has written on cosmopolitanism, he talks about his father Joseph, who was a Ghanaian independence activist. For example, in his Amnesty Lecture, which he delivered in Oxford in 1999, Appiah talks about how his father, who had been trained as a lawyer in London, ${ }^{149}$ after Ghana's independence in 1957 travelled all over the country to give legal council and to defend before court citizens whose rights were being violated by the newly instated postcolonial government. Appiah explains that his commitment to the rights and freedom of individuals even earned his father some time in prison. ${ }^{150}$ However, the greater point that Appiah wants to make is that he recognizes an analogy between his father's situation after independence in 1957 and seventeenth century England when John Locke wrote his Two Treatises; an analogy between the religious intolerance that shaped Locke's intellectual enterprises and the political intolerance of the post-independent Ghanaian government. What Appiah suggests is that liberalism, that is, the aspiration to limit the abilities of states to interfere in or impose restrictions on the freedom of individuals, is to some extent a 'natural' or 'necessary' reaction to "illiberal government." 151 This is as true of Locke - one of the originators of liberal theory - as of Appiah's father.

There are two more possible ways in which sceptics could argue against Appiah: They could, for instance, say that Appiah's father was not a genuine Ghanaian. But that he was, in fact, subjected to Western forms of power and ideology when he came to England; and transformed into an instrument of the colonizer's interests. Appiah argues against this by commenting on his father's conceptual framework for reading authors from the liberal tradition:

But more important yet, I think, to my father's concern with individual human dignity was its roots in the preoccupation of free Asante citizens, both men and women, with notions of personal dignity, with respect and self-respect. Treating others with the respect that is their due is a central preoccupation of Asante life [...]. Just as European liberalism - and demo-

\footnotetext{
149 Appiah, "Citizen of the World", p. 227

150 Ibid., p. 228.

151 Ibid.
} 
cratic sentiment - grew by extending to every man and (then) woman, the dignity that feudal society offered only to the aristocracy [...], so Ghanaian liberalism, at least in my father's form, depends on the prior grasp of concepts such as animuonyam. It is clear from well-known Akan proverbs that respect was precisely not something that belonged in the past to everybody: [...]. The point, however, is that just as dignitas, which was once, by definition, the property of an elite, has grown into human dignity, which is the property of every man and woman, so animuonyam can be the basis for the respect for all others that lies at the heart of liberalism. ${ }^{152}$

What Appiah wishes to express is that his father, of course, read Cicero and other liberal authors. But that he was not 'subjected' by them. Rather he read them against the backdrop of concepts from his own culture - Asante culture. This comparative reading enabled him to discover that Asante thought and liberal Western philosophy held something in common: the notion of individual dignity. What the two also held in common was the historical development of this concept from being an attribute of only a small group of people, to its becoming an attribute of every member of society. Appiah expresses this in the following way: "Indeed dignitas and animuonyam have a great deal in common. Dignitas, as understood by Cicero, reflects much of what was similar between republican Roman ideology and the views of nineteenth-century Asante elite; [...]." 153 And this is the reason why Appiah concludes that "it was [...] as an Asante that my father recognized and admired Cicero, not as a British subject."154

Of course, sceptics could still contend that Appiah's redemption of liberal philosophy is not really foundational since his father's appropriation of liberalism depends on particular cultural constellations. However, I do not believe that Appiah means his approach to be foundational at all. Appiah writes in this context: "Then, as I said, we cosmopolitans believe in universal truth, too, though we are less certain that we have it all already. It is not skepticism about the very idea of truth that guides us; it is realism about how hard the truth is to find."155 And just a little further on he argues that "[a]nother aspect of cosmopolitanism is what philosophers call 'fallibilism' - the sense that our knowledge is imperfect, provisional, subject to revision in the face of new evidence."156 Thus, as a fallibilist, Appiah combines a search for truth with ongoing doubts about his own position. It is noteworthy that, as we will see, the cosmopolitanism presented here is in part a

\footnotetext{
152 Ibid., pp. 229-230.

153 Ibid., p. 230.

154 Ibid.

155 Kwame Anthony Appiah, Cosmopolitanism: Ethics in a World of Strangers (Issues of Our Time), New York/London 2007, p. 144.

156 Ibid.. Note also that we have already come across fallibilism in David Held, another philosopher from the liberal tradition, under heading 2.3.2.
} 
result of doubts about the universal applicability of an unbounded form of liberalism.

\subsubsection{Ethical Individualism, Identity and Freedom}

One thing that is tied to the liberal framework is ethical individualism - the notion that "everything that matters morally, matters because of its impact on individuals and - so that if nations, or religious communities, or families matter, they matter because they make a difference to the people who compose them."157 Consequently "liberals value individuals over collectivities [sic]." 158 Strictly speaking, individualism does not require separate vindication from liberalism. For it is already justified on the liberal insight that collectives are in danger of arbitrarily imposing themselves on individuals, and that the freedom of the individual to be what it needs to be is what is truly worth protecting. This mistrust of collectives also appears as specifically historically justified.

But there is one possible objection to individualism that Appiah needs to deal with. This is the true allegation that liberalism, especially in its libertarian guise, has sometimes unduly elevated the individual, its freedom and especially its right to private property above society and any positive moral obligations it might have to others. This vision of individualism, as Appiah notes, is largely perceived to be selfish and is, therefore, rejected by many postcolonial societies. ${ }^{159}$ And this is, of course, justified since this is also the exact point at which liberalism's collaboration with neo-colonialism arguably takes shape. It is clear that Appiah does not condone this view although he does not examine it closely. However, he does not do so because it simply would not be a good starting-point for his approach. This is because it would defeat the purpose of individualistically-based ethics, not to mention cosmopolitanism: If we were to assume that individuals only had obligations to themselves, this would be the most unethical vision of society one could have. Instead Appiah passes on to saying that individualism, his vision of individualism that is, has nothing to do with selfishness or with being unsocial. This is partly, as he himself notes, because it is recognizable that we could not even develop without the aid of others and that many of the things we want and need are produced by society. ${ }^{160}$

Appiah claims that, in fact, there is a more profound sense in which we are related to others rather than just materially. According to Appiah, we are socially dependent on others in the sense that they give us a sense of who we are, of our

157 Kwame Anthony Appiah, The Ethics of Identity, Princeton 2005, p. ix.

158 Kwame Anthony Appiah, "Against National Culture", in: Laura García-Moreno/Peter C. Pfeiffer (eds.), Text and Nation: Cross-Disciplinary Essays on Cultural and National Identities, Columbia [SC] 1996, p. 177.

159 Appiah, "Citizen of the World", p. 218.

160 Ibid., pp. 218-219. 
identity. ${ }^{161}$ This leads Appiah to claim that without society, without a link to the social, there would not even be what liberalism refers to as freedom. ${ }^{162}$ This is quite an astonishing claim, but it is consistent with what I have already alluded to as "social constructivism", which is the idea that we are not born with an identity but that it is something that comes together on the basis of the social relations we have with others. ${ }^{163}$ Through these social relations we learn about concepts of what 'kinds of person'164 actually exist that we could be. This means that we are not born with an identity but it also implies that identity does not emerge out of nothing. ${ }^{165}$ Appiah sums up his thoughts in the following way:

Self-construction, to make human sense, must draw on what history has given each of us. And thinking about what history has, in fact, given each one of us, as materials for our identities, will allow us to answer the worry I raised about the unsociability of the liberal self. [... B] eginning in infancy it is in dialogue with other people's understandings of who I am that I develop a conception of my own identity. [...]. An identity is always articulated through concepts (and practices) made available to you by religion, society, school and state, mediated by family, peers and friends. ${ }^{166}$

In other words: Our freedom to become who we want to be is supplied by society. This surely is counter-intuitive because usually we would think that social constrains are exactly what keeps us from being free; and this is true but, paradoxically, only partially so. There is a perfect dialectical relationship here with regard to the enabling and constraining function that society executes in relation to the individual. Society enables our freedom to do things, to desire things and have an identity because it gives us choices of how to construct our identity in the first place.

Even though this idea seems plausible, it invites some objection. Homosexuals, for instance, could rightfully protest that they do not choose to be homosexuals but that they were born in this way; and that Appiah's model, in fact, suggests that they had a choice to be heterosexual. Even though homosexuals require the socially mediated concept of homosexuality in order to recognize themselves as homosexuals, this objection is important. But Appiah does not mean that the concepts we acquire are the only things that society offers us. It also gives us a language to talk about it, re-interpret it and change our identity. ${ }^{167}$ This would at

\footnotetext{
161 Ibid., p. 219; 224.

162 Ibid., p. 224.

163 All of this is also implied in Appiah, Ethics of Identity, p. 267-268.

164 Note Appiah's discussion of Ian Hacking's notion of 'kind of person.' (Appiah, “Citizen of the World", p. 220.)

165 This is implied by Appiah's comparison of the Romantic notion of identity, which Appiah calls "authenticity", and the one he calls "existentialist." (Ibid., p. 222-223.)

166 Ibid., p. 223.

167 Appiah, "Against National Culture", p. 181.
} 
first appear to suggest he is heading off into the direction of saying that we have even more of a choice. However, what he means is that we do not simply act out roles in accordance with the concepts we are given but we appropriate them. He explains:

Once labels are applied to people, ideas about people who fit the label come to have social and psychological effects. In particular, these ideas shape the ways people conceive of themselves and their projects. So the labels operate to mould what we may call 'identification', the process through which individuals intentionally shape their projects - including their plans for their own lives and their conceptions of the good life - by reference to available labels, available identities. In identification, I shape my life by the thought that something is an appropriate aim or an appropriate way of acting for an American, a black man, a philosopher. ${ }^{168}$

This goes to say that it is not the concepts which simply determine our behaviour. Instead we appropriate them and use them to shape ourselves. But in so doing they become part and parcel of the fabric of who we are and, thus, we cannot easily dismiss them at all. They appear natural to us and not as simple conscious choices.

This, I think, is the reason why it has taken humanity a good deal of time to learn this about our identities. However, to assume that our identity, which is really a highly personalized construction of idiosyncratically interpreted concepts that we have acquired throughout our life, is vital to us (because it is us), is ethically significant. Namely, the identity-concepts we appropriate are always concepts, which we share with other people - people we identify with, which, after all, is the meaning of identification. This means that to deny that an individual has moral obligation to these people - her/his family, friends, fellow countrymen, and sisters and brothers in faith - in a way is to ask that person to deny her/his identity. ${ }^{169}$ This is something Appiah finds ethically unfeasible. Identity matters from an ethical point of view and this, of course, sets limits to the demands of moral universalism.

\subsubsection{The Realm of Ethics}

What exactly is the nature of the obligations we have to those that make up the social groups to which we belong? Appiah starts discussing this question by acknowledging that there have been versions of liberal cosmopolitanism that deny the ethical significance of local attachments or ask us to become impartial to them. ${ }^{170}$ As Appiah points out, this has been found to be due to a tension, underlying liberalism in general, between what may variously be called "special obliga-

168 Appiah, "Citizen of the World", p. 221.

169 Appiah, Ethics of Identity, p. 236.

170 Ibid., p. 221. 
tions", "associative duties", or "special responsibilities" on the one side, and the liberal premise that all humans are equal on the other. ${ }^{171}$ We have, of course, already come across this difficulty in Kant and the Stoics and we remember that Pauline Kleingeld interprets Kant as relying on the difference between perfect and imperfect duties to solve this tension. However, I am not sure this strategy fully redeems the moral premise of cosmopolitanism from seeming impracticable. This is because there remains a sense that the call to treat everyone equal must degrade the very relationships that are most dear to us. And this must appear so because to treat all humans equally can only mean that

- either we adjust our treatment of strangers to the way we treat our loved ones, or

- we treat our loved ones like strangers.

Out of the two options the former, of course, is the more likely contender for cosmopolitanism. However, it clearly makes demands that would be virtually impossible to fulfil. And while there is no doubt that we owe something to strangers, this could not be the right way of interpreting this principle.

Appiah presents two arguments against this unrefined reading of the liberal premise of equality. His first contention is that it is simply a misunderstanding to believe that this premise is asking individuals to be impartial. That is just what the state needs to be. He writes:

And here's where the opposition between associative duties and moral equality (in the sense of equitable treatment) really does dissolve. For it is a category mistake to hold that persons are bound by moral equality in the first place. Liberalism, in most accounts, is indeed concerned with moral equality: the state is to display equal respect toward its citizens. Where we go wrong is to suppose that individuals should be subject to the same constraint. Social justice may require impartiality - or evenhandedness, or fairness, or (under some construction) "neutrality." But social justice is not an attribute of individuals. ${ }^{172}$

This is why partiality is justified. But Appiah needs to deliver yet another argument because now we just know that equality, as pertaining to individuals, does not mean impartiality. But what does it mean? Appiah argues that the principle is asking us to treat others equally but not, as it were, identically. ${ }^{173}$ It is useful in this context to look at a general differentiation which Appiah, following Ronald Dworkin, makes between ethics and morality. He explains this difference in the following way:

\footnotetext{
171 Ibid., p. 224.

172 Ibid., p. 228.

173 Ibid.
} 
Here, the distinction between the ethical and the moral corresponds to "thick" relations - which invoke a community founded in a shared past or "collective memory" - and "thin" relations, which we have with strangers, and which are stipulatively entailed by a shared humanity. ${ }^{174}$

It now becomes evident how Appiah seeks to circumvent the danger of playing our special obligations off against the notion that we really have responsibilities to all of humanity, and why, as Appiah puts it, "I can give you your due and still treat my friend better." 175 One question, however, that arises from this is where exactly the limits of partiality should be? How is partiality overdone to the extent that we could not give others what is their due? And what is their due anyway? These questions, of course, refer directly to the nature and content of morality, which I shall treat under chapter 3.2.6. For the time being, it, therefore, suffices to point out that the definite limit of partiality for Appiah is racism. He argues: "Racism, for example, typically involves giving people less than they are owed, failing to acknowledge their due as fellow human beings". ${ }^{176}$ I return now to partiality, to ethics and to me initial question of the nature of special obligations. How are we supposed to make sense of them? Appiah mentions that one way of approaching them is to argue that, in order for them to obtain, they must be deducible from a universal principle. ${ }^{177}$ But this approach is too rational.isticAfter all, we do not love our mothers because there is a universal value that says that we should love our mothers. There might be but the point is this: You have a mother and I have one. I assume that we both love our mothers. But we have very different reasons for this. ${ }^{178}$ And this points to an important concession that rationalists have to make; namely: that the nature of such obligations is intrinsic to these social relations themselves ${ }^{179}$ and we cannot possibly expect to justify them on universal principles or values because they just are not universal but "projectdependent." 180 Universality belongs to morality but not to ethics. If we belong to a particular group then ethics is about what we owe to the individuals who compose this group.

In this way, one might complain, that Appiah effectively staves off any commitment as to what our special obligations really are. But should he prescribe them? After all, these obligations could take many forms and what he essentially says is that this is acceptable, as long as it does not clash with the demands of

174 Ibid., p. 230.

175 Ibid., p. 229.

176 Ibid.

177 Ibid., p. 225.

178 This is the problem of "non-transferability", which Appiah discusses with regard to wives. (Ibid., p. 226-227.)

179 Appiah makes this point by arguing that special obligations are contingent on values underlying the communities we are part of. (Ibid., p. 236.) The way I see it, this is essentially what is meant by "project-dependence."

180 Ibid., p. 227. 
morality. This is precisely the way in which Appiah's cosmopolitanism appears first and foremost as a "rooted cosmopolitanism", in that it makes space for the special obligations that most people have and it is difficult to fully deny.

In the following chapter I will discuss Appiah's use of the term (cosmopolitan) patriotism, which he claims is synonymous with rooted cosmopolitanism ${ }^{181}$, and how he uses it to fend off various objections to cosmopolitanism.

\subsubsection{Patriotism, Humanism and the State}

This chapter discusses Appiah's use of the term patriotism, which goes back to the very beginning of his theoretical engagement with cosmopolitanism. Appiah essentially develops it as a critique of Martha Nussbaum's famous essay "Patriotism and Cosmopolitanism". In this article, which was originally published in 1996 in the Boston Review, Nussbaum bemoans the shortcomings of the nationally and, thus, inwardly focused American system of education that leaves pupils largely ignorant of other cultures and foreign countries. In consideration of the onslaught of globally shared problems, such as environmental pollution, Nussbaum makes the case for a cosmopolitan education that should lead Americans to engage with other cultures on the basis of a sense of shared responsibility. ${ }^{182}$ Needless to say, Nussbaum identifies patriotism - the preoccupation with and privileging of one's own country's interest - as a hindrance to this cosmopolitan project. ${ }^{183}$ She specifically attacks an earlier discussion about the meaning of US citizenship in the light of the increasing multi-ethnical composition of the United States. In this discussion Sheldon Hackney and Richard Rorty tried to synthesize patriotism with an appeal to a "politics of difference", that is, a politics based on the affirmation of America's religious, ethnic and cultural diversity. ${ }^{184}$ Nussbaum finds fault with this view and presents a counter-argument to the extent that to appeal to diversity on a national basis is contradictory. She interrogates Hackney's and Rorty's claim in the following way:

In Richard Rorty's and Sheldon Hackney's eloquent appeals to shared values, there is something that makes me very uneasy. They seem to argue effectively when they insist on the centrality of democratic deliberation of certain values that bind all citizens together. But why should these values, which instruct us to join hands across boundaries of ethnicity, class, gender, and race, lose steam when they get to the borders of the nation? By conceding that a morally arbitrary boundary such as the boundary of the nation has a deep and formative role in our deliberations, we seem to deprive our-

181 Kwame Anthony Appiah, "Cosmopolitan Patriots", in: Joshua Cohen (ed.), For Love of Country? (New Democracy Forum), Boston 2002 (originally published 1996), p. 22.

182 Martha C. Nussbaum, "Patriotism and Cosmopolitanism", in: For Love of Country?, p. 12.

183 Ibid., p. 3-4; 14.

184 Ibid., p. 4. 
selves of any principled way of persuading citizens they should in fact join hands across these barriers. [...] Why should we think of people from China as our fellows the minute they dwell in a certain place, namely the United States, but not when they dwell in a certain other place, namely China? What is it about the national boundary that magically converts people toward whom we are both incurious and indifferent into people to whom we have duties of mutual respect? I think, in short, that we undercut the very case for multicultural respect within a nation by failing to make central to education a broader world respect. ${ }^{185}$

What becomes obvious from this lengthy quote is that Nussbaum, in fact, welcomes Rorty's and Hackney's attempt to negotiate values all Americans have in common, while simultaneously calling for respect of difference. But she draws a different lesson from it. Namely, that we should not only respect the difference of others, reach out across this difference to them and negotiate what we share because they are our fellow citizens. We should do so because they are our fellow human beings. The call for respect and transcendence of difference is not plausible when it is limited to the nation because this is inconsistent.

Appiah takes issue with Nussbaum's allegation that the national boundary should be "morally arbitrary." He argues, that in the case of America the national boundary coincides with the boundary of the state. ${ }^{186}$ The problem with claiming that this boundary does not matter is, Appiah implies as much, that one must concede that there is no reason why there should not be just one world-state, surpassing all countries, governing all human individuals. I have already addressed the issue of the world-state and presented reasons as to why it is undesirable. Kant essentially justified his objection to it on the liberal imperative that one ought to respect the choices of autonomous subjects, the individuals making up the nations who, on Kant's take, wanted to remain in separate states. Appiah adds another possible solution for this problem, which, in turn, helps him alleviate two serious charges that may be rendered against cosmopolitanism; namely:

- that cosmopolitans are rootless wanderers (as in the case of Diogenes), and

- the consecutive objection that if everyone became a cosmopolitan, there would be no more cultural differences, no more particular cultures to embrace. ${ }^{187}$

For Appiah these problems apply to Nussbaum's cosmopolitanism, which he also refers to as "humanism" 188 because it renders differences insignificant in favour of what humans share. However, for Appiah the question of what state we belong to matters profoundly. He argues that "[s]tates matter morally intrinsically. They matter not because people care about them, but because they regulate our

185 Ibid., p. 14.

186 Appiah, "Cosmopolitan Patriots", p. 27.

187 Ibid., p. 22.

188 Ibid., p. 25. 
lives through forms of coercion that will always require moral justification."'189 In a way this is similar to Kant's patriotism, which ideally requires citizens to maintain the state by politically involving themselves in its operation. But this would theoretically also be possible in a world-state. Thus, what matters the most to Appiah is that people belong to different states because states are in a sense historically responsible for cultural differences. ${ }^{190}$ Conversely, if we crammed everyone into the same state, the world would become culturally homogenized and there would not be anything for the cosmopolitan to embrace. It is in large parts through the difference in governmental arrangement, the difference in political institutions that cultures came to differ from one another. ${ }^{191}$ This surely is a controversial claim and it might be necessary to examine Appiah's argument more closely.

Let us begin with ascertaining that Appiah makes a claim pertaining to a causal relation between governmental arrangements and cultural practices. This relation should not be understood to be strictly deterministic. Rather cultures appear to be different from one another for a diverse number of reasons and it is not all down to how we are governed. For all we know we cannot finally explain why they differ; and maybe we do not even have to. But can we really say that the way we are being governed has nothing to do with cultural practices? I think not. That it should have some, if not considerable, influence is, I think, plausible. Let us now take a look at how Appiah justifies his argument. Appiah begins his argument from an account of nations as given by the early nineteenth-century German philosopher Johann Gottfried Herder. For Herder, nations precede states. This means that every nation exists like a natural entity before it becomes enshrined in a state. Appiah turns Herder from his head onto his feet, so to speak, and claims that in fact states always precede nations; and that no nation is existent insofar as it is not the result of a prior state. ${ }^{192}$ This assumption certainly seems more logical than Herder's. After all, if nations are not the result of people being governed together, where would they come from? However, there is one difficulty with Appiah's view; namely there were not always states in our modern sense. I have already explained that the city-states of ancient Greece were very different from today's modern nation-states. This is why Appiah has to extend his definition of state to what he calls "state arrangement"193 in order to include every form of political government from modern states, to medieval city-councils, and African

\footnotetext{
189 Ibid., p. 28.

190 Ibid.

191 This is also implied by Appiah's reference to the notion of "hybridization" of cultures. All cultures are the result of people going to other places, taking their ideas with them and mixing them with other ideas. In this way cultures are always local and bound to specific places. And they do not become homogenized through the global spread of some ideas as long as there remain specific places. (Ibid., pp. 22-23.) The only way this may be changed is by making all places into one, by making all states into one state.

192 Ibid., p. 27.

193 Ibid.
} 
tribal gatherings under the category of state. If we understand the term state in this way it really applies that every political entity should not be naturally given but the result of a prior governmental or state-arrangement.

In her essay Martha Nussbaum develops a model of cosmopolitanism, which she borrows from the Stoic philosopher Hierocles and which demonstrates the different spheres of moral deliberation. The model consists of several concentric circles with the individual located in the middle. Next follows the family, after that the extended family and friends, fellow city-dwellers, fellow-countrymen and finally: strangers. It is Nussbaum's contention that in becoming cosmopolitans we have to learn to draw the circle of strangers closer toward ourselves and make them more like our fellow city-dwellers. ${ }^{194}$ Appiah also addresses this model and interprets it in the following way:

There are many reasons to think that living in political communities narrower than the species is better for us than would be our engulfment in a single world-state, a cosmopolis of which we cosmopolitans would be not figurative but literal citizens. [...] It is because humans live best on a smaller scale that we should defend not just the state, but the county, the town, the street, the business, the craft, the profession, and the family as communities, as circles among the many circles that are narrower than the human horizon, that are appropriate spheres of moral concern. ${ }^{195}$

Appiah conceptualizes the various spheres of moral concern, within which we are related to others, in an analogy to his notion of states. In a way the street, the profession, even gender and other things are just like political communities. But one should not be deceived into thinking that Appiah means they are political communities. If he meant that he could not justify why the state somehow matters more. The difference between the political arrangements and the different spheres of moral obligation is that the political ones matter intrinsically. ${ }^{196}$ Citizenship in them is literal. But the other arrangements matter not in this way but because they matter to people ${ }^{197}$ and this is a significant difference. Appiah's patriotism is Kantian with regard to the state but it also includes many other social arrangements of which we are citizens in a more metaphorical sense.

We have now observed how Appiah in various ways creates space for collective and individual idiosyncrasies. In particular his characterization of special obligations as project-dependent relieves the demands an otherwise unbound cosmopolitanism would have imposed. In the following chapters I will therefore gradually approach Appiah's conception of morality, or what should be taken to be universal.

\footnotetext{
194 Nussbaum, "Patriotism and Cosmopolitanism", p. 9.

195 Appiah, "Cosmopolitan Patriots", p. 29.

196 Ibid., p. 28.

197 Ibid.
} 


\subsubsection{Dialogue vs. Cultural Relativism}

In his discussion of cosmopolitanism Appiah criticizes cultural relativism on several occasions. Ulrich Beck argued that relativism, like universalism, may neither be entirely discarded nor absolutized. I have already demonstrated that Appiah does not, in fact, absolutize moral universalism at all. But he imposes serious restrictions on it. Conversely, I believe, he is not oblivious to the legitimate side of relativism. Of course, one of the prime functions of cultural relativism in the past was as an argument against intervention of the West in other cultures. In this context Appiah writes: "One reason for this scepticism about intervention is simply historical. Much well-intentioned intervention in the past has undermined old ways of life without replacing them with better ones; and, of course, much intervention was not well-intentioned." 198 Thus, Appiah is not opposing cultural relativism in principle. Instead Appiah's argument is only that relativism as a principle has limited applicability. More specifically he decides to push against it because, when taken as a dogma, it actually poses a serious obstruction to conversations between members of different cultures. This, of course, was already implied by Beck's statement that absolutized relativism yields essentialism.

I have already alluded to and quoted from Appiah's treatment of what he perceives as "recent anti-universalistic arguments" in philosophy. Such arguments Appiah finds in the works of Richard Rorty ${ }^{199}$ and Jean-François Lyotard as well as in "the formal fragmentation of postmodern literary texts." 200 He complains that "in such a context an older humanism, with the notion of a human essence, a human nature that grounds the universality of human rights, has indeed come to seem to many simply preposterous." 201 The charge that postmodernism's dismissal of universalism makes it incompatible with human rights is, I think, quite a serious problem for such approaches. However, we must also understand that postmodern anti-universalism was in part a reaction to the failure of Marxist universalism. In that it appears as historically justified. However, this is not an argument against universalism in general.Appiah discusses the interplay between relativism (or anti-universalism) and universalism on a couple of practical examples. One of them is about the question whether organizations like Amnesty International have a right to criticize human rights violations in Asian countries, or whether this amounts to colonialism since the Western notion of human rights is alien to Asian values. ${ }^{202}$ For the cultural relativist this case must appear clear: There is no way that we can arbitrarily impose our notion of human rights onto others in this way. This is because it is particular to our culture and if others do

\footnotetext{
198 Appiah, Cosmopolitanism, p. 14.

199 Regarding Appiah's treatment of Rorty see Appiah, “Citizen of the World”, pp. 204-206; 209210; 213-214.

200 Ibid., p. 205.

201 Ibid.

202 Ibid., p. 202.
} 
not share this notion and do not want it, we cannot force the issue. Let us take a look at a similar example: Jamaica is one of the most dangerous countries in the world for homosexuals to live in. Homosexual intercourse is officially outlawed and sexually deviant people often serve as scapegoats for social problems. Moreover, homosexuals are often publicly attacked and even murdered when the nature of their sexuality is uncovered. ${ }^{203}$ When Jamaican dancehall singers, who sell most of their records in Europe and the US, in their songs advocate the killing of 'batty bwoys' (gay men), are Western listeners in no position to criticize this? For the cultural relativist the same applies as before: We might label this bigoted but that is really just us, our own values, which we arbitrarily impose upon their culture.

But is the second case really as unambiguous as the relativist would have us believe? What if I described the whole issue differently and said that in reality giving a relativist argument in support of Jamaican homophobia amounts to a Western underlabouring of the hegemonic status of certain groups in this society? It would appear then that the call not to intervene has the precise effect of an intervention - only for the worse. What if I said that there are many people in Jamaica who think that hatred of gays is wrong 204 but who are afraid to say so publicly because they fear persecution? Would the relativist be able to maintain his position? There are two problems here:

203 As far as I am aware the topic has not received attention from social scientists. However, there is a lot of information on the internet. Here are two older but substantial articles: Tim Padgett, “The Most Homophobic Place on Earth?”, Time.com, 12/04/2006, URL: http://content.time. com/time/world/article/0,8599,1182991,00.html (accessed: 28/08/2013); Gary Young, Troubled Island, The Guardian, 27/04/2006, URL: http://www.theguar ian.com/world/2006/ apr/27/gayrights.comment (accessed: 28/08/2013).

204 That there are currents even within dancehall music that are critical of homophobia is evident from an interview with female dancehall-artist Cecile Charleton (Ce'Cile), in which she describes homophobic men as potentially misogynist. (Dave Stelfox, "Dancehall Queen", The Guardian, 12/01/2004, URL: http://www.theguardian.com/stage/2004/jan/12/dance [accessed: 28/08/2013]). 
- The relativist entertains a holistic conception of culture ${ }^{205}$, and

- $\mathrm{s} /$ he believes that if we reject or criticize some cultural practice as unethical, our next step must be to physically impose ourselves on this culture.

These issues lead her/him to conceive of moral reality in such a way as would "require[s] us to define hermetically sealed worlds, closed off from one another, within which everyone is trapped into a moral consensus, inaccessible to arguments from outside." 206 And this is exactly the same as essentialism. Appiah is good-willed and gives it another name. He calls it "anti-universalist cosmopolitanism."207 But I must say that I do not seewhat might be cosmopolitan about this position because it practically asks us to denounce our cosmopolitan conviction that we owe something to the gays of Jamaica. Yet this model's greatest problem lies in the fact that it commands us to silence when, really, we should be talking to others. It totalizes difference and conceives of different cultures as essentially incommensurable. Against this notion Appiah builds up what he refers to as "dialogue." One thing that is important to emphasize, however, is that the notion of dialogue is not solely developed by Appiah as an answer to postmodern forms of cultural relativism. It is also a response to an older notion, which relativism makes every attempt to reject; namely: moral realism. This is the notion that there are moral facts, so to speak, which may be identified with scientific certainty. According to this idea, all we need to do when we meet other cultures is to make them understand what these facts are. ${ }^{208}$ Against this view Appiah argues that "[o]nce you enter into a genuine dialogue with people who hold views other than your own $[\ldots]$, you are going to discover that there is no non-question-begging way of settling on a basis of facts, whether moral or non-moral, from which to begin to discuss." ${ }^{209} \mathrm{He}$ adds:

In real life ethical judgements are intimately bound up with metaphysical and religious belief and with beliefs about the natural order. And these are matters about which agreement may be difficult to achieve. (It's hard to persuade people there are, on the one hand, no electrons or, on the other, no witches.) Real dialogue will quickly get stymied in these circumstances because interlocutors who disagree at this level are likely to treat each oth-

205 Note that Appiah charges Richard Rorty with conceptualizing the relation between 'the West' and other cultures in this way (Appiah, "Citizen of the World", p. 210-211).

206 Ibid., p. 203.

207 Ibid., p. 202.

208 Ibid., 208. Note that Appiah also identifies this position as "humanism" (ibid., p. 208; 212) - a position he has criticized in Martha Nussbaum. (Appiah, "Against National Culture", p. 178; 188.) This could mean that Appiah is charging Nussbaum with thinking in terms of moral realism.

209 Appiah, "Citizen of the World", p. 209. 
er's claims as 'merely hypothetical' and are thus not likely to engage with them seriously. 210

In other words, the type of dialogue envisaged by moral realism fails precisely because here interlocutors are trying to agree on principles. But this seemingly requires that difference be more or less eradicated and it is, therefore, justly eyed up with scepticism by postmodern critics. ${ }^{211}$ Thus, one of the reasons why postmodern critics seemingly render dialogue impossible and put only relativism in its place is because they recognize correctly that moral realism is flawed.

\subsubsection{Agreement on Particulars}

Appiah's alternative to relativism is not to fully negate relativism but to address the deeper reason for its appearance, which is the failure of moral realism. In imagining the possibility of dialogue Appiah, thus, begins by asking whether it is really necessary to agree on principles. If both you and I wanted to prevent a war, would it matter whether we had the same reason for doing so? ${ }^{212}$ However, instead of fully negating either cultural relativism or moral realism, Appiah finds a middle ground. He claims:

What we learn from travel, but also from reading books and watching films from other places, is that we can identify points of agreement that are much more local and contingent than this. We can agree, in fact, with many moments of judgement, even if we do not share the framework within which those judgements are made, even if we cannot identify a framework, even if there are no principles articulated at all. And, to the extent that we have problems finding our way into novels, or films or neighbourhoods, they can occur just as easily with novels and films and places around the corner, as they do with those far away. ${ }^{213}$

What Appiah wishes to express here is that we can sometimes agree on things without agreeing on the reasons why, without sharing the beliefs that lead up to a shared judgement. This is both an argument against moral realism as well as its adversary cultural relativism because he both dismisses the necessity of agreeing on principles as well as the alleged total incommensurability of frameworks. In our encounters with others there will always be certain things we share, things we have in common; even if it is just that we both like looking at the stars at night. And he suggests that we will be able to identify more common-ground once we stop try-

210 Ibid.

211 Note that Appiah does not mean to say that agreement on principles or, as he calls it, "universals" may not occur at all. Appiah, "Citizen of the World", p. 213.

212 Appiah uses an analogous example of two people, who want to save a child for different reasons. Appiah, Ethics of Identity, p. 253.

213 Appiah, "Citizen of the World", p. 210. 
ing to agree on universals. Agreements, for Appiah, are much more likely to occur with regard to particulars.

We may ask how he can be sure that such agreements will occur. Appiah would probably answer to this that he cannot be sure at all. However, he would most likely hold that there are certain things that make agreement easier because they would appear to be shared by all humans. One such thing is what Appiah refers to as an "evaluative language." What does Appiah mean by saying that we share an evaluative language? Obviously we do not all share one language. Appiah's development of this idea occurs against the backdrop of his discussion of logical positivism - a position in the history of science which appears to assert that the values (of different cultures) cannot be rationally criticized. ${ }^{214}$ They simply are mutually exclusive and no reasoning will alleviate this difference. But this paves the way for someone who believes that causing everyone suffering was a value to be as correct as someone believing the opposite. Appiah argues against this by asking the following:

How, in fact, do people learn that it is good to be kind? Is it by being treated kindly and noticing that they like it? Or by being cruelly treated and disliking it? That doesn't seem quite right: kindness isn't like chocolate, where you find whether you have a taste for it by giving it a try. Rather, the idea that it's a good seems to be part of the very concept. Learning what kindness is means learning, among other things, that it's good. We'd suspect that someone who denied that kindness was good - or that cruelty was bad - didn't really understand what it was. The concept itself is value-ladden, and therefore action guiding. ${ }^{215}$

In a similar way Appiah contests that any culture truly approves of killing. The fact that Islamic terrorists justify the killing of civilians by saying they are infidels, demonstrates that they acknowledge that killing is actually wrong. If they did not think so, they would not need to give any reasons for this at all. ${ }^{216}$ One problem with our shared evaluative language, however, is that even though we share many concepts such as kindness, friendship, and cruelty we often interpret them differently, or weigh the corresponding values differently. ${ }^{217}$ Thus, there is a problem with, for instance, accusing a Muslim of oppressing his wife by finding it necessary

214 For Appiah's in-depth discussion of logical positivism, see Appiah, Cosmopolitanism, pp. 18-25 and for his subsequent treatment of its implications for values, see ibid., pp. 25-31.

215 Ibid., p. 26.

216 Appiah uses an analogous example to the extent that we are forced to justify our opinion that torture of terrorists is legitimate, which goes to show that we know that torture is actually bad (ibid., p. 27). Appiah's whole point here is to argue that logical positivism overestimates the role of reason with regard to facts but underestimates reason's stake in values (Ibid., p. 40).

217 Ibid., pp. 59-60; 66. From his comments it becomes clear that Appiah means that a shared evaluative language may even fail to produce agreement in people who live closely together and under comparable circumstances. 
for her to wear a veil. That is because he supposes that he is, in fact, protecting her in this way from the greedy gaze of other men. He simply does not recognize himself as committing an affront. ${ }^{218}$ However, what Appiah finds valuable about the insight of a shared evaluative language is that we "can often guide one another, in the cosmopolitan spirit, to shared responses; and when we cannot agree, the understanding that our responses are shaped by some of the same vocabulary can make it easier to agree to disagree." 219

It is in this context that Appiah also addresses the role of narratives and literature. All cultures enjoy and cultivate the telling of stories in one form or another whether it be in myth, telenovelas, rap-music, novels, fairy-tales or historical writing. This is because all humans share the capacity to respond to them in creative and imaginative ways. 220 Thus, what we should do is try to talk about them together, and across cultural boundaries, but also across boundaries of age, sexual orientation, race etc. However, the end-result here should not be that we can all agree on one meaning. Rather, as Appiah puts it, "evaluating stories together is one of the central human ways of learning to align our responses to the world. And that alignment of responses is, in turn, one of the ways we maintain the social fabric, the texture of our relationships." 221 Maintaining the social fabric through conversation or discussion - is that not how we, as fellow Germans, Ghanaians or British act when we, among ourselves, have discussions about whether what this or that prime-minister just did was right or wrong? Is it not what we do when we watch or contribute to political talk-shows (the better ones, of course) and paneldiscussions; when we debate with our friends, in the university, in a bar or at home with our family? And what happens in most of these discussions? We disagree. But for some reason these disagreements do not lead us to claim that this person we just have had a disagreement with does not belong to our culture. This, I believe, is the very heart of what Appiah understands as cosmopolitanism. It is, in fact, an argument against the strong assumption that coming from different cultural traditions makes us necessarily different. ${ }^{222}$ One needs to be cautious at this point because Appiah does not deny that it could make us different. He just doubts that this is the case by necessity.

This seems to me to be a very valuable insight. For, if we assume that the world is contingent, which means that there is an absence of necessity - a view, I think, many adherents of postmodern relativism agree with - cultural relativism in the sense of the mutual exclusivity of cultures, cannot obtain as a general princi-

218 A similar argument is used by Appiah (ibid., p. 59).

219 Ibid., p. 30.

220 Appiah, "Citizen of the World", p. 213.

221 Appiah, Cosmopolitanism, p. 29.

222 It certainly would not make us different in every respect because this would mean that we could not meaningfully converse with one another. Appiah specifically criticizes this attitude in Rorty, who appears to imagine the West as essentially different from non-Western societies (Appiah, "Citizen of the World", p. 211.) 
ple. However, this is not just an intellectual sophistry. It is a call not to believe that, since somebody comes from another culture, I have no social relations to maintain with him. It is Appiah's call for us to change our minds about culture and to make true dialogue possible. And this is something that, more likely than not, is already practiced by many ordinary people all over the world, who never have to think about this in philosophical terms.

\subsubsection{The Realm of Morality}

As the preceding chapter has emphasized Appiah seeks to curtail cultural relativism in its extreme form. He endorses the view that we share an evaluative language, which we can, to some degree, use to think with one another about values. However, Appiah has also defended the notion that universalism, as in the case of moral realism, must not seek to eliminate differences. In fact the right to difference is already presupposed by Appiah's commitment to liberalism as a conceptual framework. However, Appiah also admits that his brand of cosmopolitanism is also committed to certain universal standards and, thus, dialogue will in some sense also ultimately lead to more homogeneity. He argues that through dialogue

we can learn from other kinds of people and from other societies, just as they can learn from us. But if we do that, we shall inevitably move towards a world of greater uniformity. Differences will remain, naturally, but they will remain precisely in the spheres that are morally indifferent [...]. This is what I am going to call universalistic cosmopolitanism: a celebration of difference that remains committed to the existence of universal standards. ${ }^{223}$

What these "universal standards" ultimately are is not something that is merely superimposed by one side onto the other but is also subject to negotiation. For, as Appiah argues in relation to Richard Rorty's urging that in conversing with others we ought to entirely get rid of Enlightenment-style rationalism, "Rorty supposes that the rationalist is bound to think that 'we' are right and 'they' are wrong: but if there is one world only, then it is also possible that they might be right." 224

This is consistent with Appiah's fallibilist position. However, Appiah is forced to concede that there will likely be people who will not want to join this dialogue, which brings many different people from different places closer together. ${ }^{225}$ Maybe the idea that others, who have very different customs, should have something to say about the way these people live frightens them. The point is that one cannot possibly force these people to join the discussion. If they want to be left alone, there is nothing that can be done about it. But what is it that they really owe others (even if they want nothing to do with them) by virtue of being human? We

\footnotetext{
223 Appiah, "Citizen of the World", p. 202.

224 Ibid., p. 214.

225 Appiah, Cosmopolitanism, p. xx.
} 
remember that above I have, following Appiah, differentiated between two different realms of moral philosophy:

- the one of ethics, wherein (special) obligations are relative to our projects (project-dependent), and

- that of morality, wherein obligations are universal and to those with whom we share being human.

We have already seen that project-dependence is bounded by racism. Racism might correspond with a consensual value internal to the group to which we owe one or another obligation. However, it can never be consistent universally because it denies morality. 226

This, I think, is a very good argument. But what else is universal? What else do we really owe others? I shall say straightaway that I do not think Appiah answers this question sufficiently. For this reason it shall be my primary concern in this chapter to elaborate on a few titbits Appiah presents on this issue, rather than attempt to make a full and systematic argument. The reason why Appiah's comments on morality are sparse is in part, I think, due to the fact that it is notoriously difficult to find answers to this question. One must, for instance, be absolutely cautious not to prescribe here too much because there is always a danger that one might unduly exclude some cultural practices. For this reason it is helpful to think, as fallibilists would, of the discussion about morality (as about the discussion on ethics, by the way) as a work in progress that potentially never finishes but must always remain open to new arguments, occurrences and discoveries. But then such a task would require an enormous philosophical and empirical oversight and Appiah is, of course, predominantly concerned not with the practical content of morality but with its justification.

Nevertheless, certain aspects of morality ought ultimately be derivable from Appiah's justification of it; and, of course, much of his writing is pervaded by a strong sense that he is sympathetic to the idea of human rights. In his latest work on cosmopolitanism Appiah declares that he is drawn towards a certain conception of "basic needs" as laid out by Martha Nussbaum. According to this notion,

[p]eople have needs - health, food, shelter, education - that must be met if they are to lead decent lives. There are certain options that they ought to have: to seek sexual satisfaction with consenting partners; to have children if they wish to; to move from place to place; to express and share ideas; to help manage their societies; to exercise their imagination. (These are options. People should also be free not to exercise them.) And then there are

226 Appiah uses a similar argument to discuss ethics and the nature of our special obligations. He argues that ethics is based on consensus in a way that morality is not and he illustrates this point by saying that while there might exist a consensus that genocide is good within a given group (and, thus, an ethical obligation for people who belong to this group to act in accordance with it), it would still be wrong morally (Appiah, Ethics of Identity, pp. 235-236). 
certain obstacles to a good life that ought not to be imposed on them: needless pain, unwarranted contempt, the mutilation of their bodies. ${ }^{227}$

Thus, what we have here is a threefold model that differentiates between needs, options and protection from certain types of harm. Especially with regard to the meeting of needs, however, Appiah is critical of making them official human rights. This may sound astonishing because their case appears specifically pertinent. But Appiah certainly does not want to say that these are not important. Nevertheless, he criticizes the Universal Declaration of Human Rights (hereafter UDHR) exactly for characterizing access to higher education, food, clothing, medical care and social services as rights. What we must understand in order for this critique to make sense is that there are not just individuals in the world which have obligations to others but that there is at least one other sort of player: states.

Appiah criticizes the decision to refer to the meeting of basic needs as human rights for the simple reason that states would be morally obliged to grant them. But they cannot be obliged if they lack the resources to do so. ${ }^{228}$ Appiah's argument is that many postcolonial states easily come into unnecessary conflict with the human rights regime. For, more often than not, their not providing for these basic needs is not caused by unwillingness to do so but because they simply cannot do so on their own. There is a consecutive danger at this point that the idea of human rights may become discredited in the eyes of postcolonial states and this is something that must be avoided at all cost. This is also why Appiah prefers to have human rights formulated in such a way that they demand states to abstain from an action because this is principally easier to fulfil. ${ }^{229}$

This shows that talk about universal obligations does not only include what individuals owe to other indiciduals but also what states need to do.But even so, one may still ask what we, as persons, are required to do. If states cannot be obliged to guarantee that basic needs be met, could not individuals have this obligation? One way in which Appiah discusses the direct responsibility of every person is by reference to what he calls "the Singer-principle", so named after its main proponent: the Australian philosopher Peter Singer. This principle says that we should always prevent something bad from happening at the expense of something less bad. The example that Singer gives in relation to this rule is that of a child drowning in a pond and me passing by. I must save the child even if this means that I get my new suit dirty. ${ }^{230}$ The American philosopher Peter Unger has derived from this principle the conclusion that in order for us to do our duty onto others we must constantly give the greater part of our worldly possessions to charity-businesses like Oxfam or UNICEF. ${ }^{231}$ As Appiah points out, the consequences

227 Appiah, Cosmopolitanism, p. 163.

228 Appiah, Ethics of Identity, p. 261.

229 Ibid.

230 Appiah, Cosmopolitanism, p. 158.

231 Ibid., p. 158; 159. 
of this way of thinking are drastic because we would have to do so until we could be sure that the consequences of giving more benefits in this way would be worse than the consequences of not giving more. ${ }^{232}$ We would even have to accept personal financial ruin. Appiah is opposed to the idea that we have such strong obligations. He demonstrates that the Singer principle, in fact, covertly demands even more than it reveals at first sight; namely that we must always do our level best to prevent the worst thing from happening that could possibly occur. But what would that be? Appiah reduces their principle ad absurdum in the following way:

Upon reflection, however, it's not so clear that the principle even gets the drowning case right. Saving the child may be preventing something bad; but not saving the child might, for all we know, prevent something worse. After all, shouldn't I be busy about saving those hundreds of thousands of starving children? And wouldn't selling my suit raise a few hundred dollars? And wouldn't ruining it mean I couldn't raise those dollars?233

Against the strong Singer-principle Appiah introduces his principle that we ought always to avert an ill if we happen to be in the best position to do so ("emergency principle"). ${ }^{234}$

It is in this context that Appiah also suggests something that dates back to his very first engagement with cosmopolitanism. Having argued that we have special responsibility to our own state (as prime provider for the basic needs mentioned afore), he reasons that as cosmopolitans "we still have to play our part in ensuring that all states respect the rights and meet the needs of their citizens. If they cannot, then all of us - through our nations, if they will do it, and in spite of them, if they won't - share the collective obligation to change them [...]." 235 This is similar to his plea that "[w]e should, as cosmopolitans, defend the right of others to live in democratic states with rich possibilities of association within and across their borders, states of which they can be patriotic citizens."236 This is problematic because throughout all of his writing on cosmopolitanism Appiah has left one possible implication of this completely untouched: the issue of armed conflict. In fact, by failing to elaborate on this problem, Appiah falls into the same trap as Nussbaum, who in the context of her rejection of the national boundary as vital in terms of moral deliberation is lead to assume that the very values that lie at the heart of America must somehow apply to all other human beings, too. In this context Nussbaum argues:

But here one may note that the values on which Americans may most justly pride themselves are, in a deep sense, Stoic values: respect for human digni-

232 Ibid., p. 159.

233 Ibid., pp. 160-161.

234 Ibid., pp. 161-162.

235 Ibid., p. 163.

236 Appiah, "Cosmopolitan Patriots", p. 29. 
ty and the opportunity for each person to pursue happiness. If we really do believe that all humans are created equal and endowed with certain inalienable rights, we are morally required to think about what that conception requires us to do with and for the rest of the world. ${ }^{237}$

Nussbaum is careful in the last line not to suggest too much as to what this conception might require us to do. Still it is sufficiently obvious that it might justify our leading wars in its name. Now I realize, of course, that both Nussbaum's article and Appiah's response were published in 1996. However, in the light of 2003's controversial invasion of Iraq by the US both authors' statements seem to suggest all the wrong things. This is an issue against which the liberal position will have to sufficiently revise itself. What it requires, in my view, is the development of a critical theory of political action, as well as an engagement with theories of this sort that already exist,outside the liberal philosophical framework.

\subsection{Homi Bhabha’s 'Vernacular Cosmopolitanism’}

\subsubsection{Thinking in Transition: Marxism, the End of History and Beyond}

I have already mentioned under heading 3.1 that the literary and cultural theorist Homi Bhabha is often associated with post-structuralism. In his main work The Location of Culture, Bhabha frequently and consistently draws on the theoretical and methodological insights of Michel Foucault and Jacques Derrida. I have also explained that, in addition to that, Bhabha often approaches literature and theory from a psychoanalytical point of view. Hence, Sigmund Freud and especially the structuralist/post-structuralist psychoanalyst/psychoanalytical theorist Jacques Lacan are frequently referenced in his work. However, Bhabha's work is neither simply post-structuralist nor psychoanalytical but these are merely his most obvious influences. In reality, Bhabha resembles an intellectual leviathan that seems to have read and absorbed almost anything from all possible strands of theory. Here is a brief (and necessarily incomplete) list of authors Bhabha has engaged with: V.S. Naipaul, Hannah Arendt, Walter Benjamin, Frantz Fanon, Edward Said, Salman Rushdie, Antonio Gramsci, W.E.B. DuBois, and Tony Morrison. This is quite an eclectic list but it gives a good impression of what it feels like to read and engage with Bhabha's texts. Often Bhabha would cite authors as diverse as the ones named above in close proximity establishing unexpected connections between them.Hence, one may say in the vein of the anthropologist Claude LéviStrauss that Bhabha is a great bricoleur.

One thing the list above does itindicate that, as a theorist, Bhabha is not merely influenced by other theorists but also by authors of fiction. This is an important

237 Nussbaum, "Patriotism and Cosmopolitanism", p. 13. 
aspect of Bhaba's work: He is not so much a theorist of literary genres and epochs but a theorist of society and culture through literature. On the other hand, he reads other theory in a specifically literary way. This is inevitably mirrored in his writing, which at first sight comes across as impenetrable, elusive and cryptic. I think it is safe to assume that even experienced readers of his texts have difficulties figuring out the precise meaning behind many of his passages. Oddly enough, though, this has made Bhabha's work highly appealing. It has rendered it a seemingly endless reservoir of creative ideas that are unearthed and carried to the surface in dialogue between Bhabha and his respective readership rather than being developed by him alone. On the other hand, this has also made Bhabha's work quite controversial. In fact, critics have often reproached him for his obscurity; and maybe sometimes he really does not actually say anything. However, there always remains a sense that he might. Finally, one could even ask what difference it would make whether Bhabha was the originator ofall the ideas that were born out of readings of his texts or not. In this way Bhabha brilliantly exploits poststructuralist insights into the instability of meaning and the uncertainty of authorial intention.

Somewhat less surprisingly, the list also indicates that Bhabha is influenced by authors (formerly) working in the field of postcolonial studies and postcolonial theory, or who are regarded as precursors of postcolonial theory. Especially Edward Said's seminal work Orientalism as well as the writings of the Martinique-born psychiatrist Frantz Fanon are frequently quoted and discussed by him and may be regarded as highly formative of Bhabha's own intellectual legacy. ${ }^{238}$ Further, Bhabha has been strongly influenced by the Italian Marxist Antonio Gramsci and his theory of hegemony. In a way these influences form Bhabha's political backbone and this sheds some additional light on the style of his writing. For his notorious inaccessibility, his seeming unwillingness to express his ideas in a clear and understandable manner can ultimately be perceived as a discursive strategy of resistance, which is, in a way, an extension of the anti-colonialism of Fanon or the Orientalist critique of Said. For Bhabha, colonialism is deeply embedded and hidden away in the philosophical and scientific discourse of European Enlightenment, of rationalism and, in particular, of liberalism, which continues the Enlightenment's lega-

238 Note that Bhabha, who is an expert on Fanon, has contributed forewords to both a 2004 English translation of Fanon's important text The Wretched of the Earth as well as to the 1986 English translation of his Black Skin, White Mask (Homi K. Bhabha, "Foreword: Framing Fanon", in: Frantz Fanon, The Wretched of the Earth, New York 2004 [originally published in French 1961], pp. vii-xli; Homi K. Bhabha, "Remembering Fanon: Self, Psyche and the Colonial Condition", in: Frantz Fanon, Black Skin, White Mask, London 2008 [originally published in French 1952], pp. xxi-xxxvii). Also, the second chapter of Bhabha's The Location of Culture is specifically about Fanon. (Homi K. Bhabha, "Interrogating Identity: Fantz Fanon and the Postcolonial Prerogative", in: Idem, The Location of Culture, London/New York 2010 (originally published 1994), pp. 57-93.) 
cy. ${ }^{239}$ But one cannot get to its core and exorcise it if one is forced to speak in its language, to speak in accordance with the discursive regime that helped justify colonialism in the first place. Particular disciplines have their own discourses or languages. These work according to different discursive rules and, thus, they have certain customary categories, arguments and types of reasoning built into them, which one must submit to in order to be heard at all. Bhabha's strategy, as can be seen, for instance, in the case of his critique of liberalism, consists in continuously placing himself at the margin of its discourse. He picks up and, thus, appropriates its concepts and terminology, while creatively re-reading or misreading it in order to unsettle and alienate the discourse of liberal theory. The fact that this strategy is effective, that Bhabha is heard is attested to by the appearance of many of his articles in volumes together with the international crème de la crème of political theory. While Bhabha's critique of liberal theory is sometimes controversial, it is safe to say that it does not amount to a random act of destruction. In fact, his disruptions sometimes enable alternative ways of thinking, alternative perspectives, which, naturally, do not occur to occupants of just one discourse, who, in a way, are limited by its rules. In this sense Bhabha's work may also be characterized as properly inter-disciplinary or even trans-disciplinary.

Also, Bhabha, as opposed to Kwame Anthony Appiah, is clearly a theorist of the postcolonial in the sense elaborated by Ashcroft, Griffith and Tiffin. These authors conceived of the postcolonial not simply as that which comes after colonialism has ended; but that which comes after it but is covertly still related to it. For instance, Bhabha argues that the same ambiguity between 'having ended but not really' applies in the case of the Cold War. He asks: "Do we live in a postCold War world tout court, or in the long shadow of that disastrous postwar [sic] experience of superpower collusion and competition that deformed the development of the rest of the world?" 240 Bhabha casts into doubt that the passageway to the era of the Cold War has really been sealed behind us. Again, this should not be taken to mean that the Cold War did not end but that the past of "superpower collusion" may somehow unexpectedly re-enter the present. A recent example for such re-entry is the war in Syria. Here international debates over invention or noninvention have swiftly resurrected an unfortunate geopolitical polarization between the United States and its European allies on the one side and Russia and China on the other, which resembles the binary opposition of Western capitalism and democracy versus Soviet communism that marked the Cold War period.

239 Note, for instance, Bhabha's comment that liberalism ought to be confronted with its being "an ideology of conquest, or an instrument in the cultural [sic] of assimilation." on pp. 137-138 of Homi K. Bhabha, "The Vernacular Cosmopolitan", in: Ferdinand Dennis/Naseem Khan (eds.), Voices of the Crossing: The Impact of Britain on Writers from Asia, the Caribbean, and Africa, London 2000, pp. 133-142.

240 Sheldon Pollock/Homi K.Bhabha/Carol A. Breckenridge/Dipesh Chakrabarty, "Cosmopolitanisms", in: Public Culture 12:3 (2000), p. 580. 
Thus, Bhabha hints at the danger that history may repeat itself in a fatal way, at the possibility of our "going forward into the past." ${ }^{411}$ However, Bhabha's urging goes deeper than expressing fear of renewed global bipolarization. Bhabha is also aware that during the 1980s, and partly as a result of the global political constellation of the Cold War, the IWF and World Bank tried to win over Third World countries for capitalism by attempting to develop them through systematic loangiving and what is referred to as "structural adjustment programmes." 242 For Bhabha, as for other critics of these institutions, it has become plain that these efforts, in fact, have covertly reinstated colonial dependencies. Thus, colonial history was repeated under the surface of Cold War history.

Bhabha also explicitly attempts to resist the notion that, since the demise of the Soviet Union, Western capitalism has triumphantly re-modelled the world in its image, distributing peace, prosperity and opportunity via the spread of freemarkets all over the globe. ${ }^{243}$ This critique of the master-narrative of Western capitalism links Bhabha to Marxism. I have already mentioned Bhabha's indebtedness to Gramsci but my list also gives away that Bhabha is influenced by the Frankfurt School. However, Bhabha's relation with Marxism is more ambiguous. As in the case of Fanon's anti-colonial struggle, Marxism might need to be rethought because, on Bhabha's take, it cannot accurately continue in its traditional guise. ${ }^{244}$ It is no question for Bhabha that to oppose capitalism by reverting to some dogmatic form of Marxism, some hope of yet establishing a perfectly just communist society would reinforce the fatal binary opposition associated with the Cold War. Thus, he believes that it is imperative that we do not take sides here but explore what lies beyond this opposition. ${ }^{245}$ Accordingly, what Bhabha takes away from his engagement with Marxism is more its methodological tool of thinking dialectically rather than any concrete political convictions. Unfortunately, this does not exactly decrease the complexity of his writing. But it makes Bhabha into an excellent and highly counter-intuitive thinker of history as I have already tried to demonstrate above.

One way of going beyond Marxism, even methodologically, while remaining true to it, Bhabha finds in Gramsci's alleged notion of the necessity of thinking a dialectic before it unfolds itself. Bhabha puts it this way:

241 Ibid.

242 Compare especially Bhabha's reference to Joseph Stiglitz and his talk of "dual economy" in Homi K. Bhabha, "Looking Back, Moving Forward: Notes on Vernacular Cosmopolitanism", in: Location of Culture, p. xvi.

243 Ibid., p. xiv.

244 Homi K. Bhabha, "Unsatisfied: Notes on Vernacular Cosmopolitanism”, in: Text and Nation, pp. 191-192.

245 For Bhabha's rejection of both neo-liberal and the socialist grand-narratives compare Bhabha [et al.], Cosmopolitanisms, p. 580. 
The notion of continuance, as it relates to "taking stock of the situation at the precise moment of struggle," is similar to what Gramsci, in a famous passage on the subaltern subject, defines as the importance of "knowing all truths, even the unpleasant ones, which entails grasping the complex of superstructures in their rapid transience" - a form of contradiction, Gramsci informs us, that is often found outside the "formally dialectical" structures, because we need to grasp the dialectic as it is forming in the process of becoming itself in history. 246

In order to fully grasp this notion of thinking an emerging dialectic we need to examine more closely the way in which Bhabha thinks about history. According to Bhabha, when we think about history or when we draw on it for orientation in the present, we tend to think of ourselves as standing before the historical process, the historical development we depict and, thus, as disconnected from it. ${ }^{247}$ Hence, we are tempted to believe that colonialism has ended. We rest assured that today we are enlightened enough not to let something like it happen again. As we move on in time and look back again, the past seems to have changed its shape. For now we come to realize that earlier on we did not ultimately steer clear of the events we were describing, that we weresomehow still caught on their threshold, and we become aware of new dialectical structural relations which we did not recognize the first time as they had not properly unfolded. The wider point here is, of course, that no matter what we do, we cannot leave the on-going stream of events, cannot abandon history to grasp it in its entirety because it is not yet complete. $^{248}$ Thus, what Bhabha criticizes is teleology, that is, a kind of thinking which claims for itself a place outside or above the stream of events in order to infer the shape of history's completeness from its incompleteness, and which, in so doing, simulates a supposed 'end of history.'

Bhabha offers a radical alternative to this metaphysical misconception, which he variously refers to as the "moment of transition" 249 or simply "transition." According to this, our world is potentially in constant change and, thus, potentially every moment could be significant in prefiguring the emergence of a new and unforeseen dialectical development. For Bhabha, a person who wants to stay on top of this development must incessantly dart back and forth between the past, the present and possibly even the (projected) future in order to revise his/her notions of the past in the light of new developments from the present, to revise

\footnotetext{
246 Bhabha, "Unsatisfied”, p. 192.

247 Bhabha [et al.], Cosmopolitanisms, p. 580.

248 Compare Bhabha's interpretation of Adrienne Rich's poem "Eastern Wartime" and especially his comment that " $\mathrm{t}]$ he position Rich stakes out is an intervention into the flow of 'history that stops for no one' [...]" in Bhabha, "Unsatisfied", p. 199.

249 Bhabha [et al.], Cosmopolitanisms, p. 581.

250 Ibid., 580.
} 
the way in which $\mathrm{s} /$ he understands them as related to one another. ${ }^{251}$ For this purpose $\mathrm{s} /$ he must ceaselessly theorize, trying to represent and envision past and present as standing in ever new possible relations to one another. This, of course, is precisely what Bhabha does in his own theorizing. This is one more reason why Bhabha's writing mostly does not confront the reader with well-systematized ideas but discontinuous arguments and seemingly unstructured bits and pieces, with sparks of brilliance that are immediately dispersed as one carries on reading. Bhabha is no developer of systems because these are too static and tend towards hypostatization. We will see that this constant re-modelling and re-thinking Bhabha has in mind in a deeper sense corresponds to his conception of multicultural societies.

\subsubsection{Symbolic Citizenship, the Nation and the Right to Narrate}

One possible starting-point for discussing Bhabha's notion of vernacular cosmopolitanism is to address the way in which he thinks about globalization. This is a good starting-point because here Bhabha relates directly to a thinker of globalization I have discussed under heading 2.3, David Held. Further, it represents an excellent opportunity to observe Bhabha's revisionist thinking, his thinking in terms of transition at work.

Bhabha's basic contention about globalization is that the way in which it has developed up to this point is deficient. I have already alluded to his suspicion of the idea of an even global spread of democracy, equality and prosperity that is associated with Francis Fukuyama's notion of the end of history. Of course, it is clear to Bhabha that massive material and political inequalities persist. The notion that liberal globalization has out of itself created a world of equal opportunity or that it will do so in the long run is a dream. However, Bhabha does not analyze why structural equality has not been achieved or how things could be improved. This is a job for developmental economists. Instead Bhabha takes into view the multicultural societies of the West where he observes a profound dialectical entanglement between the deficiencies of liberal globalization and the failure of multiculturalism.

It is in this context that Bhabha explicitly refers to David Held's proposal that in creating a new internationalism, in envisioning a new global order, we should

251 Note that Bhabha believes this to be precisely what Rich's poem proposes when he argues "[...] Slavery, War, Holocaust, migration, diaspora, revolution. The 'I'm a' [Bhabha refers to the beginning of almost every line of Rich's poem] is less the instantiation of commonality of history and culture (pace Nussbaum), than the emphasizing, through insistent repetition of starting again, re-visioning, so that the process of being subjected to, or the subject of, a particular historicity $[\ldots]$ has to be, as they say, 'recounted' or re-constituted as a historical sign in a continua of transformation [sic] [...]." (Bhabha, "Unsatisfied", p. 199). Compare also Bhabha's remark in Bhabha [et al.], Cosmopolitanisms, p. 580 that "[a]s we negotiate this transitional territory, we often find ourselves in the interstices of the old and the new, confronting the past as the present." 
start from a reflection on mankind's darkest moments. ${ }^{252}$ As I have already demonstrated Held's political theory is, at least partly, engaged in overcoming the constitutional leftovers of the Peace of Westphalia, which, arguably, paved the way to an idolization of the nation that lead to the two most destructive wars in human history, and an attempt to exterminate entire peoples. Bhabha agrees with Held that we should indeed proceed from these dark historical moments. But he asks whether this would not prompt us to conceive differently of the global order. ${ }^{253}$ He explains that globalization has up to this point produced a global class of people which he refers to as "the stateless." These people leave mostly the Southern Hemisphere and the East in order to work in Western states where their labour is systematically exploited in order to support the wealth and comfort of Western consumers. ${ }^{254}$ According to Bhabha the question of whether these people possess a work-permit or even citizenship, whether they are legal or illegal is not necessarily of consequence ${ }^{255}$ as in everyday life they merge into a homogenous mass, which incites feelings of hostility on the part of the 'regular' citizens. Bhabha refers to the zone or domain these people inhabit as the zone of "insecure security." He writes:

This domain of 'insecure security' signifies the boundary of the nation's alterity, the frontier of democracy's agonistic double. Of course, security is politically necessary; but it is also in danger of becoming a structure of legitimation that replaces the laws of participation with the prerogatives of the 'police', while transforming public opinion into collective neurosis and xenophobic projection. Those who inhabit the space of 'insecure security' live in fear of the danger of encountering the alienation of the democratic promise. Not the extinction of the imagined community of the nation, but its reproduction through the creation of the fear of a culturally alien nation of the 'stateless' emerging in the midst of the nation's democratic habitus [sic]. ${ }^{256}$

What Bhabha claims is that this mass of immigrants represents the nation's constitutive Other. This may at first seem a bit confusing but Bhabha thinks here in terms of psychoanalysis. His idea is that our sense of who we are ultimately depends on the existence of things about which we believe that they are not us. In the case of the domain of insecure security the imagined community of regular citizens constitutes itself as a nation in contradistinction to the immigrants who, in so doing, are lumped together as the Other and excluded. This process of Othering, in my view, corresponds precisely to Edward Said's notion of 'Orientialism',

\footnotetext{
252 Homi K. Bhabha, "Notes on Globalisation and Ambivalence", in: Cultural Politics, p. 37.

253 Ibid., pp. 37-38.

254 Ibid., p. 39.

255 Ibid., p. 40.

256 Ibid.
} 
to a discursive fixing of the Other in order to constitute oneself in contradistinction to it. One possible incarnation of this covert negative nation-building is the emergence of right-wing popular movements ${ }^{257}$ like Germany's Bürgerbewegung pro NRW, the Norwegian Fremskrittspartiet, or, both of which I have already mentioned, Italy's Lega Nord and the UK Independence Party. But there is more because Bhabha's talk of insecure security indicates that the Other, the object that is the stateless, literally causes a contradiction within the liberal value of equality. In response to the threat of Islamist terrorism, which, to Bhabha, is ultimately a product of globalization and a response to the global neo-liberal hegemony of Western values and products, the liberal state is permanently under strain to suspend its own ideal of equal treatment of mostly African and Asian migrants in order to avert a possible threat. This constant suspicion ultimately feeds into the covert process of nation-building for now exclusion of those considered the Other appears more or less officially sanctioned. Thus, the liberal state is constantly forced to justify the absence of liberality in its territory, which enables otherwise rather extreme political forces to enter into a discursive proximity to liberal values like freedom and to pretend to be acting in its interest.

However, Bhabha's real criticism of Held's way of conceiving of internationalism or cosmopolitan democracy lies in his claim that there exists a dialectical relationship between the increasing dissolving of the nation in liberal conceptions of globalization and the covert resurgence of an even more aggressive version of it, of an ethnocentric nationalism within civil society, which precipitates the failure of multiculturalism. Bhabha explains:

[Hannah] Arendt's condition of statelessness opens up a space of doublearticulation (what I earlier on called an unresolved dialectic) in the midst of the discourse of global polity. Here the universally interrelated principles of international integration - civility, cosmopolitanism, rights conventions, global covenants, transnational citizenship, 'overlapping communities of fate' - are confronted in a kind of double-bind with the contingent conditions of dis-integration - exclusion, violence, injustice, security, discrimination. 258

According to Bhabha the cosmopolitan or internationalist project needs to be approached differently. It cannot mean the universal dissolution of nations because it is necessary for people to identify in groups. What would appear to be the problem with Held's approach is that, rather than overcoming just the nation, he, in fact, seeks to eradicate any source of antagonism, which would mean: all

257 Ibid.

258 Ibid., pp. 40-41. 
groups. $^{259}$ But Bhabha holds that the nation was actually a good thing, and he invokes Frantz Fanon to intimate what he

inscribes as his credo: "National consciousness, which is not nationalism, is the only thing that will give us an international dimension." It is this Fanonian paradox that is both enigmatic and essential for the continuance of discourses of cultural globality and transnationality to which we, too often, accede or concede without a necessary struggle. ${ }^{260}$

Bhabha, of course, speaks here explicitly from the postcolonial perspective. What Westerners all too easily forget is that the societies of the so-called Third World have existed as nations for a much shorter time than Western societies. They have different histories, and accordingly they see the nation in a very different light: as an important collective source of meaning, as the embodiment of a successful collective and collaborative struggle against slavery and exploitation. This must be taken into account when we think about internationalism or cosmopolitanism. However, from Bhabha's point of view it is not only that we should acknowledge this perspective for the sake of being fair but because it teaches us something about our own multicultural societies. For Bhabha, who believes that we may only come to an international perspective through the nation, the project of nationhood may not be abandoned because it is as yet incomplete. He argues:

Globalisation I want to suggest must always begin at home. A just measure of global progress requires that we first evaluate how globalizing nations deal with 'the difference within' - the problems of diversity and redistribution at the local level, and the rights and representations of minorities in the regional domain. What is the status of the Aboriginal peoples of Australia, or the Muslims in India in the midst of the transformational myths and realities of global connectivity? In the United States, for instance, the American dream is sustained by the 'wave theory' of migration - the Irish, followed by the Italians, Jews, Koreans and South Asians. There is, however, an ingrained insouciance, a structural injustice, shown towards African Americans and First Nation Peoples whose ethical and political demands for equality and fairness are based on issues of reparations and land-rights. These rights go beyond 'welfare' or 'opportunity' and make claims to recognition and redistribution in the process of questioning the very sovereignty of national traditions and territories. And it is because of their inter-

\footnotetext{
259 In the quote above reference to Held is evoked by the mention of overlapping of communities of fate, which is one of Held's main concepts in the context of his theory of cosmopolitan democracy. Bhabha criticizes Held for abandoning the idea of the nation somewhat more directly in Bhabha, "Unsatisfied", p. 194. 
rogations and interventions at this foundational level, that such movements are often considered to be 'against the American grain.'261

Bhabha makes the important point here that minorities often fail to be properly recognized or integrated because their identities contradict or challenge national narratives, the way national identity is collectively constituted in national histories, in tales that are shared by everyone who 'belongs.' And Bhabha suggests that in dealing with such problems it might not suffice to offer them national citizenship. But they must also receive what, in drawing on Avishai Margalit, he refers to as "symbolic citizenship" 262 - a place of their own within the larger national narrative, which, according to Bhabha, can be achieved by means of what he refers to as "the right to narrate." 263

This idea of a right to narrate is central to Bhabha's understanding of cosmopolitanism and it manifests itself in a number of different ways; so that it will be a recurring theme within this sub-section. In the immediately following chapter I will explore one possibility of how Bhabha thinks the right to narrate. And we will see that Bhabha is justified in arguing that thinking in terms of the nation offers a way of approaching an international perspective as the incarnation of the right to narrate, which I have decided to term the "minorization- globalization dialectic", can be applied to both a national and international context.

\subsubsection{The Minorization-Globalization Dialectic, the Minoritarian Condition and the Right to Narrate}

The minorization-globalization dialectic is connected to, or part of, another of Bhabha's interventions and attempted revisions within liberal discourse. His argument begins from a critical examination of Article 27 of the International Covenant on Civil and Political Rights, which is one of the two main implementationconventions of the UDHR. ${ }^{264}$ Bhabha criticizes that

Article $27[\ldots]$ supports 'the right of minorities, in community with the other members of their group, to enjoy their own culture, to profess and practice their own religion, or to use their own language.' However, Article

261 Bhabha, "Looking Back", p. xv.

262 Ibid., p. xvii.

263 Ibid., p. xx; xxv.

264 Note that in "Looking Back" there occurs some kind of muddle and it appears as if Bhabha claims that this is what the UDHR says, but this is a mistake. Article 27 of the UDHR reads: "(1) Everyone has the right freely to participate in the cultural life of the community, to enjoy the arts and to share in scientific advancement and its benefits [;] (2) Everyone has the right to the protection of the moral and material interests resulting from any scientific, literary or artistic production of which he is the author." (Anon, The Universal Declaration of Human Rights, URL: http://www.un.org/en/documents/udhr/index.shtml\#a27 (accessed: 25/10/2013).). This mistake is ultimately cleared up on p. 167 of Homi K. Bhabha, "On Writing Rights", in: Globalizing Rights, pp. 162-183. 
27 emphasizes the need for minorities to 'preserve' their cultural identities, rather than to affiliate across emergent minority communities. ${ }^{265}$

It may come as a surprise that Bhabha should criticize the idea that immigrants preserve their cultural traditions, given that he has spoken affirmatively about the recognition of minorities. But Bhabha is strictly opposed to any kind of identitypolitics, which he sees as related to a way of thinking about culture in terms of an adherence to a supposed cultural origin, or cultural authenticity. ${ }^{266}$ Accordingly, Turkish immigrants to Germany and their descendants should not merely think of themselves as Turks. After all, they are not only Turks but they are Turks in Germany; and Bhabha advocates that minorities explore the meaning of this "inbetween" status, which can be profoundly fulfilling and a remedy to the traumatic disruption of identity, the loss of meaning which the experience of migration often entails. Bhabha speaks in this context of "articulation." 267 The migrant-subject must ask him/herself: "Who am I here?" S/he must find an answer to this question in a new cultural context where the significance or meaning of his/her cultural heritage, customs and norms cannot be properly symbolized.

I shall return to this very interesting point at a later stage. For now, let us just look at how Bhabha's dismissal of identity-politics constitutes a critique of liberalism. The example of Turks living in Germany (what is more formally called German citizens of Turkish origin) is quite instructive in this context. The problem with the liberal notion of cultural tolerance doesnot lie in that it is not tolerant enough. Rather, paradoxically, it is its implicit premise that turns into a selffulfilling prophecy: our assumption that these people could want nothing else but their own culture. It is this originally benevolent and well-intended assumption that even though these people have come here, we must leave them alone with what they are culturally, which builds a wall instead of a bridge and finally traps the immigrant in being 'the Turk.' I have just described the liberal premise of tolerance as benevolent. But is this really so? In fact, if we are completely honest a different characterization of it would be possible: I could also say that it entails a certain ethnocentric desire to keep the alien separate from me. For in keeping him a Turk, I can remain a German. ${ }^{268}$ This is one of the instances in which Bhabha

265 Bhabha, "Looking Back", p. xxii.

266 Compare especially Bhabha's comments on conventional notions of identity in Homi K. Bhabha, "The Manifesto", in: Wasafiri: Perspectives on African, Caribbean, Asian and Black British Literature 14:29 (1999), pp. 38-39; Compare also how Bhabha and the London artist Rashid Asaeen discuss the shortcomings of identity in an interview in the same issue of Wasafiri (Patrick Wright, "Radio 3 'Night Waves' Discussion: Homi Bhabha, Susheila Nasta and Rasheed Araeen", in: Wasafiri 14:29, p. 41).

267 Bhabha, "Manifesto", pp. 38-39.

268 Compare especially pp. 49-52 of Homi K. Bhabha, "The Commitment to Theory", in: Location of Culture, pp. 28-56. This argument is also implicit in his rejection of identity-politics and his aspiration to convict liberal discourse of ethnocentrism. It is certainly implied by Bhabha's comments on the UDHR above but also becomes apparent in his critique of Will Kymlicka, who 
appropriates or, rather, misappropriates and revises a category from the discourse of liberalism. It certainly makes for a very controversial proposal. However, can we really say with absolute certainty that it is wrong? What we become aware of in this instance is that the discourse of liberalism is more ambivalent, more opentextured than would at first appear to be the case and that it appears to possess a dark side we usually are not aware of.

I will now address one of the ways in which cosmopolitanism or internationalism can be dialectically realized, and which, earlier on, I described as the minorization-globalization dialectic. In the context of his elaborations on a poem of Adrienne Rich, which, for him, represents cosmopolitan or global subjectivity, Bhabha says the following:

In the wake of these voices we are led to a philosophical and political responsibility for conceiving of minorization and globalization as the quasicolonial, a condition at once old and new, a dynamic, even dialectical relationship that goes beyond the polarization of the local and the global, the center and the periphery, or, indeed, the 'citizen' and the 'stranger.'269

He then continues in a seemingly disjunctive fashion:

A recent UNESCO report of the World Commission of Culture and Developments suggests that a minoritarian condition is, indeed, a kind of global citizenship. The last two or three decades have seen more people living across or between national borders than ever before - on a conservative estimate 40 million foreign workers, 20 million refugees, 20-25 million internally displaced people as a result of famines and wars. Immigrants, refugees and minorities who live in the midst of metropolitan centers in the North and South represent the most tangible and proximate presence of the global or transnational world as it exists within 'national' societies. ${ }^{270}$

What Bhabha tries to express in relating these two parts is a vision of globalization as a dialectical process of minorization, a process in the cause of which people to an increasing extent become minorities so that increasingly more cultures become centered around the experience of being a minority, of being displaced. Cultures increasingly contain or are built on experiences of being in the minority or what Bhabha calls the "minoritarian condition." If we combine this with the idea that liberal notions of cultural neutrality ${ }^{271}$ discourage minorities from associating with

believes that multiculturalism is all about the right of ethnical and cultural groups to move around in the world within their own culture. (Bhabha, "Writing Rights", p. 167.)

269 Bhabha, "Looking Back", p. xxi.

270 Ibid., pp. xxi-xxii.

271 Remember that "ethical neutrality" is a view specifically advanced by David Held. It is the idea that states must meet the cultural distinctiveness of citizens in an uncommitted fashion as long as these cultural traits do not impinge on other citizens' freedom (see chapter 2.3.2). I have here decided to refer to it as "cultural neutrality", which, for my taste, grasps its implications some- 
other minorities, there emerges an interesting sense that we could achieve more understanding on both a global and national scale if we let migrants and minorities exchange their respective minority-narratives. I do not want to take this idea too far but it seems that Bhabha here suggests that working in this way may precipitate a Palestinian in Israel to identify with the fate of Jews in Germany, or that a Muslim immigrant to Europe may approximate an understanding of what being in the minority must mean to a Coptic Christian in Egypt. This is another very controversial yet highly intriguing idea. However, it still leaves us partly stranded as the dialectic cannot include those people who have no experiences of migration or "minorization", and this is where the work of Bhabha's cosmopolitans begins.

\subsubsection{Culture and the Difference between Languages Lived and Languages Learned}

Bhabha's engagement with what he refers to as "vernacular cosmopolitanism" goes back to his 1994 classical study The Location of Culture. In his preface to this book, which is actually a proper essay, Bhabha offers some insights into his autobiography: He briefly mentions his youth in India, and, in particular, talks about what it was like coming to England to study its language and literature. Bhabha explains:

Setting out from Bombay in the 1970s to study English at Oxford was, in many ways, the culmination of an Indian middle class trajectory where formal education and 'high' culture colluded in emulating the canons of elite 'English' taste (or what we knew of it) and conforming to its customs and comforts. ${ }^{272}$

Here especially the aspect of desiring to conform to English taste, to English norms and customs is interesting. In a way Bhabha conveys the sense that he believed that there lay hidden within English literature a secret knowledge, an essence that formed the key to English greatness and civilizational superiority. Thus, one could say that, in a way, Bhabha was working to become English himself in order to be able to partake in English greatness. However, he remarks that when he came to England, he did not encounter such an essence. ${ }^{273}$ This was partly because he did not enter into an environment in which English was spoken in its received pronunciation or the idealized and artificially quick-witted fashion in which the characters of Jane Austen or Charles Dickens speak. Bhabha explains:

My everyday life, however, provided quite a different inheritance. It was lived in that rich cultural mix of languages and lifestyles that most cosmopolitan Indian cities celebrate and perpetuate in their vernacular existence -

what better. Though I have often used both terms to signify this relation between Held's and Bhabha's respective conceptions of multiculturalism.

272 Bhabha, "Looking Back", p. x.

273 Ibid., p. xi. 
'Bombay' Hindustani, 'Parsi' Gujarati, mongrel Marathi, all held in suspension of Welsh-missionary-accented English peppered with Anglo-Indian patois that was sometimes cast aside for American slang picked up from the movies or popular music. ${ }^{274}$

It occurred to Bhabha that to seek English in its purest expression, the quintessence of Englishness, which would radiate throughout all of its appearances, was possibly anachronistic because English, to use a winged word, was not identical with itself. Rather, it appeared as internally diverse ${ }^{275}$ and in practice was constantly polluted and inter-penetrated by things other than itself, which then irreversibly became a part of it. This is what Bhabha refers to as the discrepancy between "languages lived, and languages learned"276 (Bhabha's italics). That which Bhabha refers to as vernacular cosmopolitanism resembles the latter half; that is, it resembles languages as they are actually spoken and constantly hybridized through this usage by different speakers.

I have chosen to further elaborate on this at this point because to understand what Bhabha means by this dichotomy is not only to understand what vernacular cosmopolitanism amounts to. It also means to grasp the profoundly perplexing and original way in which Bhabha thinks about culture. One interesting thing that Bhabha has to say about languages learned, which corresponds to the metaphysical notion of Englishness is that this "canonical 'center' may, indeed, be most interesting for its elusiveness, most compelling as an enigma of authority." 277 What Bhabha draws attention to is that even if there was a central core of English culture or English literature - a core that brings to unity the spirit that pervades English literature or culture in its entirety -, it could not stand on its own. We could not adequately think or represent it in its purity because our thinking and language are essentially organized in terms of binary opposition. Thus, whatever content we consider this essence to possess, whatever concrete characteristic we attribute to it, always presupposes the existence of something other than itself: In order to finally characterize our essence, we would need to know the essence of its Other. But this Other only leads to another difference, another Other and so on indefinitely. Thus, the bottom line here is that we are only able to say what we consider typically English because there is something that stands to it in a relation of nonidentity. Yet, the precise interplay of relations can never be finally worked through because, paradoxically, there is no identity without difference. ${ }^{278}$ And, thus, what

274 Ibid., p. x.

275 Compare Bhabha's allusion to class-specific accents and regional dialects in his "Vernacular Cosmopolitan", p. 136.

276 Bhabha, "Looking Back", p. x.

277 Ibid., p. xi.

278 Compare for this especially Bhabha's comments on "the peculiarly English" on p. 153 of Homi K. Bhabha, "Signs Taken For Wonders: Questions of Ambivalence and Authority under a Tree outside Delhi, May 1817”, in: Location of Culture, pp. 145-174. This idea is also often implicitly 
we find at the metaphysical heights of Englishness is not an identity or oneness but difference because difference (and not identity) is the most basic category of our thinking. This is why the essence of Englishness must remain elusive and cannot finally reveal itself in language or representation.

This admittedly rather abstract point is quite nicely complemented by Bhabha's comment that the pure(ly) English he had been seeking "had the archaic feel of a carved almirah that engulfed you in the faded smell of moth-balls and beautiful brittle linens." 279 Apart from the fact that the reader is here intentionally left in the dark as to whether this amounts to insult or praise, what is intriguing is Bhabha's use of the term 'almirah'. For upon inspection of the dictionary we learn that this term, which is used by Bhabha to conjure up the ancientness of the English idiom, is, in fact, a loan from Urdu via Portuguese. ${ }^{280}$ In this way Bhabha signals how much the intersection of our own language and culture with the Other marks our own condition of coming into it. There simply is no way for us to go all the way back and imagine it as so ancient and so authentic that it could not be said to already contain alien elements.

Note that Bhabha does not want to claim at this point that there always were Indian loanwords in English. This would be absurd and, thus, we must not take this too literally. Of course, we possess evidence of what English was like before any person speaking it ever encountered an Indian. Back then English clearly contained no Indian loans. However, the point is that even back then it was not exactly pure either. For, it drew on and was inseparably related to other languages that existed in its proximity. If we go back even further, the notion of English as English disappears altogether and, finally, all languages appear to collapse into one. However, Bhabha's broader point here is not so much about language, but about cultural practices more broadly. ${ }^{281}$ Cultural practices, including languages, are always hybrid, are always the result of the intermingling of various heterogeneous sources. If we take this insight at face value and think back to what I have said before, we come to realize something very important about Bhabha's way of thinking about culture; namely: The source of a culture's hybridization lies not merely in its relation to an external Other but, paradoxically, also stems from an Otherness that is always already internal. In reality, of course, any supposedly unified culture always contains its own difference in that it consists of different groups and individuals, who interpret its meaning differently and which are inter-

used by Bhabha to suggest a general unreliability of empirical knowledge. For this see, for instance, his comments on "fixity" on pp. 94-95 of Homi K. Bhabha, The Other Question: Stereotype, Discrimination and the Discourse of Colonialism, in: Ibid., pp. 94-120.

279 Bhabha, "Looking Back", p. x.

280 Anon, "almirah, -myra" in: Oxford English Dictionary, 2nd ed., vol. I, Oxford 1989, p. 352.

281 Bhabha here at least partly conceives of language and culture in analogy to one another. This has a lot to do with his being influenced by post-structuralism, which is rooted in modern linguistic theory. 
locked in a struggle for hegemony, a constant process of negotiating cultural meaning. 282

It is necessary to point out that this way of absolutizing difference, of course, seriously disrupts our usual way of accounting for it in terms of culture. Cultures, on Bhabha's take, all of a sudden do not appear anymore as separate units but as potentially the same in that they are all hybrid and constantly hybridizing one another as well as themselves (through the individuals that compose them). Bhabha, thus, shares with Kwame Anthony Appiah a dislike of what I have referred to as a holistic conception of culture, which is a way of thinking about cultures that still implicitly relies on our being able to signify their singular identities, on our being able to show what they truly are in themselves. This, as I have shown, cannot be done - at least not linguistically. And this makes the supposed boundaries between cultures appear a lot more permeable than we would at first believe. Maybe the differences you feel between you and your friend really are due to the fact that the two of you grew up in what supposedly are two different cultures. But this is not necessarily so. Certainly the differences between you and your neighbour are not due to culture. But quite possibly these feel even more severe than the differences between you and your friend.

\subsubsection{Vernacular Cosmopolitanism and the Subject of Ambivalence}

Bhabha explains that the idea of languages lived, that is, the notion of English as inherently hybrid, in fact, enriched his understanding of the canonical texts he was studying 283 , while simultaneously shedding new light on his home India. However, this "vernacular existence", which Bhabha associates with Indian metropolitan spaces, did not return him to his Indian heritage. Instead, he found it epitomized in a deeper sense in the fiction of the Trinidad-born British novelist and travelwriter V.S. Naipaul284, who in much of his writing attempts to work through his own personal cultural displacement. One of Naipaul's works explicitly mentioned by Bhabha is his 1967 novel The Mimic Men. The book's title is specifically suggestive as, earlier on, I have described Bhabha's desire to mimic British taste and norms, which he associates with the notion of languages learned. And, indeed, we encounter in the novel the same theme of mimicry, an ambivalent desire on the part of a group of immigrants to London, whose story the novel tells, to reify and

282 Please note that, again, Bhabha at no point clearly states this to be his conception of culture. However, it would appear to follow more or less directly from his idea of the necessarily hybrid status of cultures. The idea that there is a kind of struggle within every society or culture for hermeneutic hegemony or a negotiation of cultural meanings appears to be suggested in some way by Bhabha's idea that "culture is less about expressing a pre-given identity (whether the source is national culture or 'ethnic' culture) and more about the activity of negotiating, regulating and authorising competing, often conflicting demands for collective self-representation." (Bhabha, "Manifesto", p. 38.)

283 Bhabha, "Vernacular Cosmopolitan", p. 136.

284 Bhabha, "Looking Back", p. xii. 
appropriate aspects of the city. For instance, the Maltese character Lieni attempts to fashion herself as a "London girl" to no avail ${ }^{285}$, while the novel's main protagonist Ralph Singh, a Caribbean-born colonial of Indian descent, tries to grasp "the god of the city" but ultimately fails as this entity remains "elusive" or "veiled." 286 Bhabha, of course, is absolutely aware that Naipaul's intention in fashioning his characters as lost and shadowless mimics is to point to the inferiority and marginality of Caribbean culture, which, on Naipaul's take, lacks all the historical greatness of England, leaving its inhabitants devoid of a full sense of identity, without a sense of cultural belonging. ${ }^{287}$ However, in complete contrast to Naipaul's intended dismissal of postcolonial cultures, Bhabha argues something surprising about his protagonists:

His [Naipaul's] characters made their way in the world, while acknowledging its fragmented structures, its split imperatives, and a prevailing sense of a loss of cultural authority. [...] It was the ability of Naipaul's characters to forbear their despair, to work through their anxieties and alienations towards a life that may be radically incomplete but continues to be intricately communitarian, busy with activity, noisy with stories, garrulous with grotesquerie, gossip, humour, aspiration, fantasies [sic] - these were signs of a culture of survival that emerges from the other side of the colonial enterprise, the darker side. Naipaul's characters are vernacular cosmopolitans of a kind, moving in-between cultural traditions, and revealing hybrid forms of life and art that do not have a prior existence within the discrete world of any single culture or language. ${ }^{288}$

If we go back to The Mimic Men and examine the novel more closely, we become aware of what Bhabha means. His reading the novel against the grain brings to the fore an unanticipated colourfulness, a warm sense of community among Naipaul's outcasts, which is otherwise suffocated by the novel's bleakness and overall atmosphere of despair and decay. In fact, the people Ralph Singh associates with stem from all walks of life and many different cultures: There are, of course, Singh's initial Maltesian companion Lieni and her "young Indian engineer with whom she had a relationship" 289 , then there are the Anglo-Italian couple, "the Countess" 290 , the "girl from Kenya [and] her man friend, a blond, vacant alcoholic [...]; the smiling, mute Burmese student; the Jewish youth [...]; the bespectacled young Cockney"291, who has two Italian fiancées and the French translator, who

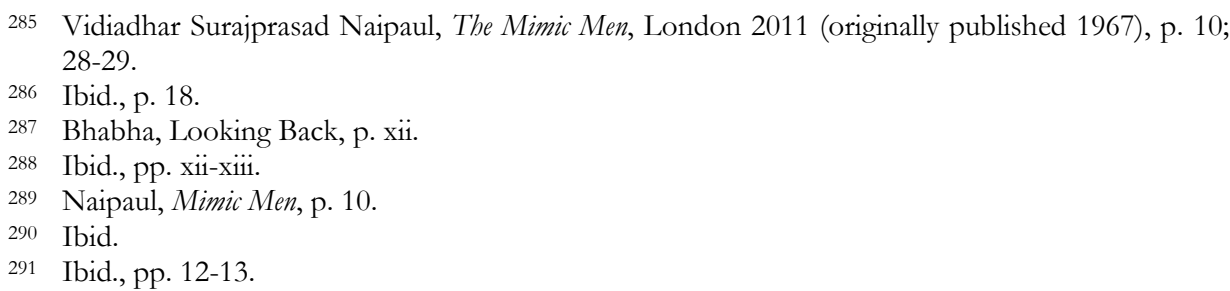


actually comes from Morocco and prefers Moroccan temperatures. ${ }^{292}$ Finally, there are "Johnny-boy", a supporter of Oswald Mosley's British Union of Fascists, his drunk wife ${ }^{293}$ and Paul, the homosexual294, which suggests that Naipaul's community of discards in its unorthodox heterogeneity possesses enough potential to encompass and accommodate even outright contradictions. It is especially this capacity to bring together and to co-locate differences without reducing them, which makes them into a model of citizenship for Bhabha.

We are now in a position to more fully appreciate why Bhabha is against politics of identity and why he did not easily find comfort in being an Indian after his discovery that the center of Englishness was, in fact, empty. Bhabha is strongly influenced by psychoanalysis and thus he is often interested in subjectivity. However, what is of interest to Bhabha is not so much the subject as it is produced by its culture, but the subject as a moment within the process of hybridization. For Bhabha to reassert himself as an Indian after having been disappointed and rejected by England would have meant to seek refuge in another monolithic identity, another dead-end; albeit, one in which differences appear much more pronounced than in England. Of course Bhabha is an Indian. However, he is also a Parsi and he suggests that upon coming to England, experiencing it and taking it in, he also became an Englishman. This doubling and tripling he expresses in a wonderfully poetic way by saying: "In another's country that is also your own, your person divides, and in following the forked path, you encounter yourself in a double movement [...] once as stranger, and then as friend." 295 For Bhabha it is this sense of existing not within one culture but, as he often says, 'in-between' different cultures, a situation, which appears to amount to alienation, that marks the condition of the vernacular cosmopolitan.

This is also the reason behind Bhabha's objection to Martha Nussbaum's model of cosmopolitanism, in which the individual is surrounded by various concentric circles of ethical concern, the outlying ones of which $\mathrm{s} /$ he must draw closer toward him/herself. The way in which Bhabha criticizes this model at first appears cryptic and unintelligible. This is partly caused by the fact that in order to get his point across he actually dissects and recycles a quote from Richard Sennett's response to Nussbaum. This is a good chance for observing Bhabha's deconstructivist technique at work. I will, therefore, have a closer look at what he does and how he does it: First Bhabha argues against Nussbaum's model by claiming that "Nussbaum too readily assumes the 'givenness' of a commonality that

\footnotetext{
292 Ibid., p. 13

293 Ibid., p. 12.

294 Ibid., p. 14.

295 Bhabha, "Vernacular Cosmopolitan", p. 142.
} 
centres on a particular image of the 'emphatic' self'. ${ }^{296}$ Then he misquotes Sennett in the following way:

[Nussbaum] neglects 'Those identities [... that] arise from fissures in the larger social fabric', as Richard Sennett suggests in his response to Nussbaum, '[containing] its contradictions and injustices [...] remaining necessarily incomplete versions of any individual's particular experience'.297

Of course, it is not immediately obvious what Bhabha means in this passage. For how may anyone possess an identity that is not part of her individual experience? It is as if Bhabha claims that these identities are not identities of complete individuals or that the identities make up only a fraction of the individuals. But then the individuals belonging to them needed to have other identities in order to be individuals in the full sense. In fact, this would at first appear to be the solution: The identities in question have to share the individual and, thus, what Bhabha criticizes is that Nussbaum cannot comprehend that individuals may have hybrid identities.

However, I would suggest that Bhabha also wants to state precisely what his misquote initially proposes: that the cosmopolitan subject is not an individual, as I have put it, 'in the full sense.' For Bhabha it is precisely clear that being a vernacular cosmopolitan, in fact, precludes our subjectivity from ever appearing as whole. Thus, what he criticizes in Nussbaum is that the individual, who stands in the middle of her circle, is represented as if it was in any sense self-contained. But anyone who considers his/her identity as whole, who possesses a firm standpoint, which s/he does not want to leave, is not really going to be open to others. Thus, for Bhabha the cosmopolitan subject appears as fragmented, incomplete and always in process. He argues that "it is precisely there, in the ordinariness of the day-to-day [...] that, unexpectedly, we become unrecognizable strangers to ourselves in the very act of assuming a more worldly [sic], or what is now termed 'global', responsibility.'" 298 For Bhabha, being a cosmopolitan subject is precisely to be alienated, to be essentially split between or in-between positions, which, in a constant discontinuous movement, we try to bring into order without there ever occurring a definite end to this process. This is also what Bhabha calls the "the subject of ambivalence." According to Bhabha, "[t]he 'subject' of ambivalence

296 Homi K. Bhabha, "Unpacking my Library... Again”, in: Iain Chambers/Lidia Curti (eds.), The Post-colonial Question: Common Skies, Divided Horizons, London/New York 1996, p. 200.

297 Ibid., p. 201; Please note that in this quote the additions in brackets that occur within the space marked by single-stroke quotation marks are not mine but Bhabha's.

298 Ibid., p. 202. Please note that the idea that the subject is essentially alienated further supplements my interpretation of how Bhabha thinks about culture. In fact, Bhabha conceptualizes culture and the subject in an analogous way in that it is not merely culture that is the site of a hegemonic struggle but also the subject itself. The subject is always already hybridized as it is the intersection of contradictory social and cultural forces. Hence, like culture, it contains its own Otherness. 
[...] moves back and forth, hither and thither [...]"299 and we now understand in how far vernacular cosmopolitanism is related to that which I have described as thinking in transition. Here, again, the subject must dart back and forth, incessantly revising not only past against present but also seeking common-ground between different contradictory and seemingly incommensurable perspectives and subjectpositions.

All of this might cause some confusion because Bhabha never actually explains whether he means this to be a recommendation or the description of a cosmopolitanism that already exists. I think it is a bit of both: Bhabha essentially attempts to conceptualize how cosmopolitanism must function within the subject, and how we can imagine it. But he also uses his ideas to identify other vernacular cosmopolitans. I have explicitely used 'other' here because it is absolutely clear that Bhabha considers himself a vernacular cosmopolitan, that, in fact, he bases his conceptualization of vernacular cosmopolitanism on his own subjectivity. In the context of the various responses to Martha Nussbaum Bhabha finds vernacular cosmopolitanism to be embodied by Richard Sennett, the son of working-class Russian immigrants to Chicago, in Vandana Shiva, the Indian nuclear physicist, advocator of women's rights and ecologist, and in Kwame Anthony Appiah, whose life is split between Ghana, Britain, and the United States. ${ }^{300}$ All of these individuals, for Bhabha, are living in-between different cultures, bringing different perspectives to the various discourses and academic disciplines in which they work and, in so doing, are hybridizing them.

\subsubsection{Translation as Transformation, Human Interest and the Right to Narrate}

Bhabha's notion of translation takes me back to the issue of recognition. As I have argued earlier on, Bhabha does not approve of politics of identity. He argues:

My aim is to get away from a view of culture as an evaluative activity concerned primarily with the attribution of identity (individual or collective) and the conferral of authenticity (custom, tradition, ritual). [...] Culture as an authenticating/identity-bestowing function, expressive of this past tradition, or that customary belief is of limited relevance to the cosmopolitan condition. ${ }^{301}$

Instead, Bhabha argues that what one should think of as culture is more "the activity of negotiating, regulating and authorising competing, often conflicting demands for collective self-representation." 302 He continues: "So the work of culture does not exist at the level at which a community expresses a demand, but at the level at which that demand becomes articulated with other demands in order to be

\footnotetext{
299 Bhabha, "Globalisation and Ambivalence", p. 41.

300 Bhabha, "Unsatisfied", p. 196.

301 Bhabha, "Manifesto", p. 38.

302 Ibid.
} 
able to claim a value and to become meaningful as a form of cultural judgement." 303 What is important here, I think, is Bhabha's reference to meaningfulness. His point is that all too often when migrants make demands relating to their ethnical and cultural needs, these remain unintelligible from the point of view of their host-society or nation. This is because they are formulated in terms of an appeal to a cultural tradition, and to norms, which might be completely selfevident for the migrant. However, we encounter here the need to "translate" or "articulate" them in such a way that they become meaningful within the discursive order of the host-society. This, of course, is another side of what Bhabha refers to as symbolic citizenship. Significantly, this translation appears to amount to a twoway transformation. This is because in translating her cultural meaning and, thus, him/herself, the migrant adapts him/herself to the discourse of the Other, of her host-society. Thus, s/he transforms him/herself but s/he also transforms the host-society because $\mathrm{s} /$ he now receives recognition within its discourses, represents a moment within them and has thus effectively hybridized them. In this way $\mathrm{s} /$ he has, paradoxically, transformed him/herself in order to remain who s/he was, to maintain his/her former subject-position. I believe that this is what Bhabha means when he speaks of "translation as transformation."304

However, in hybridizing one another the immigrant and his/her host-society have moved closer together and opened up an "intercultural"305 space, a new idiom or framework in which they can translate their differences to one another. Bhabha finds a model for this in the two main-characters from E.M. Forster's novel $A$ Passage to India. The novel, which is set in early twentieth century India, partly describes the development (and eventual destruction) of a friendship between the Muslim doctor Aziz and the young Englishwoman Adela, the prospective wife of a colonial official. In the novel their opening up of an inter-culture or in-between space eventually fails due to unfavourable external conditions, intrigue and Adela's lasting impression that she was raped by Aziz. ${ }^{306}$ Yet Bhabha still beautifully elaborates on the book's promise of a space in which the mutual loathing between Indians and their colonial masters is suspended. He argues:

Aziz and Adela were trying to create a new medium of understanding that would make it irrelevant for them to retreat to the certitudes of their own cultural foundations, and it is for this reason that Forster leads them into

\footnotetext{
303 Ibid., pp. 38-39.

304 Bhabha, "Unsatisfied", p. 196.

305 Note Bhabha's discussion of the "intercultural” in: Bhabha, "Writing Rights", pp. 175-176.

306 Edward Morgan Forster, A Passage to India, London 2005 (originally published 1924), pp. 182 183. Note that in the novel it never gets settled whether Adela was actually raped at all. There certainly occurs some incident. Yet throughout the novel there pervades a strong sense that Aziz is being framed as part of a power-struggle between the local Indians and Anglo-Indians. Compare for this especially Fielding's discussion with McBryde in: Ibid., pp. 157-161, or the courtroom-episode on pp. 204-217.
} 
the darkness of the Marabar Caves. There, prior assumptions and prejudices are flung into the void and, for a spare moment, the colonial mehmsahib and the educated native confront each other through a glass darkly [...] not seeking their own reflections, but the possibility of a proximate existence. ${ }^{307}$

This promise of an inter-culture into which we may translate our differences together with others to seek a "proximate existence" in many ways resembles that which Bhabha often terms the "third space" 308 . The metaphor of a space opening up in what is essentially meaning, may at first seem a bit ill-fitting. However, I believe that the reason Bhabha often refers to this in such a way is because he wants to suggest that to form an inter-culture does not amount to a mere dialectical sublation or synthesis but to something that opens up new potentials and possibilities of combination; in other words: to freedom. And this, of course, marks Bhabha as a thinker of human agency. For him, it is only through hybridization and, thus, through the emergence of new cultural and social forms and ways of being that we can, if only for a moment, escape from the structures that otherwise determine our every action. ${ }^{309}$

Something that is related to Bhabha's notion of inter-cultures is what, drawing on Hannah Arendt, he calls "human interest", "inter-est" or "in-between." 310 I have already used this expression several times without properly reflecting on it. In many ways it seems to refer to the position of the cosmopolitan subject. However, Bhabha also uses this idea of the in-between to comment on the discourse of human rights. In this context he is specifically critical of a certain tendency within liberalism to base the notion of what rights belong to 'the human' on a presumptuous generalization about what the human or, as Bhabha puts it, the "merely human" amounts to. Bhabha is here very suspicious of a universalism he already found in Nussbaum and which Ulrich Beck called an absolutized universalism of sameness - a universalism on which we embrace others but only on our own terms and thus at the expense of their difference. Such a notion of the merely human attempts to cast aside something that Bhabha thinks as inevitable: the symbolic embeddedness of all human behaviour. ${ }^{311}$ In reality, what it achieves is not a universal image of man but merely the universal projection of its own con-

307 Bhabha, "Vernacular Cosmopolitan", p. 138.

308 Compare for the concept of "third space" especially Jonathan Rutherford, "The Third Space: Interview with Homi Bhabha", in: Idem (ed.), Identity: Community, Culture, Difference, London 1990, pp. 207-221.

309 This is especially suggested by Bhabha's comments on the Dalit poet Prakash Jadhav, who, according to Bhabha, escapes the Hindu-Muslim-polarization of Indian mainstream culture by borrowing rhetorically from the Black Panther movement. (Bhabha, "Looking Back", pp. xxivxxv.)

310 Bhabha, Globalisation and Ambivalence, pp. 45-46.

311 Compare for this Bhabha, "Unsatisfied", p. 198; Bhabha, "Vernacular Cosmopolitan", p. 139; Compare also Bhabha's statement that "[t]he 'human', as a cultural category, frequently signifies a process of translation." (Bhabha, "Writing Rights", p. 170.) 
sciousness. Bhabha argues that this must not lead us to a rejection of human rights: "We need not, of course, dismiss the appeal to the 'merely human'. After all, we quite properly invoke the merely or purely 'human' as a horizon of moral hope and political courage when we talk of human rights in a national and international perspective." 312 Instead, he suggests: "In complex multicultural societies, the 'culture of humanity' requires that we continually translate the 'merely' human [...]."313 Thus, what Bhabha recommends is not that we should stop trying to think about human rights or what the merely human amounts to. We must, in fact, create an active culture of talking about human rights and not leave this to a few professionals. But we must not do so in the way in which religious fundamentalists discuss the Bible or the American constitution. We must not try to artificially fix the meaning of the human but always expect that in the context of our translating our subject-positions to one another, we may get to a point at which we have to adjust or revise our understanding of essential rights. This is quite reasonable since the people behind the UDHR - legal scholars should not be considered to be infallible. Bhabha also speaks in this context about "the human as a 'translational' sign." 314 The discourse of human rights in maintaining its position cannot remain the same but it must move along with and follow the flow of hybridization, re-translating and re-inscribing itself within the discursive struggle for hermeneutical hegemony.

Finally, one way in which translation and negotiation between different positions may be put into practice, is through the right to narrate; hence, through a mutual exchanging of narratives. Bhabha explains that narrative is here not meant as restricted to literature but that it extends also to film, art, historical writing and any other way in which a person's or a group's history and sense of identity may be related. He argues:

By the 'right to narrate', I mean to suggest all those forms of creative behaviour that allow us to represent the lives we lead, question the conventions and customs that we inherit, dispute and propagate the ideas and ideals that come to us most naturally, and dare to entertain the most audacious hopes and fears for the future. The right to narrate might inhabit a hesitant brush stroke, be glimpsed in a gesture that fixes a dance movement, become visible in a camera angle that stops your heart. ${ }^{315}$

Then Bhabha suggests something interesting, which is that our exchanging narratives with one another may not only help us understand the Other. Rather, this gaining insights into the Other appears as dialectically related to a gaining of deeper insights into the self. Bhabha suggests:

\footnotetext{
312 Ibid., p. 170.

313 Ibid.

314 Bhabha, "Unpacking", p. 204.

315 Bhabha, "Writing Rights", p. 180.
} 
Suddenly in painting, dance or cinema you rediscover your senses, and in that process you understand something profound about yourself, your historical moment, and what gives value to a life lived in a particular town, at a particular time, in particular social and political conditions. ${ }^{316}$

When we learn about the way others conceive of themselves, this gives us new ways of imagining ourselves or making sense of our own life. Our recognition of the difference of the Other dialectically reinforces our recognition of ourselves as Other, of our own difference. That is, we are being alienated from ourselves, which, in turn, corresponds to the condition of the cosmopolitan subject. But we now realize that this alienation is actually a source of freedom, of breaking free from the confines of our culture, in which our possibilities of accounting for who we are were limited. And the more we discover our own alienation as a source of freedom, the more we open ourselves to the narratives of others and become vernacular cosmopolitans.

It becomes obvious at this point that this dialectic forms the complementary part to the minorization-globalization dialectic, by means of which Bhabha encompasses those people who do not experience migration or partake in what he called the minoritarian condition. Bhabha compensates here by suggesting that these people should be opened to the minoritarian condition by being alienated from their own culture, which, for him, is precisely what migration and minoritarian existence entail.

\subsubsection{Global Memory and the Right to Narrate}

In chapter 3.3.2 I have argued that Bhabha believes that thinking in terms of the nation can provide us with an international or cosmopolitan perspective. In chapter 3.3.3 I then outlined the minorization-globalization dialectic that is implied by him. It was easily recognizable how this dialectic could be said to possess both a local (or national) and a global dimension. However, Bhabha does not leave it at that and attempts to also think the other half of the right to narrate, the dialectic that exists between the recognition of the Other and the self in a global or international context. This leads him to what he refers to as "memory" or "global memory."

In thinking about memory Bhabha returns to David Held and his dictum that in conceiving of cosmopolitanism, we should proceed from a consideration of human atrocities. This is to the purpose that we should not repeat them or go down roads that lead us back to them. Bhabha takes this idea seriously and he also agrees with another of Held's assessments; namely that the increasing advancement of international integration and global interconnectedness poses a serious challenge to the practice of democracy. Bhabha puts it this way: "If, as David Held argues, 'the agent at the heart of modern political discourse, be it a person, a

316 Ibid. 
group or government is locked into a variety of overlapping communities and jurisdictions, then the "proper home" of politics and democracy becomes difficult to resolve." 317 How, in other words, could we translate the procedures and practices of national democratic deliberation into a global or international context? This, of course, constitutes the most fundamental problem explored by Held in the context of cosmopolitan democracy. What we have learned from Held, from Kant and ultimately from Appiah is that there exist a variety of reasons for why the challenge that globalization poses to democracy cannot be solved by the creation of a global state. For even if the creation of such a state, the holding in coherence of its procedures was not virtually impossible to accomplish, it would still be highly undesirable for its all-encompassing centralism. This is why Held's approach rather seeks to decentralize power by thinking about the democratization of institutions of global governance and from civil society. Of course, Bhabha does not share Held's rather straightforward approach of thinking about institutions. This enables him to contribute to the discussion over cosmopolitanism in an original way: Bhabha is, of course, aware that the proper functioning of national democracies relies on the existence of a politicized and well-informed community of citizens and, thus, on public spheres like the university. But these public spheres have increasingly become subject to corporate interferences. It is Bhabha's contention that literature or narrative can compensate for this by posing as a global public sphere, organizing a global political community. ${ }^{318}$

The way in which Bhabha relates this to Held's idea that human atrocities should be our starting-points in conceiving of a new global order, is by suggesting that what memory in the sense of a global dialogue should focus on is exactly the mediation and collective negotiation of traumatic experience; experiences of collective disasters like genocide, war, slavery and exploitation via narrative. ${ }^{319}$ This, of course, also represents a way of making the discussion over global governance more susceptible to the various postcolonial histories, identities and perspectives that are often not taken into account by Western theorists and political scientists. In other words, this amounts to a global politics of recognition. Again Bhabha emphasizes that narrative must not be understood as restricted to literature or as necessarily fictional. For example, he finds an instance of global memory in the anonymous female Iraqi blogger Riverbend, whose reflections on the war in her country became internationally famous and were compiled into a book that became a bestseller. ${ }^{320}$

One way in which Bhabha supplements the notion of memory is by comparing it to Toni Morrison's notion of "rememory." 321 In Morrison's post-slavery ghost

\footnotetext{
317 Bhabha, "Globalisation and Ambivalence", p. 46.

318 Ibid., p. 45.

319 Ibid., pp. 44-46.

320 For Bhabha's discussion of Riverbend, compare ibid., pp. 44-46.

321 Bhabha, "Unsatisfied", p. 196; Bhabha, "Unpacking", p. 201.
} 
novel Beloved the main character Sethe explains rememory to her daughter Denver in the following way: "What I remember is a picture floating out there outside my head. I mean, even if I don't think it, even if I die, the picture of what I did, or knew, or saw is still out there. Right in the place where it happened." 322 Hence, according to Sethe rememory possesses a material presence and this, in turn, resonates well with Bhabha's assertion that memory "is a material 'medium' that must be 'restored and framed', cut and edited" and his further remark that "its ethical importance lies in its being at once a form of presence - an 'exposure' and a technology of 'processing', remembering, repeating and working through." 323 Thus, unlike Sethe, who wants to protect her daughter from the traumatic experience of slavery, Bhabha seeks a way in which the memory of human catastrophes can be made into rememories that last and continue to haunt us, to remind us of their presence. Yet, paradoxically, what Bhabha suggests is that we can only uphold the presence of memory in this way through, as he puts it, cutting and editing and, thus, through transformation. We have here the same problem that underlies the discursive inscription of human rights: Memory as well as the discourse of human rights needs to be translated and, in doing so, transformed. Hence, we become aware in this way that Bhabha's notion of global memory contains all the attributes of translation and transition: ever renewed reflections on the relation between past, present and future and a negotiation between the various cultural perspectives and subject-positions that are being narrated in it to the end of opening up spaces in-between them. ${ }^{324}$

One way in which this rather abstract idea may be posed as a more concrete problem is by thinking back to the Holocaust, which is also mentioned by Bhabha. In the past the way the Holocaust was conventionally narrated was as the outcome of the structural evolution of the German state. As long as this state housed a nation that was mostly ethnically German, thismemory remained relatively stable. However, today German classrooms are increasingly filling with students who are not ethnically German and whose ancestors were not present to witness the Holocaust. This, of course, reflects the increasing cultural heterogeneity of the German nation. Given this situation, it would seem that in order to maintain their presence within the nation, the lesson learned from the Holocaust need to be re-translated. They need to be transformed from a particular (German) memory into global memory. This is yet another way in which Bhabha's thinking about the multicultural nation leads to an international perspective.

Finally, I would like to finish this chapter on a more critical note. I have already implied that Bhabha's ideas are sometimes controversial. One aspect that appears particularly problematic is how Bhabha often feels called upon to speak in a moralizing tone on behalf of 'migrants' or 'minorities.' An instance of this can be

322 Toni Morrison, Beloved, London 2005 (originally published 1987), p. 43.

323 Bhabha, "Unsatisfied", p. 198; Bhabha, "Unpacking", p. 203.

324 Compare for this especially Bhabha, Globalisation and Ambivalence, p. 47. 
found in the passage where he criticizes liberal notions of secularism and egalitarianism as "privileged [and] a perspective far removed from the cultural and national context in which various minority groups like Woman against Fundamentalism in England, are demanding adherence to secularism." 325 Of course, the charge that liberalism occupies too privileged a perspective to fully comprehend the problems of minorities is definitely not made out of thin air. But this poses the question of how we could compensate for this lack. Of course, the migrantgroups and national minorities we know are often composed of people belonging to the poor and labouring classes, of people who have little education and are materially underprivileged. As we have already become aware, Bhabha's notion of vernacular cosmopolitanism is, of course, explicitly based on his own experiences as a migrant. It is a projection of his own consciousness as a migrant and a Parsi in India. In India, Bhabha belonged to the middle classes, and when he went to England it was as an exchange student to Oxford. Consequently, his experience as an immigrant to the UK most likely differed radically from the experiences of most of the immigrants he aspires to speak for. In this way Bhabha prescribes his own consciousness as a model for negotiation between mostly lower class immigrants and their host-societies. Now this may or may not be deemed permissible. Yet Bhabha attacks liberalism for being privileged as if he himself could be exempted from such a charge. Thus, to the extent that Bhabha is asking us to take material differences more seriously, it remains doubtful whether his own theorizing provides any instruments to live up to this standard.

\subsection{Synthesis: Rooted and Vernacular Cosmopolitanism Revisited and Cosmopolitanism Practice}

What I wish to do now as a final step in this section is to compare the respective approaches of Bhabha and Appiah with regard to their differences and similarities and also to point out some of the ways in which (empirical) research practices may be based on them. What is worth pointing out above all is that despite the fact that they speak from differing disciplinary perspectives, both authors' arguments possess a great deal of overall similarities. For instance, they hold in common the idea that literature can play an important role in engaging across cultural, racial and linguistic divides. Appiah's idea of dialogue or conversation, according to which we should try to find commonness of interest and partial agreement on particulars rather than more polarizing universals is fully compatible with Bhabha's notion of (global) memory; a (global) collective discussion on the historical legacy of colonialism, exploitation, genocide, displacement and the subsequent loss and transformation of identities.

325 Bhabha, "Unsatisfied", p. 204. 
Bhabha and Appiah are also remarkably close in their respective critiques of Martha Nussbaum. For instance, Appiah's criticism of Nussbaum's humanism are precisely mirrored in Bhabha's suspicion of what he refers to as the discourse of the merely human: the false universalization of a particular consciousness as an objective representation of a natural and bare humanity that appears stripped of all its cultural contingencies. Both authors are also critical of cultural relativism ${ }^{326}$, or rather, its absolutization as a foundational principle of cultural knowledge and cultural politics. In Bhabha's case this is not immediately obvious but he, of course, implicitly attacks cultural relativism through his critique of liberalism's stance of cultural or ethical neutrality. According to this, the neutrality-stance precipitates negative forms of Othering by making the difference between different groups seem essential and impermeable. The very same idea is contained in Appiah's dismissal of an ethics that views the world as consisting of several different and internally homogenous ethical sub-units that are forbidden to interpenetrate. In this way both authors attempt to open up and occupy a space in between the poles of universalism and relativism.

But it is also at this point that a complication between the two authors becomes apparent: Bhabha and Appiah have differing views on the precise nature of identity and, consequently, of recognition. Appiah seems to conceive of identity, more conventionally, in terms of an intersection of different group-affiliations within the individual and he discusses the (ethical) allegiance between the individual and the groups which constitute her/his identity. This appears to include traditions, norms and customs. Bhabha, on the other hand, is more interested in the process of identity-formation, which for him corresponds to the process of hybridization.For Bhabha, the articulation of identity is both a matter of translation/transformation and of hybridizing both the articulating entitiy and its Other.. The result is that Bhabha is not prepared to make space for identity in the way Appiah does. This regards especially the adherence to supposedly authentic cultural practices and authoritative traditions, which Bhabha rejects. This clearly is one way in which the two approaches of Bhabha and Appiah may be said to diverge: While Appiah wants to make as much space for different group-identities and only seeks consensus on vitally pressing ethical issues, Bhabha is more interested in pushing societies into a state where the constant negotiation and, hence, transformation of identities becomes more natural.

When we now think back to Bhabha's critique of neutrality we come to realize in what way this difference causes further tension between the two approaches. We have, of course, learned from Appiah that on liberalism's take the need for ethical or cultural neutrality applies not so much in the case of persons and their relations among one another but definitely to the relations between individuals and the state. What the idea of neutrality entails in this context is the state's

326 What would appear to follow from this is that both of them also reject holistic conceptions of culture. 
recognition of each of its citizens as an autonomous individual. Now, strictly speaking, all citizens are different from one another and they have very different needs. But some of our most important needs have to do with the groups to which we belong. Thus, in order to best pave the way to individual freedom the state must recognize groups in their idiosyncrasy and pave the way for the legality and social acceptability of their practices. In other words, the state is ethically obliged to categorize and, thus, implicitly fix the groups as distinct from one another in construing a framework for their coexistence. This is an absolutely necessary procedure that is achieved most fully where the recognition and categorization of groups on the part of the state corresponds to the ways in which these groups define themselves. This procedure is necessary since it is done to the end of ensuring overall equality. For if the state was able to recognize and meet an individual's needs more fully than another's on account of her/his group being recognized by the state while the other's is not, then, all things being equal, this amounts to unequal treatment. But, all things being equal, we do not want to abandon the ideal of equality and equal treatment of individuals by the state. This is why I believe, whatever critical issues Bhabha may raise about liberal multiculturalism, that we still need it, and that a dismissal of neutrality would be problematic. Sometimes groups will not have reached a point where they can conceive of themselves as in-between, or where they can easily translate themselves. In such a situation the state is obliged to respect their difference to the end of treating them equally.

What I suggest, therefore, is that a relative suspension of neutrality and of cultural relativism may only be properly exercised at the level of civil society as, for instance, in what Bhabha calls (global) memory or what Appiah refers to as dialogue or conversation. Here identities become subject to a complex process of negotiation that is not bound by the legal pressures which (at least ideally) bind the state. However, the outcome of this negotiation may ultimately feed back into revised claims for legal recognition addressed to the state. Maybe this is exactly what Bhabha has in mind. But be that as it may, if we interpret his work in this way it again appears as fully compatible with Appiah. What we learn about in this way is one context in which cultural relativism, which is interrogated by both authors, remains necessary. This also leads us to a definite understanding of the kind of citizenship envisaged by Bhabha and Appiah: It is citizenship in a more metaphorical sense that has to do with one's taking part in a global conversation, a process of negotiating values and identities, commonalities and differences. It does not refer to the citizenship in a literal world-state that was already rejected by Kant.

Another way in which Bhabha's theorizing differs from liberal theory and thus also from Appiah, is Bhabha's thinking in terms of discursive strategies as well as his use of concepts from psychoanalysis. This kind of thinking is unparalleled in the more principled analytical arguments of philosophers like Appiah and Held. 
However, it seems indispensable since it gives us alternative and ultimately more profound ways of imagining and conceptualizing what actually happens in processes of cross-cultural negotiation. Further, it can help us interrogate various unquestioned notions that liberal theory, which is the principle discourse on human rights. One of the ways in which cosmopolitanism may be turned into a concept for research is, for instance, by drawing on Kwame Anthony Appiah's treatment of identity (see chapter 3.2.2). As we have seen, our identity is, according to Appiah, not something that is simply given but something that comes together on the basis of the relations we stand in as social beings. It is through others that we learn about what categories of people exist, which we may then use to fashion our selves. One thing I pointed out in my discussion is that there are many such social categories, which we cannot help belonging to. In a way these are especially important for us since they also appear to especially bind us to specific groups and, thus, to a social consensus of sorts. One of the problems with these categories is that more often than not they are exclusive. You cannot both be black and South East Asian. Cosmopolitanism is when we, in our social capacity, overstep or transcend boundaries, which appear as formative of such group-identities, in order to allow the sameness of difference without ultimately collapsing them together.

If we conceptualize cosmopolitanism along these lines we may, for instance, discover it in Andrea Levy's novel Small Island. The novel is staged shortly before, during and shortly after World War II in Jamaica, England and India. One of Levy's main female protagonists, a white upper middle class-bred Englishwoman called Queenie spends the war years working at a "rest center." 327 Queenie at several points in the novel transcends class-differences when she repeatedly cares for and protects a bombed out Cockney-family. ${ }^{328}$ She also uses her position at the office to allocate a new flat in a fashionable London-area to a lower class family, whose home has been destroyed. ${ }^{329}$ This she does much to the annoyance of the local residents, who defy "those people" to be living in their "respectable street." 330 After the war Queenie lets out part of her husband's house for rent. During this time - and after she had a sexual relationship with the black Jamaican pilot Michael Roberts ${ }^{331}$ - Queenie becomes friendly with and takes on Jamaican lodgers like Gilbert ${ }^{332}$ and his wife Hortense. Queenie's cosmopolitan transcendence of the racial boundaries, again, is very much opposed by her racist neighbour Mr Todd and various other white people from her area. 333 In the end what we learn from Levy's novel is that a cosmopolitan stance is not necessarily something

327 Andrea Levy, Small Island, London 2004, p. 278.

328 Ibid., pp. 269-271; 275-277.

329 Ibid., pp. 281-286.

330 Ibid., p. 286.

331 Ibid., pp. 289-302.

332 How Queenie and Gilbert get to know each other and become friends is described on p. $168 \mathrm{ff}$. in ibid.

333 Ibid. pp. 111-113; 116-118. 
one may only acquire through extensive travelling. For, Queenie, of course, does not resemble the image of the well-travelled globetrotter that is usually associated with the term cosmopolitan. If anything this more customary understanding of cosmopolitanism would apply to her husband Bernard, who goes abroad to fight in India but who, nevertheless, turns out every bit as racially prejudiced and resentful of otherness as Mr Todd. ${ }^{334}$ Thus, the cosmopolitanism of Small Island is, as the novel's name suggests, an "insular cosmopolitanism", one that can be practiced at home by discovering and embracing one's own place as internally heterogeneous.

This idea of discovering one's own place as internally heterogeneous leads us to another, albeit totally different way of putting cosmopolitanism to practical use. As Bhabha has argued, modern (Western) societies are stricken with the condition that there exist communities of otherness all around us, communities that emerge, as Bhabha puts it, "in the midst" 335 of our nation. He has also argued that what he calls narrative must not be thought of as restricted to works of fiction. Hence, if we take seriously Bhabha's and also Appiah's call for cosmopolitanism, it seems prudent to no longer limit efforts to the analysis and critique of works of literature. In chapter 3.3.3 I have discussed Bhabha's idea that what national minorities and immigrant communities need to do is exchange their respective minoritynarratives. Under heading 3.3.6 it then became apparent that they should ultimately share them with us to make us more familiar with them and in a way defamiliarize our sense of self. It is to this that we, as academics, can contribute. For instance, we can try to set up contact with immigrant communities and request interviews with people from these communities regarding their experience as migrants. I am sure that we would find that these people - should they be willing to talk to us - have very interesting stories to tell, stories that would exactly defamiliarize our notions of the national space we share. We would suddenly perceive voices coming from a previously unknown part of the very space we occupy every day and which we thought we knew inside out. These voices would show us an image of our society and ourselves from an unfamiliar perspective, a precarious and threatened perspective. And this would alert us to the myriad of problems that immigrants face in our societies and about which we naturally possess no knowledge. Thus, one objective could be to look for structural problems immigrants are facing collectively to the end of raising awareness of them and, ultimately, removing them.

There is a danger that the people we interview will not give us very useful information for improving their situation. Maybe they would rather talk about other things, which, by all means, we should not keep them from talking about; Iin this way, our project may be carried through best if, for the time being, we substituted

334 For Bernard's dismissive attitude towards Jamaicans and blacks more generally see especially ibid., p. 430 and 435-437.

335 Bhabha, "Looking Back", p. xxii. 
our scientific interest of ascertaining facts about them for an ethical interest of letting them articulate themselves to us. Within the methodological repertoire of the social sciences there exist certain techniques that may help generate what Gabrielle Rosenthal refers to as a "biographical narrative", that is, a narrative that does not rely on pre-given questions and answers but that preserves the uniqueness and idiosyncrasy of what the teller has to say. ${ }^{336}$ In this way and by letting them speak about whatever they deem appropriate, we would be communicating to our immigrants that they matter to us, a sense of appreciation. This appreciation they can return by asking how we got to be the ones we are; so that we would gradually establish a culture of taking an interest in one another and of exchanging our stories, a community wherein the various 'wes' and 'thems' become less polarizing.

\section{Conclusions: Necessary Humanist Residues in Cosmo- politanism}

In this chapter I would like to return to my various opening questions and, in retracing the various stages of cosmopolitanism step by step, address in how far the postcolonial perspectives on cosmopolitanism are related to and rooted in the Western discourse of cosmopolitanism and, especially, to what extent they are related to the Enlightenment and whether this is damaging.

In my analysis of the classical to contemporary perspectives on cosmopolitanism I first examined the philosophy of the ancient Greek Diogenes, who originated the term cosmopolitanism as such. As a Cynic Diogenes radically rejected worldly existence and, instead, advocated a life in accordance with nature - an ideal he most literally adhered to. He lived in poverty and without any possessions which he branded as vices of civilization, on the streets of Athens, whose citizens he often provocatively enticed to abandon their worldly ways and to live in his manner. Significantly, as a result of his rejection of civilization Diogenes also disapproved of any form of worldly government or state and, therefore, also of contemporary forms of citizenship. Accordingly, his notion of being a cosmopolitan, that is, a citizen of the cosmos invokes less a literal citizenship but citizenship is here meant as a metaphor for a state of unity with all things and all beings, which is, of course, exactly what, for Diogenes, the state of nature was all about.

The idea that cosmopolitanism refers to a metaphorical rather than a literal citizenship is something that runs like a red thread through most, if not all, conceptions of cosmopolitanism we have encountered. For instance, Kant rejected the notion of a world-state and suggested the founding of a voluntary league of nations instead. Likewise both Appiah's notion of dialogue (or conversation) and

336 Gabrielle Rosenthal, Erlebte und Erzählte Lebensgeschichte: Gestalt und Struktur biographischer Selbstbeschreibung, Frankfurt New York 1995, pp. 186-207. 
Bhabha's concept of global memory imply metaphorical citizenship since their efforts to globally forge allegiances across difference must be understood as located at the level of international civil society. Thus, based on Cynic cosmopolitanism most - if not all - notions of cosmopolitanism I have examined reject literal world-citizenship.

As I have argued, ancient Greece, the world wherein Diogenes lived, was composed of different interrelated city-states. Consequently, any foreign citizen and especially those who existed outside this order altogether and whom the Greeks regarded as barbarians would have posed as Other. Thus, for Diogenes to dismiss contemporary notions of citizenship in the way he did was meant as an appeal to identify with the Other, to try and imagine one's sameness with so-called barbarians but also with slaves and with women. This notion of bridging socially constructed inequalities in some way is especially interesting to the postcolonial perspective. However, one difference between the Cynics and later cosmopolitans is their belief that cosmopolitanism should unite within one realm not only humans but, ultimately, all beings, including metaphysical entities such as gods and spirits. This spiritual or religious dimension of cosmopolitanism was not included in the adoption of the concept by the Enlightenment, which, instead, was based on the political and legal implications of the Cynic and especially the Stoic perspectives; and it is not an element of either the contemporary or postcolonial versions I have examined.

Further, what becomes clear in retrospect is that Cynic cosmopolitanism is clearly inhabited by an undesirable universalism, which Ulrich Beck referred to as an absolutized universalism of sameness. As I have explained, the Cynics took to the streets and what they did to convert people to authoritatively prescribed truths. In order for the Other to exist in harmony with the Cynics' world-view it would have had to become identical with it. In this way Cynic cosmopolitanism reaches out to the Other only to make it into the self. My second stage in exploring the various historical incarnations of cosmopolitanism from the classic to contemporary perspectives was Immanuel Kant, who within the confines of this work represents the Enlightenment's conception of cosmopolitanism. Kant's perspective is complex and he differentiates between several different kinds of cosmopolitanism such as a moral and political cosmopolitanism, which are also related to one another in intricate ways. Kant's moral cosmopolitanism is an inheritance from the Stoic notion that ideally all humans ought to be seen and treated as equals. What follows from this is that everyone has obligations to all other humans rather than just to their own kin. The way Kant connects this notion to political cosmopolitanism is through his concept of patriotism: Good patriots, who take an interest in the moral advancement of their state will criticize it for treating others unfairly. By this they aim at changing their state for the better. In retrospect what appears clear is that especially Bhabha's idea of creating an international public sphere or a global discussion on the legacy of violence, war and 
suffering (global memory) is structurally equivalent and rooted in Kant's idea that politicized subjects from civil society should intervene to make states more just. In a way, what Bhabha (and also Appiah) suggests is the building of a league of patriots who make connections beyond their own states.

We have also become aware that Kant's philosophy differed very much from that of the Stoics and especially the Cynics. While the latter were more interested in justifying certain personal attitudes they described as cosmopolitan, Kant sought to use these ideas to construct a framework for international legal agreements that could ensure peaceful coexistence (perpetual peace). Kant is clearly not guilty of the kind of universalism that we perceived in the Cynics. The reason for that is that his cosmopolitanism is not primarily about the interaction across a divide between self and Other. Rather, Kant starts from an overarching sameness of all human beings (moral cosmopolitanism). Yet this does not mean that Kant cannot comprehend difference. As we have seen, Kant's political cosmopolitanism is dedicated to ensuring peaceful coexistence and opposed to an all encompassing world-state. This grew partly out of moral cosmopolitanism and his subsequent recognition of each human being as an autonomous reasonable agent. Accordingly, for Kant an overarching moral equality is entirely compatible with the recognition of individual differences or the differences between different states and peoples. It is precisely this double-perspective that we find in Kwame Anthony Appiah's differentiation between ethics (what one owes to the groups one belongs to) and morality (what one owes all humans). Thus, one major result of this work must be that both postcolonial perspectives I have addressed and analyzed in this work are firmly rooted in the cosmopolitanism of Kant.

David Held's notion of cosmopolitan democracy - which was the first of two contemporary conceptions of cosmopolitanism I discussed - builds on Kant just like Bhabha and Appiah. However, Held also does so in a way that is very different from the two postcolonial theorists. Basically, he is concerned with how democracy can be maintained institutionally in a globalized world. The necessity for institutional and procedural makeovers arises from the fact that in the age of globalization we can no longer solve many of the most pressing issues on a national basis. Also the differences between states seem to increasingly blur since some issues concern groups of people who exist in many different states. Held suggests, that in order to solve problems which we are increasingly facing together, we cannot simply transfer the model of state-based democracy to an international level. What we must rather do is to always re-interpret democracy's underlying principles and this, of course, resonates well with Bhabha, who is interested in translation. But Bhabha also has disagreements with Held and with liberal theory more generally. He criticizes the way Held seeks to re-imagine democracy to the end of transcending the idea of the nation. We have seen that Held does not think that nation-states should be abandoned.However, there is a difference between the state and the nation, although, more often than not, the two coincide.. It is rea- 
sonable of Bhabha to object to Held's project of cosmopolitan democracy, which aspires to globally clear out the damaging remnants of the Westphalian Order, on grounds that this endeavour is insufficiently open to the perspectives of postcolonial nations, whose histories have to be respected. Thus, although Bhabha's cosmopolitanism appears rooted in Kantianism, this does not mean that he is unable to criticize other Kantian perspectives.

Ulrich Beck's cosmopolitanism appears as related to the perspective of Held in that it also attempts to take stock of the conditions brought on by globalization, or what Beck refers to as Second Modernity. However, Beck is not so much interested in thinking about how democracy may be re-organized institutionally but in the development of a new sociology that can do justice to the changed ontological conditions of the global age. Beck wants to conceptualize and explore the various ways in which social interactions extend beyond national societies and how, partly as a result of this, the latter emerge as increasingly heterogonous. In a way this is very similar to what Homi Bhabha means by hybridization, and there are also some notable similarities between the ways in which Bhabha and Beck dialectically conceptualize social developments: Beck identifies the same dialectic as Bhabha that prompts the emergence of anti-cosmopolitan forces (such as reactionary political movements). But unlike Bhabha, Beck draws attention to the fact that there is another dialectic development that may potentially counter-act the anticosmopolitan dialectic. This is the emergence of what Beck refers to as world risk society. This concept, which is in itself dialectical, presumes that the more pressing issues we face together (as world-citizens), the greater becomes the urge to sit down together and engage with one another. Finally, Beck also contributes some very important coordinates that help us think about and critically evaluate the various more philosophical frameworks explored in this work: On Beck's take such frameworks must attempt to levitate between universalism and relativism and may never collapse into one or the other extreme.

Beck's caution against absolute principles is clearly reflected in Kwame Anthony Appiah's rejection of absolute cultural relativism, which negates the necessity and viability of our trying to find global agreement on certain very pressing moral issues such as human rights. However, Appiah also uncovers for us why relativism, which he specifically detects in the works of postmodern philosophers like Jean-François Lyotard and Richard Rorty, might have appeared as necessary. This was as a counter-balance against the intellectual hegemony of moral realism a philosophical position that maintains that we may acquire factual knowledge about morals and which in its extreme seeks to erase all difference. In other words: moral realism amounts to a perfect absolutized universalism. In contradistinction to moral realism Appiah's cosmopolitanism is dedicated to maintaining differences as much as possible, while trying to only find consensus on issues that are so pressing that they cannot be ignored. 
Cultural relativism is also criticized by Bhabha who believes it to derive fromliberal notions of multiculturalism. There are many aspects on which Bhabha and Appiah concur and others on which they do not. It is not self-evident that these authors should possess any overall agreements at all since they adhere to different theoretical orientations, communicating in completely different disciplinary languages and idioms; so that they might as well not agree on anything at all. But this is not the case and in a way their above agreement with simultaneous difference epitomizes perfectly what cosmopolitanism is all about, which is essentially to go beyond one's own discourse and to hybridize others as well as oneself. This is particularly obvious in the case of Bhabha, who can no longer be safely attached to any one theoretical school or discipline. But it also applies to Appiah, who is prepared to critize the sometimes exaggerated rationalism of analytical philosophy For instance, he critiques Nussbaum and other liberal authors for being totally removed from actual emotions. He advocates patriotism and the love of the particular, while simultaneously maintaining that we also owe something to everyone. It is this desire on Appiah's part for both patriotism and universal morality, rationality and emotion that lets him appear every bit as hybrid as Bhabha. I argue that this boldness to 'go beyond', to appropriate and intervene, even at the risk of having to transform oneself, is particular to postcolonial studies, which, in a way, can be seen as a space in-between different disciplines and discourses, wherein disciplinary differences converge, by and by give rise to new perspectives and create an atmosphere in which such differences in perspective gradually come to appear less polarizing.

In drawing to a close, let me return to the beginning, to Stuart Hall, who took exception with cosmopolitanism's Enlightenment heritage. I was not able to ultimately dispel his worries that cosmopolitanism might serve to license Eurocentrism. What I have demonstrated is that there are authors who engage with the idea of cosmopolitanism, while maintaining a critical awareness of its roots in Western thought. For I was able to show that while both Appiah and Bhabha appear as rooted in Kantianism, there are also certain elements within the discourse of cosmopolitanism they dismiss. For instance, both of them oppose unbounded universalisms. Significantly, both Appiah and Bhabha go up against humanism. However, the way in which this is done is ambivalent. Bhabha criticizes the universalization of particular consciousness to derive what are supposedly objective underlying principles of 'the human' but he also acknowledges that we may not stop thinking about it either. The same goes for Appiah, who believes that Nussbaum's humanism is akin to the universalism of moral realists but holds that even though differences ought to be respected and maintained, we must, nevertheless, converge on certain vital ethical issues. Thus, for both authors some form of humanism is inescapable. Notably, this same humanism already occurs in Kant, who universalizes his account of how human beings leave behind a life that is devoid of the rule of law (state of nature) and enter into the state. This may be 
said to constitute a form of essentialism, an unwarranted reduction of the fullness of human diversity. However, one problem that arises from opposing this kind of argument in Kant is, of course, that we would have to undermine his argument in favour of democracy. For in thinking about and universalizing the relation between the state and the individual Kant inevitably prescribes certain normative notions as to how states should ideally be run in order to ensure human freedom. This is also why for Bhabha and Appiah humanism remains an ambivalent affair: In some way it appears as a necessary starting-point for arguing in favour of democracy and for human rights. However, there also is a sense that it might not take us all the way and that it becomes most critical where it re-introduces through the backdoor an absolute universalism of sameness. This is the limit set by the Kantian framework that both Appiah and Bhabha adhere to; and postcolonial critics must now debate and evaluate whether this is something they can live with. However, if a culture of rights and democracy is agreeable then it would appear that the Enlightenment is here to stay with us.

\section{Bibliography}

\section{Primary Literature}

Forster, Edward Morgan, A Passage to India, London 2005 (originally published 1924).

Levy, Andrea, Small Island, London 2004.

Morrison, Toni, Beloved, London 2005 (originally published 1987).

Naipaul, Vidiadhar Surajprasad, The Mimic Men, London 2011 (originally published 1967). 
Secondary Literature

Anon, "almirah, -myra" in: Oxford English Dictionary, 2nd ed., vol. I, Oxford 1989, p. 352.

-, "The Universal Declaration of Human Rights", URL: http://www.un.org/ en/documents/udhr/index.shtml\#a27 (accessed: 25/10/2013).

Appiah, Kwame Anthony, "Against National Culture", in: Laura GarcíaMoreno/Peter C. Pfeiffer (eds.), Text and Nation: Cross-Disciplinary Essays on Cultural and National Identities, Columbia [SC] 1996, pp. 175-190.

-, "Citizen of the World", in: Matthew J. Gibney (ed.), Globalizing Rights: The Oxford Amnesty Lectures 1999, Oxford 2003 pp. 189-232.

-, Cosmopolitanism: Ethics in a World of Strangers (Issues of our Time), New York/London 2007.

-, "Cosmopolitan Patriots", in: Joshua Cohen (ed.), For Love of Country? (New Democracy Forum), Boston 2002 (originally published 1996), pp. 21-29.

-, The Ethics of Identity, Princeton 2005.

Ashcroft, Bill/Griffith, Gareth/Tiffin, Helen, The Empire Writes Back: Theory and Practice in Post-Colonial Literatures, London/New York 1989.

Archibugi, Daniele, "Cosmopolitan Democracy and its Critics: A Review", in: European Journal of International Relations 10:3 (2004), pp. 437-473.

Bhabha, Homi K., "Foreword: Framing Fanon", in: Frantz Fanon, The Wretched of the Earth, New York 2004 (originally published in French 1961), pp. vii-xli.

-, "Interrogating Identity: Fantz Fanon and the Postcolonial Prerogative", in: Idem, The Location of Culture, London/New York 2010 (originally published 1994), pp. 57-93.

-, "Looking Back, Moving Forward: Notes on Vernacular Cosmopolitanism", in: Idem, The Location of Culture, London/New York 2010 (originally published 1994), pp. ix-xxv.

-, "Notes on Globalisation and Ambivalence", in: David Held/Henrietta L. Moore (eds.), Cultural Politics in a Global Age: Uncertainty, Solidarity and Innovation, Oxford 2008, pp. 36-47.

-, “On Writing Rights", in: Matthew J. Gibney (ed.), Globalizing Rights: The Oxford Amnesty Lectures 1999, Oxford 2003, pp. 162-183.

-, "Remembering Fanon: Self, Psyche and the Colonial Condition", in: Frantr. Fanon, Black Skin, White Mask, London 2008 (originally published in French 1952), pp. xxi-xxxvii.

-, "Signs Taken For Wonders: Questions of Ambivalence and Authority under a Tree outside Delhi, May 1817', in: Idem, The Location of Culture, London/New York 2010 (originally published 1994), pp. 145-174. 
-, "The Commitment to Theory", in: Idem, The Location of Culture, London/New York 2010 (originally published 1994), pp. 28-56.

-, "The Manifesto", in: Wasafiri: Perspectives on African, Caribbean, Asian and Black British Literature 14:29 (1999), pp. 38-39.

-, "The Other Question: Stereotype, Discrimination and the Discourse of Colonialism", in: Idem, The Location of Culture, London/New York 2010 (originally published 1994), pp. 94-120.

-, "The Vernacular Cosmopolitan", in: Ferdinand Dennis/Naseem Khan (eds.), Voices of the Crossing: The Impact of Britain on Writers from Asia, the Caribbean, and Africa, London 2000, pp. 133-142.

-, "Unpacking my Library ... Again", in: Iain Chambers/Lidia Curti (eds.), The Postcolonial Question: Common Skies Divided Horizons, London/New York 1996, pp. 199-211.

-, "Unsatisfied: Notes on Vernacular Cosmopolitanism", in: Laura GarciaMoreno/Peter C. Pfeiffer (eds.), Text and Nation: Cross-Disciplinary Essays on Cultural and National Identities, Columbia [SC] 1996, pp. 191-207.

Beck, Ulrich, "Kosmopolitisierung ohne Kosmopolitik: Zehn Thesen zum Unterschied zwischen Kosmopolitismus in Philosophie und Sozialwissenschaft", in: Helmuth Berking (ed.), Die Macht des Lokalen in einer Welt obne Grenzen, Frankfurt [a.M.]/New York 2006, pp. 252-270.

—, "Realistic Cosmopolitanism: How Do Societies Handle Otherness?", in: David Held/Henrietta L. Moore (eds.), Cultural Politics in a Global Age: Uncertainty, Solidarity and Innovation, Oxford 2008, pp. 60-67.

-, "The Cosmopolitan Society and Its Enemies", in: Theory, Culture \& Society: Explorations in Critical Social Science 19:17 (2002), pp. 17-44.

Cartledge, Paul, "Greek Political Thought: The Historical Context”, in: Christopher Rowe/Malcolm Schofield [et al.] (eds.), The Cambridge History of Greek and Roman Political Thought, Cambridge/New York/Melbourne [et al.] 2000, pp. 7-22.

Cohen, Jeffrey Jerome, Hybridity, Identity, and Monstrosity in Medieval Britain: On Diffcult Middles (The New Middle Ages), New York 2006.

- (ed.), The Postcolonial Middle Ages, New York 2000.

Füssel, Marian, Der Siebenjährige Krieg: Ein Weltkrieg im 18. Jabrhundert, München 2010.

Gagnon, Jean, “An Interview with Professor David Held: Exploring the Concepts of Cosmopolitanism and Democracy", in: Journal of Democratic Theory 1:1 (2011), pp. 1-18.

Gilroy, Paul, After Empire: Melancholia or Convivial Culture, London/New York 2004. 
Graeber, David, “On Cosmopolitan and (Vernacular) Democratic Creativity: Or, There Never was a West", in: Pnina Werbner (ed.), Anthropology and the New Cosmopolitanism: Rooted, Feminist and Vernacular Perspectives (ASA Monographs 45), Oxford/New York 2008, pp. 281-305.

Hall, Stuart, Introduction: “Who Needs Identity”, in: Idem/Paul Du Gay (eds.), Questions of Cultural Identity, London/Thousand Oaks/New Delhi 2003 (originally published 1996), pp. 1-17.

Held, David, "Cultural Diversity, Cosmopolitan Principles and the Limits of Sovereignty", in: Idem/Henrietta L. Moore (eds.), Cultural Politics in a Global Age: Uncertainty, Solidarity and Innovation, Oxford 2008, pp. 156-164.

Hobsbawm, Eric J., Nations and Nationalism since 1780: Programme, Myth, Reality (The Wiles Lectures given at the Queen's University Belfast), Cambridge/New York/Melbourne [et al.] 1990.

Kabir, Ananya Jahanara/Williams, Deanne (ed.), Postcolonial Approaches to the European Middle Ages (Cambridge Studies in Medieval Literature 54), Cambridge 2005.

Kleingeld, Pauline, Kant and Cosmopolitanism: The Philosophical Ideal of World Citizenship, Cambridge/New York/Melbourne [et al.] 2012.

Moles, John L., "Cynic Cosmopolitanism”, in: Robert Bracht Branham/MarieOdile Goulet-Cazé (eds.), The Cynics: The Cynic Movement in Antiquity and Its Legacy (Hellenistic Culture and Society 23), Berkeley/Los Angeles/London 1996, pp. 105-120.

-, "The Cynics", in: Christopher Rowe/Malcolm Schofield [et al.] (eds.), The Cambridge History of Greek and Roman Political Thought, Cambridge/New York/Melbourne [et al.] 2000, pp. 415-434.

Nussbaum, Martha C., "Kant and Stoic Cosmopolitanism", in: The Journal of Philosophy 5:1 1997, pp. 1-25.

—, "Patriotism and Cosmopolitanism", in: Joshua Cohen (ed.), For Love of Country? (New Democracy Forum), Boston 2002 (originally published 1996), pp. 2-17.

Padgett, Tim, “The Most Homophobic Place on Earth?”, Time.com, 12/04/2006, URL: http://content.time.com/time/world/article/0,8599,1182991,00.html (accessed: 28/08/2013).

Pollock, Sheldon/Bhabha, Homi K./Breckenridge, Carol A./Chakrabarty, Dipesh, "Cosmopolitanisms", in: Public Culture 12:3 (2000), p. 577-589.

Rosenthal, Gabrielle, Erlebte und Erzählte Lebensgeschichte: Gestalt und Struktur biographischer Selbstbeschreibung, Frankfurt/New York 1995.

Rutherford, Jonathan, "The Third Space: Interview with Homi Bhabha”, in: Idem (ed.), Identity: Community, Culture, Difference, London 1990, pp. 207-221.

Said, Edward, Orientalism, London 2003 (originally published 1978). 
Stelfox, Dave, "Dancehall Queen", The Guardian, 12/01/2004, URL: http://www.theguardian.com/stage/2004/jan/12/dance_ (accessed: 28/08/2013).

Werbner, Pnina, "Introduction: Toward a New Cosmopolitan Anthropology", in: Idem (ed.), Anthropology and the New Cosmopolitanism: Rooted, Feminist and Vernacular Perspectives (ASA Monographs 45), Oxford/New York 2008, pp. 1-29.

-, "Cosmopolitanism, Globalisation and Diaspora: Stuart Hall in Conversation with Pnina Werbner, March 2006", in: Idem (ed.), Anthropology and the New Cosmopolitanism: Rooted, Feminist and Vernacular Perspectives (ASA Monographs 45), Oxford/New York 2008, pp. 345-360.

Wright, Patrick, “Radio 3 'Night Waves' Discussion: Homi Bhabha, Susheila Nasta and Rasheed Araeen", in: Wasafiri: Perspectives on African, Caribbean, Asian and Black British Literature 14:29 (1999), pp. 39-43.

Young, Gary, "Troubled Island", The Guardian, 27/04/2006, URL: http://www.theguardian.com/world/2006/apr/27/gayrights.comment (accessed: 28/08/2013). 